Aus der Abteilung Neuropathologie

(Prof. Dr. med. W. Brück)

im Zentrum Pathologie und Rechtsmedizin

der Medizinischen Fakultät der Universität Göttingen

\title{
Multiple Sklerose und Dopamin-Rezeptoren
}

\author{
INAUGURAL-DISSERTATION \\ zur Erlangung des Doktorgrades \\ der Medizinischen Fakultät \\ der Georg-August-Universität zu Göttingen
}

vorgelegt von

\section{Jakob Schumacher}

aus

Filderstadt

Göttingen 2010 
Dekan: Prof. Dr. med. C. Frömmel

1. Berichterstatterin: Prof. Dr. med. C. Stadelmann-Nessler

2. Berichterstatter: Prof. Dr. med. A. Flügel

3. Berichterstatter: Prof. Dr. med. T. Croizer

Tag der mündlichen Prüfung: 13.04.2011 


\section{Inhaltsverzeichnis}

1 Einleitung $\quad 8$

1.1 Multiple Sklerose . . . . . . . . . . . . . . . . . . . . . . . . . 8

1.1 .1 Epidemiologie . . . . . . . . . . . . . . . 8

1.1.2 Krankheitsverlauf und Klinik . . . . . . . . . . . . . . . . . . . . 9

1.1.3 Diagnostik der MS . . . . . . . . . . . . . . . . . . . 10

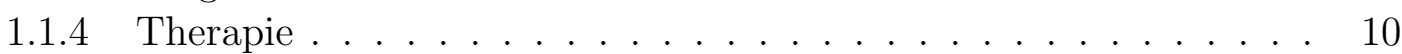

1.1 .5 Pathophysiologie . . . . . . . . . . . . . . . 12

1.1 .6 Ätiologie . . . . . . . . . . . . . . . . . . . . . . . . . 13

1.1 .7 Histopathologie . . . . . . . . . . . . . . . . . . . 15

1.1 .8 Tiermodelle . . . . . . . . . . . . . . . 16

1.2 Dopamin . . . . . . . . . . . . . . . . . . . . . . 18

1.2.1 Dopamin und Dopamin-Rezeptoren . . . . . . . . . . . . . 18

1.2.2 Krankheiten, die auf Störungen des Dopaminsystems beruhen . . 19

1.2.3 Medikamentöse Beeinflussung des Dopaminsystems . . . . . . . . 20

1.2.4 Funktionen von Dopamin . . . . . . . . . . . . . . . . . 20

1.2.5 Prolaktin und sein Einfluss auf das Immunsystem . . . . . . . . . 22

1.2.6 Knockout-Mäuse mit Veränderungen im Dopaminsystem . . . . . 23

1.2.7 Dopaminmodulierende Therapieversuche bei EAE und MS . . . . 24

1.3 Fragestellung der vorliegenden Arbeit . . . . . . . . . . . . . . . . 25

2 Material und Methoden 26

2.1 Durchführung der Tierexperimente . . . . . . . . . . . . . 26

2.2 Durchführung der histologischen Färbungen . . . . . . . . . . . . . 26

2.3 Durchführung der Auswertung . . . . . . . . . . . . . . . . . . . . . . . 28

3 Ergebnisse 32

3.1 Klinischer Verlauf der Erkrankung EAE . . . . . . . . . . . . . . . . 32

3.1.1 Verlauf der Erkrankung bei akuter und chronischer EAE bei D2defizienten Mäusen . . . . . . . . . . . . . . . . . 32

3.1.2 Verlauf der Erkrankung bei akuter und chronischer EAE bei D3defizienten Mäusen . . . . . . . . . . . . . . . . . . 34

3.2 Entzündungsaktivität . . . . . . . . . . . . . . . . . . 35

3.2.1 Entzündungsaktivität bei D2-defizienten Mäusen . . . . . . . . . 35

3.2.2 Entzündungsaktivität bei D3-defizienten Mäusen . . . . . . . . . 36

3.3 Entmarkung . . . . . . . . . . . . . . . . . . 37

3.3.1 Entmarkung bei D2-defizienten Mäusen . . . . . . . . . . . . 38 
3.3.2 Entmarkung bei D3-defizienten Mäusen . . . . . . . . . . . . . 38

3.4 Axonale Schädigung . . . . . . . . . . . . . . . . . . . . . . 38

3.4.1 Axonale Schädigung bei D2-defizienten Mäusen . . . . . . . . . . 38

3.4 .2 Axonale Schädigung bei D3-defizienten Mäusen . . . . . . . . . . 39

3.5 Oligodendrozytendichte . . . . . . . . . . . . . . . . . 39

3.5.1 Oligodendrozytendichte bei D2-defizienten Mäusen . . . . . . . . 39

3.5.2 Oligodendrozytendichte bei D3-defizienten Mäusen . . . . . . . . 40

4 Diskussion $\quad 41$

4.1 Dopamin wirkt auf Immunzellen . . . . . . . . . . . . . . . . . . 41

4.1.1 Dopamin wirkt über Dopamin-Rezeptoren auf Immunzellen . . . . 41

4.1.2 Prolaktin übt einen Einfluss auf das Immunsystem aus. . . . . . . . 43

4.2 Dopamin wirkt auf Neurone und Gliazellen . . . . . . . . . . . . . . . . . 45

4.3 Wirkungen von Dopamin auf die EAE . . . . . . . . . . . . 47

4.4 Wirkungen von Dopamin auf die MS . . . . . . . . . . . . . 50

4.5 Folgerungen für Forschung und Praxis . . . . . . . . . . . . . . 51

5 Zusammenfassung $\quad 52$

6 Anhang 53

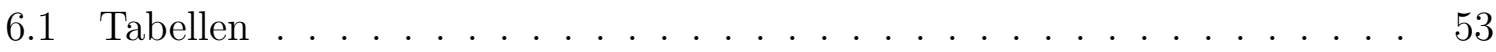

6.2 Abbildungen . . . . . . . . . . . . . . . 66

$\begin{array}{llr}7 & \text { Literaturverzeichnis } & 86\end{array}$ 


\section{Tabellenverzeichnis}

6.1 Literaturübersicht zu Dopamin-Rezeptoren auf humanen und murinen

Lymphozyten sowie Oligodendrozyten. . . . . . . . . . . . . . . 53

6.2 Symptomskala zur Evaluation der EAE . . . . . . . . . . . . . . . 54

6.3 Verlauf der EAE bei D2 ${ }^{-/-}$Mäusen . . . . . . . . . . . . . . . . . . . . . 54

6.4 Verlauf der EAE bei D3-/--Mäusen . . . . . . . . . . . . . . . . 54

6.5 Induktion der EAE . . . . . . . . . . . . . . . . . . . . . . 55

6.6 Perfusion und Präparation der Versuchstiere . . . . . . . . . . . . 55

6.7 Durchführung der Bielschowsky-Versilberung . . . . . . . . . . . . . . . . 56

6.8 Durchführung der LFB/PAS-Färbung . . . . . . . . . . . . . . . . 57

6.9 Durchführung der immunhistochemischen Färbungen . . . . . . . . . . 58

6.10 Durchführung der immunhistochemischen Doppelfärbung . . . . . . . . . 59

6.11 Verwendete Tiermodelle . . . . . . . . . . . . . . . . . 60

6.12 Verwendete Chemikalien zum Hervorrufen der EAE, zur Perfusion und zur Präparation der Mäuse . . . . . . . . . . . . . . . . . 60

6.13 Verwendete Chemikalien für die histologischen Färbungen Teil 1. . . . . . 61

6.14 Verwendete Chemikalien für die histologischen Färbungen Teil 2. . . . . . 62

6.15 Verwendete Primärantikörper . . . . . . . . . . . . . . . 63

6.16 Verwendete Sekundärantikörper . . . . . . . . . . . . . . . . 64

6.17 Verwendete Materialien für die Mikroskopie und Auswertung . . . . . . . 65 


\section{Abbildungsverzeichnis}

6.1 Krankheiten des Dopaminsystems . . . . . . . . . . . . . . 66

6.2 Expositionsmöglichkeiten der Immunzellen gegenüber Dopamin . . . . . . 67

6.3 Wirkung von Dopamin auf Immunzellen . . . . . . . . . . . . . . . . . . 68

6.4 Ergebnisse der histologischen Untersuchungen der Wildtyp- und D2/-Mäuse im akuten Stadium der EAE . . . . . . . . . . . . . . . . . 69

6.5 Ergebnisse der histologischen Untersuchungen der Wildtyp- und D2 ${ }^{-/-}$ Mäuse im chronischen Stadium der EAE . . . . . . . . . . . . . . . 70

6.6 Ergebnisse der histologischen Untersuchungen der Wildtyp- und D3/-Mäuse im akuten Stadium der EAE . . . . . . . . . . . . . . . . . . . 71

6.7 Ergebnisse der histologischen Untersuchungen der Wildtyp- und D3/-Mäuse im chronischen Stadium der EAE . . . . . . . . . . . . . . . . . . 72

6.8 Krankheitsverlauf der chronischen EAE über 43 Tage. D3-/--Mäuse vs. Wildtyp-Mäuse . . . . . . . . . . . . . . . . . . . . 73

6.9 Entzündliche Infiltrate bei akuter und chronischer EAE . . . . . . . . . . 74

6.10 Dichte der Makrophagen im Vergleich zwischen Wildtyp-Mäusen und D2/-Mäusen. . . . . . . . . . . . . . . . . . . 75

6.11 Dichte der T-Lymphozyten im Vergleich zwischen Wildtyp-Mäusen und D2-/-Mäusen . . . . . . . . . . . . . . . . . 76

6.12 Dichte der B-Lymphozyten im Vergleich zwischen Wildtyp-Mäusen und D2-/-Mäusen. . . . . . . . . . . . . . . . . . . 76

6.13 Entmarkung im Vergleich zwischen Wildtyp-Mäusen und D2-/--Mäusen. . 77

6.14 Axonale Schädigung und axonaler Verlust bei akuter und chronischer EAE. 78

6.15 Dichte der Oligodendrozyten im Vergleich zwischen Wildtyp-Mäusen und D2-/-Mäusen . . . . . . . . . . . . . . . . . . . 79

6.16 Entzündliche Infiltrate bei akuter und chronischer EAE . . . . . . . . . . 80

6.17 Dichte der Makrophagen im Vergleich zwischen Wildtyp-Mäusen und D3-/-_ Mäusen. . . . . . . . . . . . . . . . . . . 81

6.18 Dichte der T-Lymphozyten im Vergleich zwischen Wildtyp-Mäusen und D3-/-Mäusen . . . . . . . . . . . . . . . . . . . 82

6.19 Dichte der B-Lymphozyten im Vergleich zwischen Wildtyp-Mäusen und D3-/-Mäusen. . . . . . . . . . . . . . . . . . . . 82

6.20 Entmarkung im Vergleich zwischen Wildtyp-Mäusen und D3-/--Mäusen. . 83

6.21 Axonale Schädigung und axonaler Verlust bei akuter und chronischer EAE. 84

6.22 Dichte der Oligodendrozyten im Vergleich zwischen Wildtyp-Mäusen und D3-/-Mäusen . . . . . . . . . . . . . . . . . . 85 


\title{
Abkürzungsverzeichnis
}

\author{
APP \\ Amyloid-Vorläuferprotein \\ cAMP \\ zyklisches Adenosinmonophosphat \\ D2 \\ Dopamin-Rezeptor D2 \\ D2 ${ }^{-/-}$-Maus ..... Maus ohne den Dopamin-Rezeptor D2 \\ D3 $\ldots . . . \ldots \ldots$ Dopamin-Rezeptor D3 \\ D33---Maus .... Maus ohne den Dopamin-Rezeptor D3 \\ EAE ......... experimentelle autoimmune Enzephalomyelitis \\ EDTA ......... Ethylendiamintetraessigsäure \\ FCS .......... Fetales Kälberserum \\ LFB/PAS ..... Luxol-Fast-Blue/Perjodsäure-Schiff \\ MBP ......... Myelin-basisches-Protein \\ MOG ......... Myelin-Oligodendroglia-Glykoprotein \\ mRNA ........ messenger-Ribonukleinsäure \\ MS ........... Multiple Sklerose \\ MSTKG ....... Multiple-Sklerose-Therapie-Konsensus-Gruppe \\ PBS ......... Phosphat-gepufferte Salzlösung \\ PFA $\ldots \ldots \ldots$. Paraformaldehyd \\ PLP ........... Proteolipid-Protein \\ ROS $\ldots . . . \ldots$ Reaktive Sauerstoffspezies \\ SD ............ Standardabweichung \\ Th1 ......... T-Helferzelle Typ 1 \\ Th2 ........ T-Helferzelle Typ 2 \\ WT .......... Wildtyp-Mäuse
}




\section{Einleitung}

\subsection{Multiple Sklerose}

Die Multiple Sklerose (MS), auch Encephalomyelitis disseminata genannt, ist eine Erkrankung des Zentralnervensystems. Sie ist eine chronisch-entzündliche demyelinisierende Erkrankung und gehört zu der Gruppe der idiopathischen inflammatorischen demyelinisierenden Erkrankungen. Sie wird vermutlich durch Autoimmunprozesse ausgelöst. Die geographische Verteilung der Krankheit ist sehr variabel. MS betrifft vornehmlich jüngere Erwachsene und ist durch eine Vielzahl neurologischer Symptome gekennzeichnet. Es gibt bis dato keine zufriedenstellenden Therapiemöglichkeiten.

\subsubsection{Epidemiologie}

Die Prävalenz und Inzidenz ist sehr unterschiedlich verteilt. Die Erkrankung weist in der nördlichen Hemisphäre ein Nord-Süd-Gefälle auf und in der südlichen Hemisphäre ein Süd-Nord-Gefälle: in Nordeuropa, Nordamerika, sowie Australien und Neuseeland gibt es eine hohe und auf der arabischen Halbinsel, Asien, Afrika und Süd-Amerika ein niedrige Prävalenz. Auffällig ist, dass besonders Menschen kaukasischer Abstammung betroffen sind und innerhalb dieser Gruppe besonders Menschen skandinavischer Herkunft (Hogancamp et al. 1997). Innerhalb von Regionen mit hoher Inzidenz gibt es aber auch Bevölkerungsgruppen, die eine sehr geringe Inzidenz aufweisen. So ist zum Beispiel in Rumänien die Inzidenz bei den dort lebenden Sinti und Roma sehr gering, während die Menschen slawischer Abstammung eine dem europäischen Durchschnitt entsprechende Inzidenz zeigen (Kalman und Lublin 1999). Die höchste Inzidenz scheint es in Schottland zu geben (Rothwell und Charlton 1998).

Weltweit gibt es geschätzte 2,5 Millionen MS-Patienten (Compston und Coles 2002). In Deutschland geht man von einer Anzahl an Neuerkrankungen von 7 auf 100000 Personen aus und einer Prävalenz von 150 auf 100000 Personen. Dies würde einer Gesamtzahl von 122000 Patienten in Deutschland entsprechen (Hein und Hopfenmüller 
2000). Ca. 8\% der neurologischen Patienten leiden an MS. Somit ist diese Krankheit die häufigste chronisch-entzündliche Erkrankung des Zentralnervensystems in Deutschland und die häufigste zu permanenten Behinderungen führende Erkrankung der Personen zwischen 20 und 50 Jahren (Compston und Coles 2002). Das Erkrankungsalter liegt meist zwischen 20 und 50 Jahren. Es gibt auch Krankheitsfälle in der Kindheit (Chitnis 2006). Das Geschlechterverhältnis Frauen zu Männer wird mit 1,6:1 angegeben, abhängig von der Verlaufsform der Erkrankung.

\subsubsection{Krankheitsverlauf und Klinik}

Die Erkrankung ist durch einen sehr variablen Verlauf gekennzeichnet und kann fast jedes neurologische Symptom beinhalten. Auf Basis klinischer Untersuchungen lassen sich unterschiedliche Verläufe der MS unterscheiden (Bitsch und Brück 2002). Hierbei teilt man die unterschiedlichen Subgruppen nach dem zeitlichen Auftreten von Symptomen ein:

- Die mit 85\% häufigste Variante, der schubförmig remittierende Verlauf, ist durch ein schubartiges Auftreten von Symptomen mit anschließender Verbesserung gekennzeichnet.

- Der primär progrediente Verlauf geht von Anfang an mit einer schleichenden Zunahme der Symptome einher.

- Der sekundär progrediente Verlauf beinhaltet einen progredienten Verlauf, der nach einem schubförmig remittierenden Verlauf auftritt.

- Der schubförmig progrediente Verlauf ähnelt dem Verlauf der sekundär progredienten MS mit aufgesetzten Schüben.

- Der progredient remittierende Verlauf wird von Vielen als Variante der primär progredienten MS gezählt.

Ob diese unterschiedlichen klinischen Verlaufsformen auf einer echten Heterogenität der Krankheit beruhen (Bitsch und Brück 2002; Lucchinetti et al. 2000), oder ob sie nur Ausdruck der Komplexität der Erkrankung sind (Confavreux und Vukusic 2006), ist Gegenstand der aktuellen Debatte (Thompson 2004). Die unterschiedlichen Verläufe unterscheiden sich in einer Reihe von Aspekten. Am auffälligsten sind die Unterschiede zwischen der schubförmig remittierenden MS und der primär progredienten MS. So ist 
bei diesen zwei Verlaufsformen der durchschnittliche Zeitpunkt des Symptombeginns unterschiedlich, das Geschlechterverhältnis ist anders, die Prognose unterscheidet sich, die kognitiven Fähigkeiten unterscheiden sich und es lassen sich sowohl durch die Kernspintomographie als auch durch das immunogenetische Profil Unterschiede zwischen diesen beiden Formen feststellen (Thompson 2004).

Die Symptome sind vielfältig und relativ unspezifisch. Sie beinhalten meist Seh- oder Sensibilitätsstörungen. Zusätzlich können aber auch weitere Symptome auftreten, wie zum Beispiel Gangstörungen oder Paresen, variable Schmerzsymptome, Störungen der Blasen- oder Mastdarmfunktion, Schwindel, Kleinhirnsymptome, sexuelle Dysfunktionen, kognitive Einbußen und affektive Störungen. Zusätzlich entwickeln bis zu $80 \%$ der Patienten ein Fatigue-Syndrom. Das Ausmaß der Krankheit wird normalerweise durch den sogenannten „extended disability status scale“ oder die „Kurtzke Skala“ angegeben (Roxburgh et al. 2005). Trotz der vielfältigen Symptome haben die Patienten keine oder nur eine leicht verringerte Lebenserwartung.

\subsubsection{Diagnostik der MS}

Als aktueller Standard der Diagnose gelten die 2005 revidierten McDonald-Kriterien, die eine frühe Diagnosestellung der MS möglich machen und die die aktuelle Entwicklung der MS-Forschung berücksichtigen. Als diagnostisches Hauptkriterium gilt die zeitliche und örtliche Dissemination von Läsionen. Der Nachweis dieser Läsionen erfolgt über die klinische Untersuchung, die Kernspintomographie, die Liquorbestimmung und die elektrophysiologische Untersuchung (Polman et al. 2005). Die Diagnostik der MS ist insbesondere bei untypischen Krankheitsverläufen der MS schwierig. Als problematisch gilt die Diagnosestellung der primär progredienten MS sowie die Abgrenzung der MS von anderen Krankheiten aus dem Formenkreis der idiopathischen inflammatorischen demyelinisierenden Erkrankungen.

\subsubsection{Therapie}

Entsprechend dem Modell einer Autoimmunkrankheit beruht die Therapie der MS auf immunmodulatorischen und immunsuppressiven Prinzipien. Die Multiple-Sklerose-Therapie-Konsensus-Gruppe (MSTKG), die seit 1999 Empfehlungen für die Behandlung der MS herausgibt, schlägt die immunmodulatorische Stufentherapie der MS vor. Nach diesem Prinzip gibt es eine Schubtherapie, eine Basistherapie sowie Maßnahmen für eine 
Therapieeskalation (Rieckmann und Toyka 1999). Diese krankheitsbeeinflussenden Medikamente werden ergänzt durch symptomatische Therapiemaßnahmen.

Zur Schubtherapie wird die Steroidtherapie eingesetzt. Sie weist eine signifikante Verbesserung des Grades der Behinderung nach 30 Tagen auf. Eine Verbesserung nach einem Zeitraum von 6 Monaten ist jedoch nicht nachweisbar, ebensowenig eine Reduktion der Schubanzahl oder Schubfrequenz (Brusaferri und Candelise 2000). Die aktuellen Therapieempfehlungen der MSTKG empfehlen die Gabe von 3 x 1g Methylprednisolon sobald wie möglich nach Beginn klinischer Symptome. Bei Versagen dieser Therapie wird eine zweite Gabe von 5 x 2g Methylprednisolon oder die Durchführung einer Plasmaersatztherapie in einem MS-Zentrum (Rieckmann et al. 2004) empfohlen.

Als Basistherapie wird die Anwendung von Beta-Interferonen oder die Gabe von Glatirameracetat empfohlen (Rieckmann 2006). Beta-Interferon kann, eventuell abhängig von der Dosis, die Schubfrequenz senken (Rieckmann et al. 2004). Eingeschränkt wird die Therapie allerdings durch sogenannte neutralisierende Antikörper (Rieckmann 2006). Alternativ zu Beta-Interferon kann auch Glatirameracetat in einer täglichen Dosis von $20 \mathrm{mg}$ s.c. gegeben werden. Diese Therapie reduziert die Schubrate und veringert die durch Kernspintomographie gemessene Krankheitsaktivität (Simpson et al. 2002). Immunglobuline der IgG-Klasse werden nicht als erste Wahl empfohlen, ebensowenig die Behandlung mit Azathioprin; ihr Stellenwert bleibt als Behandlungsmittel der zweiten Wahl aber bestehen. Bei Therapieversagen oder sehr schweren Krankheitsverläufen befürwortet die MSTKG den Einsatz von Natalizumab, einem Hemmer der Interaktionen zwischen Immunzellen und der Blut-Hirn-Schranke, Mitoxantron oder eine Zyklophosphamid-Puls-Therapie (Rieckmann 2006).

Bei der Entwicklung neuer Therapieformen oder der Weiterentwicklung bestehender Therapien muss die Heterogenität der Erkrankung beachtet werden. So ist die Behandlung der primär progredienten und sekundär progredienten MS anders als die Behandlung der schubförmig remittierenden MS. Die vorgeschlagene histopathologische Einteilung der MS nach Lassmann (Lucchinetti et al. 2000) könnte auch therapeutische Konsequenzen nach sich ziehen. So scheint es plausibel, dass die Behandlung durch eine Plasmaersatztherapie den größten Erfolg bei der zweiten histopathologischen Variante, der Antikörper-verursachten Demyelinisierung, zeigt. 


\subsubsection{Pathophysiologie}

Das vorherrschende Konzept zur Pathogenese der MS geht von einem Autoimmunprozess aus, der gegen Bestandteile des Zentralnervensystems gerichtet ist, namentlich die Myelinscheiden, die die Nervenfasern umhüllen. Anhand des Mausmodells der MS wurde eine Reihe von Überlegungen entwickelt, die heute als Grundlage der Erkankungen angesehen werden. So ist die MS eine Erkrankung, die mit der Aktivierung von CD4 ${ }^{+}$ T-Lymphozyten einhergeht. Diese Zellen haben mehrere Ausprägungsformen, unter anderem T-Helferzellen des Typs 1 (Th1), des Typs 2 (Th2) und des Typs 17. In der MS ging man lange Zeit davon aus, das Th1-Zellen den wichtigsten Part übernehmen. Neuere Untersuchungen sprechen auch anderen Zellen des Immunsystems eine wichtige Rolle zu.

Zunächst konzentrierte sich die pathologische Forschung auf aktive Läsionen, die vor allem in der schubförmigen Phase der Erkrankung auftreten. Durch die Weiterentwicklungen der Kernspintomographie-Technik sind aber auch die sich langsam ausbreitenden chronischen Läsionen und die sogenannte normal erscheinende weiße Substanz in den Fokus des Interesses gerückt (Lassmann et al. 2007).

In der aktiven Phase der Krankheit wird den autoreaktiven, vermutlich gegen Myelinbestandteile gerichteten CD ${ }^{+}{ }^{+}$-Zellen eine große Rolle zugesprochen. Solche autoreaktiven Zellen entstehen sowohl bei gesunden Menschen als auch bei erkrankten Menschen. Über die Entstehung gibt es verschiedene Theorien, zum Beispiel, dass diese Zellen sich durch eine Kreuzreaktion mit viralen Proteinen entwickeln oder mit Hilfe von sogenannten Superantigenen. Warum diese Zellen sich bei manchen Menschen aktivierten, ist ungeklärt. Die autoreaktiven T-Lymphozyten penetrieren mit Hilfe von Adhäsionsmolekülen das Endothel in Gehirngefäßen und durchdringen die Astrozytenbarriere mit Metalloproteinasen. Im Zentralnervensystem interagieren die T-Lymphozyten dann mit Mikroglia und initiieren über proinflammatorische Zytokine wie INF $\gamma$, TNF $a$ und IL12 eine Entzündung, die zu einer Zerstörung der Myelinscheiden führt. Weiterhin führt die Entzündungsreaktion zu einer Schädigung der Blut-Hirn-Schranke und erlaubt es Monozyten, Antikörpern und weiteren T-Lymphozyten ins Zentralnervensystem zu gelangen. Dem Verlust der Myelinscheiden wird zum Teil durch Remyelinisierung entgegengewirkt (Goldschmidt et al. 2009). Diese Remyelinisierung kann durch sogenannte Oligodendrozyten-Vorläuferzellen erfolgen, die die zu Grunde gegangenen Oligodendrozyten ersetzen. Neben der Schädigung der Myelinscheiden kommte es auch zu einem variablen Verlust an Axonen. In letzter Zeit wird der Einfluss der B- Lymphozyten besonders diskutiert. Diese werden vermutlich in sogenannten B-Zell-Follikeln durch T- 
Lymphozyten aktiviert und können durch die geschädigte Blut-Hirn-Schranke in das Zentralnervensystem gelangen und dort ihre Antikörper ausschütten. Die Autoantikörper dieser Zellen können dann eine Komplementkaskade aktivieren, die zu einer direkten Lyse der Zellen führt.

In der progressiven Phase der Krankheit sieht das histologische Bild der Krankheit anders aus. Hier entstehen weiterhin Läsionen, allerdings in einer geringeren Anzahl. Zusätzlich scheinen aber die bereits vorhandenen Läsionen langsam zu expandieren und zeigen eine mäßig starke Immunreaktion an den Rändern, wobei hier die Zellzusammensetzung anders als in den aktiven Läsionen ist und nur sehr wenig Makrophagen enthält. Daten der Kernspintomographie weisen auf eine Kompartimentalisierung hin, wobei die histopathologischen Daten dies noch nicht bestätigen können. Neben diesen Veränderungen scheint auch die normal erscheinende weiße Substanz durch eine diffuse Entzündung betroffen zu sein, die sich nicht alleine mit Wallerscher Degeneration erklären lässt. Histologisch finden sich hier weniger T- und B-Lymphozyten, dafür aktivierte Mikroglia. Die Ursache für diese Schädigung ist noch nicht bekannt, könnte aber auf einem Energie- oder Sauerstoffmangel beruhen (Lassmann et al. 2007).

Auch die Entstehung von oxidativem Stress durch reaktive Sauerstoffspezies (ROS) hat einen Anteil an der Entwicklung der MS. Die Sauerstoffradikale entstehen pathologisch durch Makrophagen oder physiologisch durch Glutamat und tragen zur Schädigung des Zentralnervensystems bei (Gilgun-Sherki et al. 2004). Antioxidative Therapie hat sich in mehreren Studien am Mausmodell in vivo als erfolgreich erwiesen. Eine Anwendung bei der MS hat sich bislang noch nicht als wirksam erwiesen. Als Begründung wird vermutet, dass am Ort des Geschehens keine ausreichende Konzentration der antioxidativen Medikation erreicht werden kann (Schreibelt et al. 2007).

\subsection{6 Ätiologie}

Trotz jahrzehntelanger intensiver Forschung ist die Ursache der Erkrankung nicht geklärt. Es gibt sowohl Hinweise auf einen Einfluss von Umweltfaktoren als auch Hinweise auf einen genetischen Hintergrund.

Epidemiologische Untersuchungen und Migrationsstudien weisen auf die Umweltfaktoren hin. Die unterschiedliche Verteilung der Inzidenzen läßt sich nicht allein durch 
Genetik erklären. In Australien und Neuseeland gibt es Gradienten in der Häufigkeit der Inzidenzen, bei denen nicht davon ausgegangen werden kann, dass diese alleine auf genetischen Unterschieden beruhen können (Compston und Coles 2002). Die Konkordanzrate bei eineiigen Zwillingen beträgt $35 \%$.

Migrationsstudien konnten nachweisen, dass Kinder, die vor dem 15. Lebensjahr in eine Region mit einer anderen Inzidenz ziehen, das Erkrankungsrisiko der neuen Region übernehmen und Kinder, die nach dem 15. Lebensjahr umziehen, ihr altes Erkrankungsrisiko behalten (Marrie 2004). Kinder von Immigranten in Großbritannien besitzen das gleiche Risiko, MS zu entwickeln, wie Kinder von Nicht-Immigranten. Damit tragen die Kinder der Immigranten ein höheres Risiko als ihre Eltern (Marrie 2004).

Potentielle Umweltfaktoren sind Infektionen, Impfungen, Stress, Berufsgewohnheiten, Klima und Ernährungsgewohnheiten. Generell kann bei keinem der vielen Faktoren von einem klaren Zusammenhang ausgegangen werden. Vielfach wird nach Zusammenhängen zwischen MS und Infektionskrankheiten gesucht. So fanden mehrere Studien eine erhöhte Seroprävalenz von Epstein-Barr-Virus-Antikörpern bei MS-Patienten (Marrie 2004). Neuerdings werden vor allem das Humanes-Herpes-Virus 6 und Chlamydia pneumoniae untersucht. Jedoch ist die Evidenz für einen Zusammenhang bei beiden Erregern schwach.

Frauen sind, wie bei vielen Autoimmunerkrankungen, häufiger von der MS betroffen. Diese Tatsache ist Gegenstand vielfältiger Untersuchungen. Ursachen werden in dem veränderten hormonellen Profil vermutet. Eine Hypothese besagt, dass Frauen generell eher zu einem Th1-Shift neigen. Östrogene scheinen die Produktion der Th1-Zytokine anzuregen, während Testosterone diese eher hemmen (Whitacre 2001). In der Schwangerschaft kommt es, vor allem im letzten Drittel, zu einer Verbesserung der Erkrankung, während es post partum zu einer Exazerbation kommt. Dies könnte daran liegen, dass es während der Schwangerschaft zu einer Suppression der Th1-Zytokine kommt (Whitacre 2001).

Die MS wird durch die Genetik beeinflusst, ist aber keine klassische Erbkrankheit und folgt keinem Mendelschen Erbgang. Sie ist also als eine polygenetische Krankheit anzusehen. Hinweise auf eine genetische Beteiligung liefern Untersuchungen von Multiplex-Familien. Aus diesen weiß man, dass die Konkordanz bei erstgradigen Ver- 
wandten zwischen 3\% und 5\% liegt. Gegenüber dem Risiko der Normalbevölkerung von 0,1\% bedeutet das ein um 30\%-50\% erhöhtes Risiko. Das Erkrankungsrisiko eines monozygotischen Zwillings liegt bei 35\%, während das Risko von zweieiigen Zwillingen unter $5 \%$ beträgt (Kalman und Lublin 1999). Das relative Risiko ist für Halbgeschwister geringer als für normale Geschwister. Auffallend ist der Mangel an Vater-Sohn-Konkordanz, der auch einen mitochondralen Erbgang möglich erscheinen lässt.

Polygenetische Krankheiten beruhen in der Regel nicht auf einer Mutation, die ein einzelnes Gen betrifft, sondern meist auf verschiedenden Genen und Polymorphismen, deren Zusammenspiel eine Person anfälliger für die Krankheit machen kann. Auf Basis der Autoimmunhypothese wurde vornehmlich nach Genen gesucht, die entweder eine Rolle im Immunsystem oder in der Myelinproduktion spielen. Bislang wurden 6 genetische Assoziationsstudien bei der Erkrankung MS durchgeführt. Dabei zeigt sich, dass Nukleotidvariationen des Interleukin-7-Rezeptors, des Interleukin-2-Rezeptors und des Proteins CLE16a (C-typ Lectin Domäne Familie 16 member A) häufig mit MS assoziiert sind (Hoffjan und Akkad 2010). Ebenfalls wird eine Verbindung zwischen dem Haupthistokompatibilitätskomplex (MHC) der Klasse DR15, DQ6 und Dw2 und der Erkrankung hergestellt. Studien über andere Gene, wie zum Beispiel Gene der Komplementkaskade, Transportproteine, Tumor-Nekrose-Faktoren oder Myelin-Oligodendrozyten-Glykoproteine, lieferten widersprüchliche Resultate (Kalman und Lublin 1999).

\subsubsection{Histopathologie}

MS ist histopathologisch durch verschiedene Merkmale gekennzeichnet: durch Entzündungsherde mit T-Lymphozyten, B-Lymphozyten, Makrophagen, Mikroglia, durch Demyelinisierung, durch Verlust von Oligodendrozyten, durch axonale Schädigung, durch Gliose mit Astrozytenproliferation, aber auch durch regenerative Prozesse wie Remyelinisierung (Brueck und Stadelmann 2005). Das histologische Bild ist heterogen. Im Jahr 2001 schlugen Lassmann et al. eine histologische Einteilung vor, die aus vier Kategorien besteht:

- In der ersten Kategorie wird das Bild von Makrophagen und T-Lymphozyten dominiert. Die Läsionen sind meist um Venen gruppiert, es gibt ein scharf begrenztes Areal, das radial expandiert. Es kommt zu starker Demyelinisierung, aber auch zu rascher Remyelinisierung. Als Mechanismus käme eine Schädigung der Myel- 
inscheiden durch Makrophagentoxine in Frage, wobei die Entzündung auf einem starken Einfluss der T-Lymphozyten beruht.

- Die zweite Kategorie ähnelt der ersten, ist aber zusätzlich durch eine Ablagerung von Komplementfaktoren und Immunglobulinen in den Läsionen gekennzeichnet. Hier ließe sich ein Abbau des Myelins auch durch Komplement-assoziierte Immunreaktionen erklären.

- Die dritte Kategorie ist durch die Apoptose der Oligodendrozyten und eine Entzündung der kleinen Gefäße „small vessel vasculitis“ gekennzeichnet. Auch hier spielen T-Lymphozyten und Makrophagen eine wichtige Rolle. Die Ursache der Schädigung könnte auf ischämischen Ursachen beruhen.

- In der vierten Kategorie gibt es einen primären Untergang der Oligodendrozyten im periläsionalen Bereich und eine sekundäre Demyelinisierung. Bei dieser Kategorie könnte ein metabolischer Defekt der Oligodendrozyten beteiligt sein (Lassmann et al. 2001).

Diese vier Kategorien lassen sich nicht mit den bekannten klinischen Subtypen korrelieren und die aktuelle Debatte beschäftigt sich damit, ob die einzelnen Kategorien bei einem Patienten stabil während der ganzen Zeit ausgeprägt sind, oder ob die beobachteten Kategorien eine Zeitabfolge der Schädigung darstellen (Barnett und Sutton 2006; Brueck und Stadelmann 2005; Breij et al. 2008).

\subsubsection{Tiermodelle}

Um die MS abzubilden, gibt es mehrere Tiermodelle. Die experimentelle autoimmune Enzephalomyelitis (EAE) ist das am häufigsten benutzte Modell. Neben diesem gibt es noch die toxischen Tiermodelle wie das Cuprizon-Modell, die viralen Tiermodelle wie die Theilersche Enzephalomyelitis, und genetische Modelle. Diese Tiermodelle reflektieren gewisse Merkmale der MS und werden jeweils für andere Teilaspekte der Krankheit benutzt. So wird zum Beispiel das Cuprizon-Modell hauptsächlich dafür benutzt, die Vorgänge der De- und Remyelinisierung aufzuklären. Die Versuche mit EAE reichen bis in die Anfänge des letzten Jahrhunderts zurück. Seitdem wurde die EAE in zahlreichen Versuchstierspezies etabliert (Baxter 2007). 
Es gibt eine aktive EAE und eine passive EAE. Die aktive EAE wird üblicherweise durch die Applikation von Bestandteilen des Zentralnervensystems zusammen mit einem Adjuvans hervorgerufen. Früher wurde ein ZNS-Homogenat benutzt, gegenwärtig verwendet man aufgereinigte Bestandteile der Myelinscheiden, insbesondere das Myelinbasische-Protein (MBP), das Myelin-Oligodendrogliale-Glykoprotein (MOG) und das Proteolipid-Protein (PLP). Eine EAE kann aber auch durch Astrozyten- oder Neuronenbestandteile hervorgerufen werden. Die passive EAE, auch Adoptive-Transfer-EAE genannt, wird durch aktivierte, gegen Myelinbestandteile gerichtete T-Lymphozyten hervorgerufen, die den Tieren „passiv“ gespritzt werden. Jede dieser unterschiedlichen Techniken zeigt je nach Tierspezies und Tierstamm Unterschiede in der Ausprägung der EAE: Die Injektion von PLP z.B. ruft eine mehrphasische Variante der EAE hervor, bei der Injektion von $\mathrm{MOG}_{33-55}$ bleibt es bei einer monophasischen Krankheit.

Auf der Basis der Studien über EAE wurden mehrere Medikamente entwickelt, die derzeit beim Menschen eingesetzt werden: Glatirameracetat, Mitoxantron und Natalizumab (Baxter 2007). Trotz dieser Erfolge ist die EAE-Forschung aber auch durch herbe Rückschläge gekennzeichnet: so sind diese drei genannten Medikamente die einzigen aus einer langen Liste von versuchten Therapiemöglichkeiten, die im Tiermodell der EAE entwickelt wurden (Sriram und Steiner 2005).

Die EAE und die MS haben viele Ähnlichkeiten miteinander: die Zerstörung der Myelinscheiden, das Vorhandensein von multiplen Läsionen des Zentralnervensystems, die Disseminierung in Zeit und Raum, die hauptsächlich perivaskuläre Lokalisation der Läsionen, die Entwicklung der Läsionen, die mit Entzündung anfängt und über Demyelinisierung und Gliose zur teilweisen Remyelinisierung fortschreitet, und das Vorhandensein von Immunglobulinen in der Nervenflüssigkeit (Baxter 2007). Trotz aller Gemeinsamkeiten gibt es viele Unterschiede zwischen den beiden Erkrankungen: Erstens ist die EAE meist eine monophasische Krankheit und ähnelt damit mehr der akuten disseminierten Enzephalomyelitis, einer anderen Erkrankung aus dem Formenkreis der idiopathisch inflammatorischen demyelinisierenden Erkrankungen (Sriram und Steiner 2005). Zweitens befinden sich die Läsionen bei der EAE eher im Rückenmark und bei der MS im Gehirn. Drittens sieht man eine andere Zusammensetzung der Zellen: in der EAE, die durch MBP und PLP hervorgerufen wird, bestimmen $\mathrm{CD} 4^{+}$-Zellen das histologische Bild, während in der MS mehr CD8 ${ }^{+}$-Zellen zu finden sind. Viertens ist die Rolle der B-Lymphozyten in der EAE unterrepräsentiert (Lassmann et al. 2007; Sriram und Steiner 2005). 
Aufgrund dieser Unterschiede beurteilen viele dieses Tiermodell kritisch. Doch sind viele pathophysiologische Vorgänge der MS durch die EAE verständlicher geworden. Die EAE ist als Modell für Teilaspekte der Erkrankung MS weithin anerkannt (Gold et al. 2006).

\subsection{Dopamin}

\subsubsection{Dopamin und Dopamin-Rezeptoren}

Dopamin ist ein Hormon und Neurotransmitter und erfüllt viele Funktionen im menschlichen Körper. Es ist ein Katecholamin und wird aus Tyrosin über die Zwischenstufe Dopa synthetisiert. Dopamin selber kann in Noradrenalin umgewandelt werden. Aufgrund seiner Herkunft als Katecholamin wirkt es auch auf die Katecholaminrezeptoren. Des Weiteren wirkt es über sogenannte Dopamin-Rezeptoren, die bei den Säugetieren in zwei große Klassen eingeteilt werden: Die Rezeptoren vom D1-Typ und die Rezeptoren vom D2Typ. Zum D1-Typ gehören der Dopamin-Rezeptor D1 und der Dopamin-Rezeptor D5, der früher Dopamin-Rezeptor D1b genannt wurde. Zum D2-Typ gehören die DopaminRezeptoren D2, D3 und D4. Die zwei unterschiedlichen Typen unterscheiden sich in ihrer Wirkungsweise: so sind die Rezeptoren D1 und D5 dadurch gekennzeichnet, dass sie über die Adenylatzyklase eine Erhöhung des zyklischen Adenosinmonophosphat verursachen, die Rezeptoren D2, D3 und D4 dagegen wirken über ein hemmendes G-Protein negativ auf cAMP ein. Alle Dopamin-Rezeptoren sind G-Protein-gekoppelte Rezeptoren und bestehen aus 7 Transmembrandomänen (Pivonello et al. 2007).

Der D2-Rezeptor exisistert in zwei Unterformen. Diese entstehen durch alternatives Splicing. Es gibt die lange Form D2l und die kurze Form D2s. Die lange Form besitzt in der dritten Schleife 29 Aminosäuren mehr als die kurze Form. Längere Zeit hielt man die beiden Isoformen für funktional identisch. Usiello et al. konnten jedoch zeigen, dass die Isoformen unterschiedliche Wirkungen besitzen. Man geht davon aus, dass die lange Form D21 häufiger postsynaptisch sitzt und synergistisch mit D1 wirkt, während die kurze Form D2s häufiger präsynaptisch sitzt und hemmend auf die D1-Funktion einwirkt (Usiello et al. 2000).

Dopamin-Rezeptoren sind weit verbreitet und kommen auf vielen Zellen vor. D2Rezeptoren kommen vor allem im Striatum vor, aber auch im präfrontalen, temporalen, 
entorhinalen Kortex, im Gyrus cinguli, im Septum, in der Amygdala, im Hippokampus und in der Schilddrüse. D3-Rezeptoren sind vornehmlich in den limbischen Gebieten zu finden, wobei sie auch im Septum, im Hippokampus und im medialen Temporallappen zu finden sind (Rosin et al. 2005). Dopamin-Rezeptoren sind auch auf Gliazellen, wie Oligodendrozyten (Rosin et al. 2005; Bongarzone et al. 1998), zu finden. In der Peripherie sind Dopamin-Rezeptoren vor allem auf Endothelzellen, in der Niere, im Nebennierenmark, auf Thrombozyten und im peripheren Nervensystem exprimiert (Missale et al. 1998; Beck et al. 2004). Daneben befinden sich Dopamin-Rezeptoren aber auch auf Zellen des menschlichen Immunsystems, wie T-Lymphozyten, B-Lymphozyten, Makrophagen und natürlichen Killerzellen (Basu und Dasgupta 2000; McKenna et al. 2002). Bisher wurde der Schwerpunkt auf humane Lymphozyten gelegt. Murine Immunzellen sind weniger gut untersucht. Bislang gibt es Nachweise für Dopamin-Rezeptoren auf murinen Lymphozyten allgemein (Fur et al. 1980; Caronti et al. 1998; Tomassoni et al. 2002) beziehungsweise auf Subgruppen wie den CD8 ${ }^{+}$-Zellen (Watanabe et al. 2006) und regulatorischen T-Lymphozyten (Kipnis et al. 2004). Für eine Literaturübersicht vergleiche Tabelle 6.1 auf Seite 53.

\subsubsection{Krankheiten, die auf Störungen des Dopaminsystems beruhen}

Veränderungen des Dopaminhaushaltes werden für verschiedene Krankheiten mitverantwortlich gemacht: Schizophrenie, idiopathisches Parkinson-Syndrom, Chorea Huntington, Tourette-Syndrom, Aufmerksamkeitsdefizit-/Hyperaktivitätsstörung, Drogenabhängigkeit, Depression, Übergewicht, Epilepsie. Vergleiche Schaubild 6.1 auf Seite 66

Beim idiopathischen Parkinson-Syndrom beruhen die Symptome auf einem Untergang der dopaminproduzierenden Neurone in der Substantia nigra. Die Kardinalsymptome bestehen aus Akinese, Rigor und Ruhetremor, zusätzlich kommt es zu sensorischen Symptomen, vegetativen Störungen und psychischen Veränderungen. In der Behandlung war die Entdeckung des L-Dopa ein großer Durchbruch für die Patienten. L-Dopa wird im Gehirn in Dopamin umgewandelt und führt zu einer Verbesserung der Symptomatik. Neben L-Dopa werden auch Mutterkornalkaloide wie Bromocriptin und Pergolid gegeben, sowie selektive D2/D3-Agonisten wie Pramipexol.

Bei der Schizophrenie wird eine Entgleisung des Dopaminsystems mit regionalem Mangel bzw. regionalem Überfluss an Dopamin angenommen. Bei dieser Krankheit kommt es zu Störungen des Denkens, der Wahrnehmung und der Affektivität. Behandelt werden 
Schizophrenie-Patienten mit Neuroleptika, deren Hauptwirkung auf der Hemmung von Dopamin beruht.

Sowohl beim idiopathischen Parkinson-Syndrom als auch bei der Schizophrenie gibt es Veränderungen in der Immunantwort. So ist beim idiopathischen Parkinson-Syndrom die Proliferation von peripheren Lymphozyten vermindert, die Patienten haben eine verringerte Antikörper-Produktion, eine geringere Anzahl von CD4 ${ }^{+}$-T-Lymphozyten, und es gibt Hinweise auf eine reduzierte Anzahl an zytotoxischen T-Lymphozyten (Basu und Dasgupta 2000). Bei Schizophrenie gibt es eine erhöhte Anzahl an CD4 ${ }^{+}{ }_{-}$T- $^{-}$ Lymphozyten und veränderte Werte von IL-2 und IL-6. Da allerdings auch Patienten mit Neuroleptika-Therapie in der Studie zugelassen wurden, könnten diese Effekte auch von der Behandlung kommen (Basu und Dasgupta 2000).

\subsubsection{Medikamentöse Beeinflussung des Dopaminsystems}

Das Dopaminsystem lässt sich therapeutisch relativ gut beeinflussen. Schon seit längerer Zeit werden mit L-Dopa, Dopaminagonisten oder Dopaminantagonisten verschiedene Krankheiten therapiert. Bei einer Überdosierung von Dopaminantagonisten kommt es zu parkinsonoiden Symptomen, während es bei einer Überdosierung von L-Dopa, bzw. Dopaminagonisten zu wahnhaften Vorstellungen kommen kann.

Bei den Dopaminagonisten kann man Mutterkornalkaloidderivate, wie z. B. Bromocriptin, Cabergolin, Dihydroergocryptin, Lisurid und Pergolid von synthetischen Agonisten wie Pramipexol und Ropinirol unterscheiden. Die Agonisten unterscheiden sich in ihrem Vermögen, bestimmte Unterklassen der Dopamin-Rezeptoren zu erregen. Die Mutterkornalkaloide, die synthetischen Agonisten und auch L-Dopa besitzen zusätzlich antioxidative Effekte (Spencer et al. 1996; Ferrari-Toninelli et al. 2010).

\subsubsection{Funktionen von Dopamin}

In der Peripherie wirkt Dopamin als Hormon über Katecholaminrezeptoren und ändert den Gefäßtonus, die Herz- und Nierenfunktion und die Hormonausschüttung (Missale et al. 1998). Zusätzlich wirkt Dopamin aber auch hemmend auf das Immunsystem, indem es die Ausschüttung von Zytokinen, Chemokinen und Adhäsionsmolekülen verringert und anti-inflammatorische Mediatoren ausschüttet (Beck et al. 2004). 
Im menschlichen Gehirn wirkt Dopamin als Neurotransmitter. Man kann drei bis vier unterschiedliche Dopaminsysteme unterscheiden: das Mesolimbische, das Nigrostriatale, das Mesokortikale und das Tuberoinfundibuläre (Schüle et al. 2007; Bozzi und Borrelli 2006). Vergleiche Schaubild 6.1 auf Seite 66. Diese Systeme beeinflussen eine Reihe von Funktionen wie die Extrapyramidalmotorik, die Wahrnehmung, die Motivation, die emotionale Steuerung, die Nahrungsaufnahme, die Suchtentwicklung und die Inhibition des Hormons Prolaktin.

Dopamin besitzt immunmodulatorische Eigenschaften. Bei Untersuchungen zur Schockbehandlung stellte man neben dem erwünschten vasopressorischen auch einen immunmodulatorischen Effekt fest. 1980 wurden von Fur et al. erste Hinweise für DopaminRezeptoren auf Lymphozyten publiziert (Fur et al. 1980). Auch wurde nachgewiesen, dass Lymphozyten selber Dopamin ausschütten können (Ricci et al. 1999). Die genaue Wirkung von Dopamin auf das Immunsystem ist noch nicht eindeutig charakterisiert. Vielfach wird eine Änderung im Zytokinprofil postuliert. Es scheint, als ob eine Aktivierung der D1-ähnlichen Rezeptoren eher einen Th2-Shift auslöst und eine Aktivierung von D2-ähnlichen Rezeptoren einen Th1-Shift (Nakano et al. 2009; Ilani et al. 2004). Dopamin fördert die Ausprägung verschiedener Oberflächenmarker und Zelladhäsionsmoleküle (Ilani et al. 2004; Levite et al. 2001), auch die Lymphozyten-Proliferation wird beeinflusst (Saha et al. 2001; Cosentino et al. 2007; Morkawa et al. 1993; Beck et al. 2004).

Neben der Immunmodulation spielen Dopamin-Rezeptoren auch eine Rolle beim Zellüberleben. Verschiedene Arbeiten zeigen, dass die Aktivierung von neuronalen D2 und D3-Dopamin-Rezeptoren neuroprotektiv wirken. Dazu wurden sowohl in vivo als auch in vitro Ansätze gewählt. In vivo kann Bromocriptin Neurone vor einem Glutamatinduzierten Zelltod schützen. Der hierbei vermutete Mechanismus läuft über die Aktivierung der Phosphatidyl-Inositol-3-Kinase durch den D2-Rezeptor und den darauffolgenden Weg über AKT hin zum antiapoptotischen Protein Bcl-2 (Kihara et al. 2002). Ein weiterer Weg, über den Dopaminagonisten neuroprotektiv wirken könnte, ist über die Synthese von Radikalfängern, die von dopaminergen Neuronen produziert werden und sowohl dopaminerge, als auch nicht-dopaminerge Neurone schützen können. Als mögliche Radikalfänger werden die Superoxid-Dismutase und der „glial cell line-derived neurotrophic factor" genannt (Sawada et al. 1998). Es wird gezeigt, dass Bromocriptin auch in vivo einen neuroprotektiven Effekt aufweist und bei experimenteller zerebraler 
Ischämie das Zellüberleben verbessert (Liu et al. 1995). Diese Experimente könnten eine Erklärung für den von Struck gezeigten Effekt sein, dass Parkinson-Patienten mit Behandlung ein verringertes Risiko für einen Schlagafall haben (Struck et al. 1990). Dopamin-Rezeptoren auf Oligodendrozyten können diese gegen oxidativen Stress schützen. Dabei spielen rezeptorvermittelte Wirkungen eine entscheidende Rolle (Rosin et al. 2005). Bongarzone et al. schlagen vor, dass Dopamin-Rezeptoren auf Oligodendrozyten die Proliferation beeinflussen (Bongarzone et al. 1998).

\subsubsection{Prolaktin und sein Einfluss auf das Immunsystem}

Prolaktin ist ein Hormon und Zytokin, das im Hypophysenvorderlappen und in der Plazenta gebildet wird. Es ähnelt dem Wachstumshormon und ist strukturell den Zytokinen ähnlich. Stimuliert wird die Ausschüttung von Thyreoliberin und inhibiert durch Dopamin über D2-Rezeptoren (Fitzgerald und Dinan 2008). Es unterliegt einem zirkadianen Rhythmus, mit dem höchsten Spiegel nachts. Prolaktin wird bei Frauen vermehrt ab der zweiten Hälfte der Schwangerschaft sowie während der Laktation gebildet. Dabei kommt das Prolaktin zum Teil aus dem Endometrium.

In den letzten Jahren hat sich herausgestellt, dass Prolaktin eine wichtige Rolle im Immunsystem spielt. Es kann neben seiner Eigenschaft als Hormon als Zytokin wirken und moduliert das angeborene und das spezifische Immunsystem (Jara et al. 2009). Kelley et al. sprechen von einer „Two-Way-Street“, also einer hormonellen Wirkung auf der einen und einer Immunmodulatorischen Wirkung auf der anderen Seite (Kelley et al. 2007). Varianten von Prolaktin, zum Beispiel das sogenannte immunoreaktive Prolaktin, werden von Lymphozyten synthetisiert. Prolaktin-Rezeptoren sind bei Menschen und Nagetieren auf Monozyten und Lymphozyten vorhanden (Russell et al. 1984; Jara et al. 2009).

Bei manchen Immunerkrankungen kann der Einfluss der Hyperprolaktinämie als gesichert gelten, zum Beispiel bei der Rheumatoiden Arthritis, beim systemischen Lupus erythematodes und bei der Autoimmunthyreoiditis (McMurray 2001). Bei der MS wird ein Zusammenhang vermutet (Nociti et al. 2010). Azar und Yamout fanden einen leicht erhöhten Basis-Wert von Prolaktin sowie eine stärkere Prolaktinantwort auf ThyreoliberinGabe (Azar und Yamout 1999). Kira et al. zeigen ebenfalls einen erhöhten Prolaktinwert bei MS-Patienten und eine Korrelation mit der Kurtzke-Skala (Kira et al. 1991). Harrichian et al. dagegen führten eine Case-Control Studie durch, wobei sie keinen Unterschied 
im Prolaktinniveau von MS-Patienten im Vergleich zu Kontrollpersonen fanden (Harirchian et al. 2006). Nociti et al. berichten von einem Patienten, dessen MS-Schübe durch eine Hyperprolaktinämie getriggert wurden (Nociti et al. 2010). Im Ratten-EAE-Modell finden sich erhöhte Prolaktinwerte (Riskind et al. 1991).

Die Prolaktin-Rezeptoren führen über Dimerisierung des Rezeptors zu einer Aktivierung einer Janus Kinase, die dann wiederum sogenannte STAT-Moleküle aktiviert (Tomio et al. 2008). Weiterhin sind Moleküle wie MAPK und PI3K als mögliche Zielmoleküle in der Diskussion (Jara et al. 2009).

Die genauen Effekte von Prolaktin auf das Immunsystem sind noch nicht geklärt. Vermutet wird ein Dosis-abhängiger Effekt, der bei niedrigem Level von Prolaktin (10-30 ng $\mathrm{ml}^{-1}$ ) die Ausschüttung von Th1-Zytokinen fördert und bei hohen Dosen (mehr als 100 ng $\mathrm{ml}^{-1}$ ) eine milden supprimierenden Effekt hat (Tomio et al. 2008). Darüber hinaus führt Prolaktin zu einer Ausschüttung von Antikörpern (Jara et al. 2009). Besonders relevant für die MS und die EAE könnte die Rolle von Prolaktin in der Stimulierung der oligodendrozytären Vorläuferzellen sein. Diese Vorläuferzellen spielen eine wichtige Rolle bei den Reparaturen der Myelinscheiden. Über die genaue Regulation dieser Zellen ist bislang wenig bekannt. Es gibt Vermutungen, dass Prolaktin hier eine Rolle spielen könnte, indem es die oligodendrozytären Zellen fördert (Gregg 2009).

Bouchard et al. untersuchten aufgrund der Entdeckung der Rolle von Prolaktin als Immunmodulator Prolaktin-Knockout Mäuse. Diese zeigten keine Veränderung in ihrem immunologischen Verhalten. Die Autoren vermuten also, dass die Rolle von Prolaktin als Immunmodulator eher gering oder redundant ist (Bouchard et al. 1999).

\subsubsection{Knockout-Mäuse mit Veränderungen im Dopaminsystem}

In den 90er-Jahren wurden mit Hilfe von homologer Rekombination mehrere Mausmodelle etabliert, die defizient für Dopamin, Dopamintransporter oder spezifische DopaminRezeptoren sind (Glickstein und Schmauss 2001). Mäuse mit einem veränderten Dopaminlevel oder veränderter Anzahl von Dopamintransportern sind schwer beeinträchtigt. Gut sichtbar ist dies am Aktivitätslevel. Mäuse, die defizient für Dopamin sind, entwickelten eine schwere Hypoaktivität, die bis zum Tode führt, Mäuse mit einer Veränderung der Dopamintransporter sind hyperaktiv. Im Vergleich dazu sind die Ausprägungen bei einem Ausschalten der Rezeptoren gering. 
Mäuse mit einer D2-Null-Mutation wurden erstmalig 1995 von Baik generiert. Diese Mäuse zeigen eine starke neurologische Fehlsteuerung mit verändertem motorischen Verhalten, einer mangelnden Fortpflanzungsfähigkeit, Veränderungen im Suchtverhalten gegenüber Morphin, eine anteriore Hypophysenhyperplasie und eine Hyperprolaktinämie (Baik et al. 1995; Sibley 1999). Die vorliegende Arbeit verwendet Mäuse, die von Kelly 1997 entwickelt wurden (Kelly et al. 1997). Hierbei handelt es sich um eine DeletionsMutation. Diese Mäuse wurden durch gezielte Mutagenese erstellt, bei der ein Stück des C-Terminalen Segments des Dopamin-Rezeptors entfernt wurde. Sie zeigen eine selektive Hyperplasie der laktotrophen Zellen der Hypophyse, eine Hyperprolaktinämie und ein vermehrtes Vorhandensein von Uterus-Adenomen. Im Gegensatz zu den von Baik entwickelten Mäusen zeigen die Deletionsmäuse keine Veränderung des motorischen Verhaltens. Auch eine Fortpflanzung ist möglich. Diese Unterschiede könnten neben der unterschiedlichen Genveränderung an den verwendeten Mausstämmen 129 und C57BL/6 liegen (Sibley 1999). Usiello et al. konnten 2000 ein Knockout-Modell für den Subtyp D2l herstellen (Usiello et al. 2000).

Die von uns verwendeten Mäuse ohne D3-Rezeptor wurden von Accili 1996 entwickelt (Accili et al. 1996). Hierbei wurde eine Veränderung der genetischen Sequenz in der zweiten intrazellulären Schleife induziert, die zu einem Abbruch der Protein-Translation führt (Accili et al. 1996). Diese Mäuse zeigen eine normale Fortpflanzungsfähigkeit, ein normales Aussehen und Wachstum. Neurologisch fällt in veränderter Umgebung eine vermehrte Hyperaktivität auf, die auf ein reduziertes Angstlevel zurückgeführt wird (Sibley 1999).

\subsubsection{Dopaminmodulierende Therapieversuche bei EAE und MS}

Angesichts des Zusammenhangs zwischen Prolaktin und dem Immunsystem führten Riskind und Kollegen eine Experiment durch, bei dem sie Lewis-Ratten mit Meerschweinchen-Rückenmarks-Homogenat immunisierten und mit Bromocriptin behandelten. Die Autoren zeigten, dass die Gabe von Bromocriptin den klinischen Verlauf der EAE positiv beeinflussen konnte (Riskind et al. 1991). 1993 führten Dijkstra und Kollegen (Dijkstra et al. 1994) ein ähnliches Experiment durch und fanden ebenfalls einen Unterschied im klinischen Verlauf, auch wenn die Behandlung erst nach Beginn der ersten Symptome erfolgte. Balkowiec et al. verwendeten eine Dopamin-Depletion durch MPTP und fan- 
den, dass der Krankheitsverlauf der EAE sich dadurch verschlechterte (Bałkowiec-Iskra et al. 2007).

Aufgrund der erfolgreich verlaufenden Experimente von Riskind führten Bissay und Kollegen eine offene klinische Studie durch. Dabei bekamen 18 Patienten während des Zeitraums von einem Jahr täglich 2 mal 2,5 mg Bromocriptin. Evaluiert wurde nach der „expended disability status scale“. Drei Patienten haben die Therapie abgebrochen. Bei den 15 gewerteten Patienten konnte nicht auf einen positiven Effekt von Bromocriptin auf MS geschlossen werden (Bissay et al. 1994).

MS-Patienten bekommen häufig nächtliche Unruhezustände, die sich vor allem auf die Beine auswirken, das sogenannte Restless-Legs-Syndrom. Die Standard Therapie besteht in der Gabe von L-Dopa oder Dopaminagonisten. Über eine Beeinflussung des Verlaufs der MS liegen keine Daten vor.

\subsection{Fragestellung der vorliegenden Arbeit}

Dopamin ist einer der wichtigsten und einflussreichsten Neurotransmitter im Nervensystem. Darüber hinaus ist der Botenstoff in vielen anderen Bereichen mit eingebunden, unter anderem im Immunsystem als Zytokin. Die EAE und die MS stellen hochkomplexe Krankheitsentitäten dar und interagieren mit einer Vielzahl an Systemen. Insofern sind die Interaktionen zwischen Dopamin und MS bzw. EAE mannigfaltig. Mehrere Wege sind hier zu bedenken: 1) Die rezeptorgebundene Wirkung des Dopamins auf Lymphozyten und andere Immunzellen. 2) Der rezeptorvermittelte Einfluss von Dopamin auf Oligodendrozyten und Neurone. 3) Eine Veränderung des Prolaktinspiegels. 4) Die Eigenschaften von Dopaminagonisten und L-Dopa als Radikalfänger. Von Bedeutung sind aber auch die Interaktionen zwischen Dopamin auf der einen Seite und dem Katecholamin-System auf der anderen Seite und die Wirkung von Dopamin auf Endothelzellen.

In der vorliegenden Arbeit soll die Rolle der Dopamin-Rezeptoren bei der EAE untersucht werden, um den Stellenwert des Dopaminsystems im Krankheitskomplex der entzündlich-entmarkenden Krankheiten bestimmen zu können. Dazu verglichen wir im Mausmodell der EAE die Entmarkung von Dopamin-Rezeptor-Knockout-Mäusen im Vergleich zu den dazugehörigen Wildtyp-Mäusen . Einen besonderen Fokus legten wir auf myelinbildende Zellen. 


\section{Material und Methoden}

\subsection{Durchführung der Tierexperimente}

Die Experimente wurden entsprechend den institutionellen und nationalen Vorschriften durchgeführt. Die käuflich erworbenen Mäuse (Jackson Laboratories) wurden für mindestens fünf Tage an die Haltungsbedingungen gewöhnt. Alle Mäuse wurden in licht- und temperaturregulierten Räumen gehalten, hatten freien Zugang zu Wasser und Pressfutter bzw. Breifutter. Für die Induktion der EAE wählten wir die Methode der aktiven MOG $33-55$-Immunisierung, zusammen mit komplettem Freund'schen Adjuvans. Zur Evaluation der EAE wurden die Mäuse ab Tag 7 täglich nach der international gebräuchlichen Symptomskala evaluiert (vergleiche Tabelle 6.2 auf Seite 54), zusätzlich wurde das Gewicht gemessen. Die Tiere wurden entweder kurz nach dem Beginn der ersten Symptome oder nach einem Zeitraum von 77 Tagen perfundiert und für die Histologie vorbereitet. Um die Belastung der Tiere so gering wie möglich zu halten, galt eine Paraplegie als Indikation zur sofortigen Perfusion. Eine Übersicht über die verwendeten Materialen befindet sich auf Seite 60 in der Tabelle 6.12, eine Übersicht über die verwendeten Tiermodelle befindet sich auf Seite 60 in der Tabelle 6.11. Die Induktion erfolgte gemäß dem Protokoll in Tabelle 6.5 auf Seite 55, die Perfusion gemäß dem Protokoll in Tabelle 6.6 auf Seite 55 .

\subsection{Durchführung der histologischen Färbungen}

Die Färbungen der Rückenmarksquerschnitte wurden in Zusammenarbeit mit den Mitarbeitern der neuropathologischen Abteilung der Georg-August-Universität Göttingen durchgeführt. Wir verwendeten histologische und immunhistochemische Methoden. Ein Überblick über die verwendeten Materialen ist in Tabelle 6.13 auf Seite 61 und in Tabelle 6.14 auf Seite 62 zu finden.

Die histologischen Färbungen färben intrazelluläre und/oder extrazelluläre Bestand- 
teile an und ermöglichen so das Erkennen von Gewebseigenschaften. Wir verwendeten die Bielschowsky-Versilberung und die Luxol-Fast-Blue/Perjodsäure-Schiff-Färbung (LFB/PAS).

- Die Bielschowsky-Versilberung ist eine Verbesserung der Färbetechnik nach Ramon y Cajal. Dabei werden neuronale Fortsätze schwarz bzw. dunkelbraun angefärbt. Das Protokoll befindet sich auf Seite 56 in Tabelle 6.7.

- Bei der LFB/PAS-Färbung werden Markscheiden blau angefärbt und neutrale Glykosaminoglykane, Kohlenhydrate und Glykogen rot. Dabei reagiert LFB mit den Basen der Lipoproteine des Myelins und ändert dabei die Farbe in ein tiefes Blau. PAS oxidiert unsubstituierte 1,2 Glykole und färbt damit Bindegewebsfasern, Basalmembrane, Zellwände und glykogenhaltige Zellen rot an. Das Protokoll befinden sich auf Seite 57 in Tabelle 6.8.

Die Immunhistochemie beruht auf Antikörpern, die bestimmte Antigene binden und damit sichtbar machen können. Dadurch ist es möglich, bestimmte Zellpopulationen, die durch die Expression eines Antigens charakterisiert werden, anzufärben. Der erste Antikörper, der gegen das Antigen gerichtet ist, wird dabei durch einen zweiter Antikörper sichtbar gemacht, der an den $\mathrm{F}_{\mathrm{c}^{-}}$-Teil des ersten Antikörpers bindet. Dieser zweite Antikörper ist meistens biotinyliert. Biotin geht mit Avidin-gekoppelten Enzymen eine feste Verbindung ein. Diese Enzyme können dann durch Zugabe von Peroxidase sichtbar gemacht werden.

Die immunhistochemischen Einfachfärbungen fertigten wir gemäß dem Protokoll in Tabelle 6.9 auf Seite 58 an; die immunhistochemischen Doppelfärbungen gemäß dem Protokoll in Tabelle 6.10 auf Seite 59. Die dabei verwendeten Primärantikörper sind in Tabelle 6.15 auf Seite 63 zu finden und die Sekundärantikörper in Tabelle 6.16 auf Seite 64.

Wir haben folgende immunhistochemischen Färbungen angefertigt:

- Eine Färbung von Amyloid-Vorläuferprotein (APP). Dieses wird in den Axonen anterograd zu den Synapsen transportiert. Bei einer Störung des axonalen Transports, also bei einer Schädigung des Axons, kommt es zu einem sichtbaren Anstau des Proteins proximal der Läsionsstelle. Diese Akkumulation des Proteins ist nur 
in einem Zeitraum von ca. 30 Tagen nach Schädigung zu beobachten und ist somit ein Marker für akute axonale Schädigung.

- Eine Färbung von T-Lymphozyten durch Antikörper gegen CD3. Dieses ist ein Proteinkomplex und ist aus vier Ketten aufgebaut. Es dient als Ko-Rezeptor für den T-Zell-Rezeptor. CD3 ist spezfisch für T-Lymphozyten.

- Eine Färbung von B-Lymphozyten über das Antigen B220, eine Variante von T200. Das T200-Protein ist ein Oberflächenprotein, welches auf Lymphozyten zu finden ist. Es existiert in verschiedenen Formen. Spezifisch für B-Lymphozyten sind die Formen dieses Proteins mit einem Molekulargewicht von ungefähr 220000 (Coffman und Weissman 1981).

- Eine Färbung gegenüber Mac3. Dieses ist ein Glykoprotein, dass von Makrophagen produziert wird. Antikörper gegen Mac3 färben Makrophagen und aktivierte Mikroglia, sowie in einem geringeren Ausmaß Lungen-, Leber-, Milz- und Knochenmarksstrukturen, nicht jedoch Gehirn-, Herz- und Thymussturkturen (Ho und Springer 1983).

- Eine Doppelimmunhistochemie mit einer Färbung von MBP zusammen mit einer Färbung von p25. Das Phosphoprotein p25 ist spezifisch für Oligodendrozyten und spielt vermutlich eine Rolle bei der Bildung Mikrotubuli (Song et al. 2007). MBP ist eines der wichtigsten Bestandteile der Myelinschicht und spielt eine wichtige Rolle in der Strukturgebung der Oligodendrozyten (Harauz et al. 2009).

\subsection{Durchführung der Auswertung}

Die gefärbten Schnitte haben wir mikroskopisch ausgewertet. Dazu haben wir standardisierte Zellzählgitter bzw. Axonzählgitter verwendet. Die Auswertung erfolgte an einem Lichtmikroskop, entweder per Auge oder durch das Abfotographieren der Rückenmarksquerschnitte und die Untersuchung der daraus entstandenen Bilder unter Zuhilfenahme des Programms Cell F. Die erhobenen Daten wurden mit einem Tabellenkalkulationsprogramm notiert und gespeichert sowie mit einer Statistiksoftware analysiert. Ein Überblick über die zur Auswertung verwendeten Materialen ist auf Seite 65 in Tabelle 6.17 zu finden. 
Zur statistischen Vergleich der Gruppen hinsichtlich Entzündungsaktivität, Entmarkung, axonale Schädigung, axonaler Verlust und Oligodendrozytendichte verwendeten wir den ungepaarten t-Test mit Welch-Korrektur, wobei wir $p$-Werte von $p \leq 0,05$ als statistisch signifikant werteten. Zur Abschätzung des statistischen Mittels verwendet wir den Mittelwert und zur Abschätzung des statistischen Fehlers verwendet wir die Standardabweichung (SD).

Bei der Bestimmung der klinischen Verläufe verwendeten wir einen Tag-für-Tag-Vergleich mit Hilfe eines Mann-Whitney-U-Test mit einem Signifikanzniveau von $\mathrm{p} \leq 0,05$ beziehungsweise $\mathrm{p} \leq(0,05 /$ Anzahl der Meßzeitpunkte). Zusätzlich bestimmten wir bei den Experimente mit einem akuten Stadium der EAE eine repeated-measurement Anova und für den Vergleich des gesamten chronischen Verlaufs ein nicht parametrisches Rangverfahren für abhängige longitudinale Daten nach Brunner (Edgar Brunner 2001), da für chronische Verläufe keine Messung einer repeated-measurement Anova möglich ist, weil die Anzahl der Messzeitpunkte die Anzahl der Mäuse überschreitet. Zur Angabe des statistischen Mittels des Beginns der Erkrankung wählten wir den Median mit der Angabe der mittleren absoluten Abweichung.

Wir untersuchten die gefärbten Rückenmarksquerschnitte hinsichtlich der Parameter: Entzündungsaktivität, Entmarkung, axonale Schädigung, axonaler Verlust und Oligodendrozytendichte.

- Die Entzündungsaktivität läßt sich im akuten Stadium mit Hilfe des Entzündungsindex, der Anzahl der Makrophagen/aktivierten Mikroglia pro $\mathrm{mm}^{2}$ und der Anzahl der T-Lymphozyten pro $\mathrm{mm}^{2}$ untersuchen. Im chronischen Stadium kann man den Entzündungsindex, die Anzahl der Makrophagen/aktivierten Mikroglia pro $\mathrm{mm}^{2}$ und die Anzahl der B-Lymphozyten pro mm verwenden.

- Der Entzündungsindex besteht aus der Anzahl der perivaskulären Infiltrate pro Maus, geteilt durch die Anzahl der Rückenmarksquerschnitte. Zur Messung verwendeten wir die mit LFB/PAS gefärbten Rückenmarksquerschnitte. Wir wählten eine 100fache Vergrößerung und zählten alle Infiltrationen auf allen Rückenmarksquerschnitten. Anschließend teilten wir die dadurch erhaltene Zahl durch die Anzahl der Rückenmarksquerschnitte.

- Die Anzahl der Makrophagen/aktivierten Mikroglia bestimmten wir durch eine Färbung mit dem Antikörper Mac3. Die Mac3-positiven Zellen bestimmten 
wir bei einer Vergrößerung von 1000. Hierbei wählten wir die entzündlichen Infiltrate der drei am stärksten betroffenen Rückenmarksquerschnitte aus, wobei wir mindestens $0,3 \mathrm{~mm}^{2}$ pro Maus auswerteten. Wir zählten die durch Mac3 gefärbten Zellen mithilfe eines Zählgitters. Anschließend rechneten wir aus, wieviele Mac3-positiven Zellen pro $\mathrm{mm}^{2}$ vorhanden waren.

- Um die Anzahl der T-Lymphozyten zu bestimmen, wählten wir bei einer Färbung mit dem Antikörper CD3 eine Vergrößerung von 1000, wobei wir die entzündlichen Infiltrate der drei am stärksten betroffenen Rückenmarksquerschnitte auswählten. Wir werteten mindestens $0,3 \mathrm{~mm}^{2}$ pro Maus aus. Wir zählten die mit einem Zählgitter gezählten Zellen pro $\mathrm{mm}^{2}$.

- Die Anzahl der B-Lymphozyten bestimmten wir durch eine Färbung mit dem Antikörper B220. Die B220-positiven Zellen sind vornehmlich meningeal lokalisiert. Hierbei bestimmten wir bei einer Vergrößerung von 1000 alle angefärbten Zellen pro mm der Menignen, wobei wir alle Menignen um die Rückenmarksquerschnitte der Maus auswerteten.

- Zur Messung der Entmarkung wählten wir eine LFB/PAS-Färbung der Rückenmarksquerschnitte, die wir bei einer 200fachen Vergrößerung betrachteten. Wir werteten alle Rückenmarksquerschnitte der Mäuse aus. Mithilfe des Programms CellF maßen wir die Größe der entmarkten Bereiche und die Größe der gesamten weißen Substanz jedes Rückenmarksquerschnitts. Danach rechneten wir den Prozentsatz der entmarkten Fläche an der gesamten weißen Substanz aus.

- Die axonale Schädigung im akuten Krankheitsstadium der EAE quantifizierten wird durch die Zählung von APP-positiven Sphäroiden. Die durch Antikörper gegen APP gefärbten Rückenmarksquerschnitte betrachteten wir bei einer Vergrößerung von 1000 und zählten die Sphäroide innerhalb der entzündlichen Infiltrate mithilfe eines Zählgitters. Wir werteten die drei am stärksten betroffenen Rückenmarksquerschnitte aus, mindestens jedoch 0,6 $\mathrm{mm}^{2}$ pro Maus. Das Ergebnis rechneten wir in APP-positive Sphäroide pro $\mathrm{mm}^{2} \mathrm{um}$.

- Die axonale Schädigung lässt sich nur im akuten Stadium der Erkrankung EAE mithilfe von APP-positiven Sphäroiden messen. Im chronischen Stadium läßt sich dagegen ein axonaler Verlust nachweisen. Zur Quantifizierung des axonalen Verlusts wählten wir eine Bielschowsky-Versilberung der Rückenmarksquerschnitte. Diese betrachteten wir bei einer Vergrößerung von 1000 und werteten alle ent- 
markten Areale aus. Mithilfe eines 25 Kreuzungspunkte aufweisenden Zählgitters zählten wir alle Axone, die auf einen Kreuzungspunkt zu liegen kamen. Die Angabe erfolgt in Axone pro 25 Kreuzungspunkte.

- Die Oligodendrozytendichte maßen wir mithilfe einer Doppelimmunhistochemie gegen MBP und p25. Wir wählten alle Rückenmarksquerschnitte einer Maus und bestimmten die Größe der entmarkten Fläche mithilfe des Computerprogramms CellF, sowie die Anzahl der durch p25 angefärbten Zellen, die innerhalb dieser entmarkten Fläche zu liegen kamen. Die Auswertung erfolgte bei einer 400fachen Vergrößerung. Wir untersuchten alle entmarkten Areale einer Maus. 


\section{Ergebnisse}

Die Erkrankung EAE ist gekennzeichnet durch multifokale entzündliche Läsionen im Rückenmark. Es kommt zu Demyelinisierung und axonalem Schaden. Die Läsionen werden infiltriert durch inflammatorische Zellen, unter anderem durch T-Lymphozyten, BLymphozyten und Makrophagen/aktivierte Mikroglia. Oligodendrozyten helfen bei der Remyelinisierung. Diese Parameter untersuchten wir bei Mäusen, denen der DopaminRezeptor D2 bzw. D3 fehlt, und verglichen sie mit Wildtyp-Mäusen. Hiermit prüften wir, inwieweit ein Zusammenhang zwischen dem Dopaminsystem und der Erkrankung EAE besteht. Wobei wir insbesondere auf die oligodendroglialen Reaktionen achteten.

\subsection{Klinischer Verlauf der Erkrankung EAE}

\subsubsection{Verlauf der Erkrankung bei akuter und chronischer EAE bei D2-defizienten Mäusen}

Zur Untersuchung des Krankheitsverlaufes und der Charakterisierung der Läsionen bei D2 ${ }^{-/-}$-Mäusen führten wir zwei Experimente durch: eines zur Untersuchung des akuten Krankheitsstadiums mit 21 Tagen Dauer und eines, dass mit 77 Tagen Dauer ein chronisches Stadium darstellt.

Im akuten Experiment verwendeten wir insgesamt 11 Wildtyp-Mäuse und 15 D2-/Mäuse. Die Immunisierung erfolgte mit MOG $33-55$. Nach 8-10 Tagen erkrankten die Mäuse mit den üblichen Symptomen wie Gewichtsverlust, struppiger werdendem Fell, beginnenden Lähmungen. Die Mäuse wurden am Tag 21, im ersten Krankheitsschub, perfundiert und anschließend präpariert. Bei beiden Gruppen wurden im Verlauf alle Mäuse krank, der mediane Tag des Krankheitsbeginns betrug bei den Wildtyp-Mäusen 8 Tage \pm 1,6 Tage mittlere absolute Abweichung und bei den Knockout-Mäusen 10 Tage \pm 1,5 Tage mittlere absolute Abweichung. Die EAE-Symptom-Skala zeigte keinen unterschiedlichen Verlauf der EAE. Bei diesem Experiment ist eine repeated-measurement 
Anova möglich, da die Anzahl der Mäuse größer ist als die Anzahl der Messzeitpunkte. Der $\mathrm{p}$-Wert dieser Messung beträgt $\mathrm{p}=0,5456$. Der frühere Beginn der Erkrankung und der erniedrigte Mittelwert bei den Wildtyp-Mäusen ist nicht signifikant. Eine vergleichende Tabelle zur Inzidenz und zum Krankheitsbeginn befindet sich in Tabelle 6.3 auf Seite 54, eine visuelle Darstellung des Krankheitsverlaufes befindet sich in Abbildung 6.4 auf Seite 69.

Der Versuch zum chronischen Verlauf wurde mit insgesamt 18 Mäusen durchgeführt, wobei 9 D2-/--Mäuse und 9 Wildtyp-Mäuse verwendet wurden. Bei den Wildtyp-Mäusen erfolgte der mediane Krankheitsbeginn am Tag $16 \pm$ 9,5 Tage mittlere absolute Abweichung bei den D2-/--Mäusen am Tag $17 \pm 1,5$ Tage mittlere absolute Abweichung. Die Erkankung erfolgte monophasisch mit einem Schub am Anfang. Die Perfusion erfolgte am 77. Tag nach der Immunisierung. Bis zu diesem Zeitpunkt wurden in beiden Gruppen jeweils 8 Tiere krank. Die Grafik der EAE-Symptom-Skala zeigte im chronischen Verlauf Unterschiede zwischen den beiden Mäusegruppen. Dieser Unterschied in der Krankheitsausprägung begann am 22. Tag nach der Immunisierung und dauerte über den gesamten Verlauf bis zur Perfusion an. Wir verglichen die Gruppen an einzelnen Tagen mit Hilfe des Mann-Whitney-U-Tests auf ein Sigifikanzniveau von $\mathrm{p} \leq 0,05$, hierbei ergaben sich signifikante Unterschiede am Tag 23, 24, 27, 39, 40, 41 und 44. Durch die wiederholten Messungen - insgesamt 77 - war bei dieser Herangehensweise jedoch mit einem hohen Alpha-Fehler zu rechnen. Bei einem adjustierten p-Wert, der die Häufigkeit der Messungen berücksichtigt, in diesem Fall $\mathrm{p} \leq(0,05 / 77)$, gab es keine signifikanten Unterschiede für den Vergleich an einzelnen Tagen. Allerdings bestand bei diesem Verfahren ein großer Beta-Fehler. Zum Vergleichen der beiden Gruppen über den gesamten Verlauf führten wir ein nicht parametrisches Rangverfahren für abhängige longitudinale Daten nach Brunner durch (Edgar Brunner 2001). Bei der Verwendung eines solchen Tests zeigte sich kein signifikanter Unterschied zwischen den Mäusegruppen. Der p-Wert beträgt $p=0,16908$. Eine visuelle Darstellung des Krankheitsverlaufes befindet sich in Abbildung 6.5 auf Seite 70 . 


\subsubsection{Verlauf der Erkrankung bei akuter und chronischer EAE bei D3-defizienten Mäusen}

Zur Untersuchung der EAE bei D3//--Mäusen führten wir drei Experimente durch: eins mit 25 Tagen Dauer, eines mit 43 Tagen Dauer und eines mit 77 Tagen Dauer. Zur Analyse der klinischen Symptomatik untersuchten wir das Experiment mit 43 Tagen Dauer und das Experiment mit 77 Tagen Dauer. Zur histopathologischen Untersuchung verwendeten wir zur Darstellung des akuten Verlaufs das Experiment mit 25 Tagen Dauer, und zur Darstellung des chronischen Stadiums das Experiment mit 77 Tagen Dauer.

Das Experiment mit 25 Tagen Dauer wurde mit insgesamt 9 Wildtyp-Mäusen und 11 D3---Mäusen durchgeführt. Zur Analyse der klinischen Symptomatik war das Experiment nicht geeignet, da die Perfusion der Tiere nicht einheitlich am selben Tag erfolgte. Die Inzidenz betrug im Falle der Wildtyp-Mäuse 77\% und im Falle der D3---Mäuse 63\%. Für eine Tabelle zur Inzidenz und zum Krankheitsbeginn vergleiche Tabelle 6.4 auf Seite 54.

Im Experiment mit 43 Tagen Dauer verwendeten wir 5 D3-/--Mäuse und 5 WildtypMäuse. Der mediane Tag des Krankheitsbeginns war der Tag $14 \pm$ 1,8 Tage mittlere absolute Abweichung im Falle der Wildtyp-Mäuse und der Tag 14,5 \pm 1,9 Tage mittlere absolute Abweichung im Falle der D3/---Mäuse. Die durchgeführten Analysen der EAESymtpom-Skala zeigten einen ähnlichen Verlauf bei beiden Populationen. Es bestehen keine signifikanten Unterschiede bei einem Vergleich der einzelnen Tage. Auffällig war das geringere Erkranken beider Gruppen. Eine visuelle Darstellung des Krankheitsverlaufes befindet sich in Abbildung 6.8 auf Seite 73.

Im Falle des 77 Tage dauernden Experiments immunisierten wir 9 Wildtyp-Mäuse und 9 D3-/--Mäuse. Die Krankheitsinzidenz war ähnlich, wobei die D3---Mäuse etwas seltener erkrankten als die Wildtyp-Mäuse. Vergleiche Tabelle 6.4 auf Seite 54. Der mediane Beginn der Erkrankung lag bei Tag $13 \pm 3,9$ Tage mittlere absolute Abweichung im Falle der D3-/--Mäuse und bei Tag $19 \pm$ 2,8 Tage mittlere absolute Abweichung im Falle der Wildtyp-Mäuse. Diese Unterschiede im Krankheitsbeginn zeigten sich nur in diesem Experiment. Im weiteren Verlauf zeigten sich keine Unterschiede zwischen den Gruppen bei einem Vergleich zwischen den einzelnen Tagen. Eine visuelle Darstellung des Krankheitsverlaufes befindet sich in Abbildung 6.7 auf Seite 72. 


\subsection{Entzündungsaktivität}

Bei der EAE kommt es zu entzündlichen Infiltraten, die unter anderem aus Makrophagen/aktivierte Mikroglia, T-Lymphozyten und B-Lymphozyten bestehen. Zählt man die entzündlichen Infiltrate pro Rückenmarksquerschnitt und die Dichte der infiltrierenden Zellen, so hat man ein Maß für die Entzündungsaktivität. Normalerweise korreliert diese histologisch gemessene Entzündungsaktivtät mit dem klinischen Verlauf der Erkrankung. Die Fragestellung dieser Arbeit beschäftigt sich mit dem Stellenwert des Dopaminrezeptors D2 und D3. Würden nun bei einem unserer Experimente sowohl der klinische Verlauf, als auch die histologisch gemessene Entzündungaktivität zeigen, dass D2- oder D3-defiziente Mäuse weniger oder mehr erkranken, wäre dies ein Hinweis für eine wichtige Rolle der Dopaminrezeptoren bei der EAE-Erkrankung.

\subsubsection{Entzündungsaktivität bei D2-defizienten Mäusen}

Entzündliche Infiltrate sind Stellen innerhalb der weißen Substanz, in denen eine Entzündungsreaktion und damit einhergehend Entmarkung stattfindet. Bei der Erkrankung EAE befinden sich diese Infiltrate vorwiegend im Rückenmark. Die Anzahl der entzündlichen Infiltrate pro Rückenmarksquerschnitt betrug beim akuten Experiment 3,8 \pm 0,45 Standardabweichung (SD) im Falle der Wildtyp-Mäuse und 3,2 \pm 0,22 SD im Falle der Knockout-Mäuse. Im chronischen Experiment 1,2 \pm 0,21 SD entzündliche Infiltrate pro Rückenmarksquerschnitt im Fall der Wildtyp-Mäuse und 1,1 \pm 0,22 SD entzündliche Infiltrate pro Rückenmarksquerschnitt im Fall der Knockout-Mäuse. Es bestand kein Unterschied. Vergleiche Abbildung 6.9 auf Seite 74.

Die Makrophagen/aktivierten Mikroglia sind die häufigste Zellpopulation in entmarkten Läsionen. Durch Freisetzung von Entzündungsmediatoren tragen sie einerseits zur Entzündungsreaktion bei, andererseits ist ihre Phagozytosefunktion wichtig für die Remyelinisierung. Bei unserer Untersuchung der Makrophagen/aktivierten Mikroglia zeigten sich uns keine Unterschiede in der Anzahl dieser Zellen bei den Knockout-Mäusen im Vergleich zu den Wildtyp-Mäusen, sowohl im akuten als auch im chronischen Experiment. Vergleiche Abbildung 6.10 auf Seite 75. (Akut D2-/-: $3488 \pm 191,7$ Mac3-positiveZellen pro $\mathrm{mm}^{2}$; WT: $3884 \pm 346,8$ Mac3-positive-Zellen pro $\mathrm{mm}^{2}$; p-Wert des t-Tests: 
0,3335. Chronisch: D2-/- : $1121 \pm 342,0$ Mac3-positive-Zellen pro $\mathrm{mm}^{2}$; WT: $1090 \pm 263,0$ Mac3-positive-Zellen pro $\mathrm{mm}^{2}$; p-Wert des t-Tests: 0,9452).

Die T-Lymphozyten spielen eine wichtige Rolle in der Pathogenese der MS. Bei ihnen wird eine Autoreaktivität gegenüber Myelinbestandteilen vermutet. Die Dichte der TLymphozyten ließ sich nur im akuten Stadium auswerten und war tendenziell geringer in der Gruppe der D2-/--Mäuse. Es bestand jedoch keine Signifikanz. Vergleiche Abbildung 6.11 auf Seite 76. (Akut: D2 $2^{-/-}: 72 \pm 6,4 \mathrm{Cd} 3$-positive-Zellen pro $\mathrm{mm}^{2}$; WT: $56,7 \pm 4,5$ Cd3-positive-Zellen pro $\mathrm{mm}^{2}$, p-Wert des t-Tests: 0,0588).

Die Rolle der B-Lymphozyten in der Pathogenese der MS wird zur Zeit stark diskutiert. Die B-Lymphozyten ließen sich nur im chronischen Experiment auswerten, wobei die B-Lymphozyten vornehmlich meningeal lokalisiert waren. Es zeigte sich keine signifikante Differenz in der Dichte der B-Lymphozyten zwischen den beiden Gruppen. Vergleiche Abbildung 6.12 auf Seite 76. (D2 ${ }^{-/-}: 0,9017 \pm 0,2330$ B220-positive-Zellen pro mm; WT: 0,5239 \pm 0,1596 B220-positive-Zellen pro mm; p-Wert des t-Tests: 0,2057).

Insgesamt zeigten die beiden Gruppen also eine vergleichbare Entzündungsaktivtät an. Für eine Zusammenschau der Streudiagramme des 21 Tage dauernden Experiments vergleiche Abbildung 6.4 auf Seite 69, für das 77 Tage dauernde Experiment vergleiche Abbildung 6.5 auf Seite 70.

\subsubsection{Entzündungsaktivität bei D3-defizienten Mäusen}

Der Entzündungsindex, dass heißt die Anzahl der entzündlichen Stellen pro Rückenmarksquerschnitt, war sowohl im chronischen als auch im akuten Verlauf für beide Gruppen vergleichbar. Im akuten Experiment gab es 1,4 \pm 0,2 SD entzündliche Infiltrate pro Rückenmarksquerschnitt im Falle der Wildtyp-Mäuse und 1,4 \pm 0,4 SD im Falle der D3---Mäuse. Im chronischen Experiment zählten wir bei den Wildtyp-Mäusen 2,2 \pm 0,3 SD entzündliche Infiltrate pro Rückenmarksquerschnitt und bei den D3---Mäusen 2,1 \pm 0,2 SD entzündliche Infiltrate pro Rückenmarksquerschnitt. Vergleiche Abbildung 6.16 auf Seite 80.

Die Dichte der Makrophagen/aktivierten Mikroglia, gekennzeichnet durch den Mac3Antikörper, zeigte im akuten Stadium eine signifikant höhere Zellinfiltration in der Grup- 
pe der Wildtyp-Mäuse als in der Gruppe der D3-/--Mäuse. Hierbei betrug die Anzahl der auswertbaren Tiere in der Gruppe der Knockout-Mäuse 3 Tiere. Vergleiche Abbildung 6.17 auf Seite 81. (Akut: D3-/-: $7400 \pm 218$ Mac3-positive-Zellen pro $\mathrm{mm}^{2}$; WildtypMäuse: $8570 \pm 251$ Mac3-positive-Zellen pro $\mathrm{mm}^{2}$; p-Wert des t-Tests: 0,0129). Im chronischen Stadium zeigten sich in der Knockout-Gruppe zwei Tiere mit besonders starker Infiltration von Mac3-positiven Zellen, so dass das Gesamtergebnis der Gruppe höher lag als in der Gruppe der Wildtyp-Mäuse. Der Unterschied war allerdings nicht signifikant (Chronisch: D3-/-: $2134 \pm$ 529,1 Mac3-positive-Zellen pro $\mathrm{mm}^{2}$; Wildtyp-Mäuse: $1369 \pm$ 117,8 Mac3-positive-Zellen pro $\mathrm{mm}^{2}$; p-Wert des t-Tests: 0,2079).

Die T-Lympozyten werteten wir im akuten Experiment aus. Sie waren in etwa gleichen Maßen in beiden Gruppen vorhanden. Vergleiche Abbildung 6.18 auf Seite 82. (Akut: D2 $2^{-/-}: 145,3 \pm 24,3$ Cd3-positive-Zellen pro mm$^{2}$; WT: 111,1 \pm 12,9 Cd3-positive-Zellen pro $\mathrm{mm}^{2}$, p-Wert des t-Tests: 0,2545). Im chronischen Experiment war die Anzahl dieser Zellen zur Auswertung zu gering.

Im 76 Tage dauernden Experiment werteten wir die B-Lymphozyten aus, die mit Hilfe des Antikörpers B220 angefärbt wurden. Die B-Lymphozyten waren überwiegend meningeal lokalisiert, so dass wir diese Zellen pro mm der Menignen auswerteten. Die Dichte der B-Lymphozyten war in beiden Gruppen ähnlich. Vergleiche Abbildung 6.19 auf Seite 82. (D3-/-: 0,66 \pm 0,01 B220-positive-Zellen pro mm; WT: 0,71 \pm 0,18 B220-positiveZellen pro mm; p-Wert des t-Tests: 0,8062).

Für eine Zusammenschau der Streudiagramme des 24 Tage dauernden Experiments vergleiche Abbildung 6.6 auf Seite 71, für das 76 Tage dauernde Experiment vergleiche Abbildung 6.7 auf Seite 72.

\subsection{Entmarkung}

Entmarkung ist ein wesentlicher Bestandteil der Pathologie der EAE. Durch den Einfluss der Entzündungszellen kommt es zu einem Abbau der Myelinschicht. Die Myelinschicht lässt sich durch eine Färbung gegen MBP gut histologisch darstellen. Wir untersuchten Rückenmarksquerschnitte von D2- und D3-defizienten Mäuse auf die Größe der entmarkten Areale. 


\subsubsection{Entmarkung bei D2-defizienten Mäusen}

Die Ausdehnung der entmarkten Läsionen in Prozent der weißen Substanz war bei den Wildtyp-Mäusen leicht größer als bei den Knockout-Mäusen. Im Falle des akuten Experiments betrug die entmarkte Fläche 5,8\% für die Wildtyp-Mäuse und 4,7\% für die D2-/--Mäuse. Im Fall des chronischen Experiments 3.6\% für die Wildtyp-Mäuse und $3.9 \%$ für die D2 ${ }^{-/-}$-Mäuse. Die Differenz ergab für beide Experimente keine Signifikanz (p-Wert des t-Testes beim akutes Experiment: 0,3047, p-Wert des t-Testes beim chronisches Experiment: 0,8150). Vergleiche Abbildung 6.13 auf Seite 77.

\subsubsection{Entmarkung bei D3-defizienten Mäusen}

Die demyelinisierten Areale in Prozent der gesamten weißen Substanz zeigten keine Unterschiede im Vergleich zwischen der Gruppe der D3 ${ }^{-/-}$-Mäuse und der Gruppe der Wildtyp-Mäuse. Dies zeigte sich sowohl im akuten Stadium als auch im chronischen Verlauf. Vergleiche Abbildung 6.20 auf Seite 83. (Akut: WT: 8,126\% $\pm 1,629 \% \mathrm{~N}=7$; D3-/-: $6,685 \% \pm 2,128 \% \mathrm{~N}=3$; p-Wert: 0,6194. Chronisch: WT: $5,254 \% \pm 1,287 \% \mathrm{~N}=9 ; 3,507 \%$ $\pm 0,6606 \% \mathrm{~N}=7$; p-Wert: 0,2525).

\subsection{Axonale Schädigung}

Die axonale Schädigung trägt stark zur Ausbildung der neurologischen Symptomatik der MS-Patienten bei. Deshalb ist es wichtig, die Mechanismen hinter dieser Störung der Axone zu verstehen. Wir untersuchten, ob eine Ausschaltung der D2- oder der D3Rezeptoren Auswirkung auf die axonale Schädigung bei der EAE hat.

\subsubsection{Axonale Schädigung bei D2-defizienten Mäusen}

Die axonale Schädigung quantifizierten wir im Rahmen des akuten Experiments mit einer Zählung APP-positiver Sphäroide. Hierbei ergaben sich ähnliche Mittelwerte: 172,1 APP-positiver Sphäroide pro $\mathrm{mm}^{2} \pm 12,92 \mathrm{SD}$ für die D2-/--Mäuse zu 181,7 APPpositiver Sphäroide pro $\mathrm{mm}^{2} \pm 12,92 \mathrm{SD}$ für die Wildtyp-Mäuse (p-Wert des t-Tests: 0,6064). Beim chronischen Experiment versilberten wir die Rückenmarksquerschnitte nach Bielschowsky und zählten die Axone direkt mit einem speziellen Zählgitter, welches 25 Prüflinien besitzt. Hier ergab sich ein nicht signifikanter Unterschied von 7,604 Axonen pro 25 Kreuzungspunkte \pm 0,49 SD für die Wildtyp-Mäuse zu 6,938 Axonen 
pro 25 Kreuzungspunkte \pm 1,04 SD für die D2-/--Mäuse (p-Wert des t-Tests: 0,5763). Vergleiche Abbildung 6.14 auf Seite 78.

\subsubsection{Axonale Schädigung bei D3-defizienten Mäusen}

Um die axonale Schädigung zu messen, untersuchten wir für das akute Experiment die Anzahl der APP-positiven Sphäroide und für das chronische Experiment zählten wir die Axone pro 25 Kreuzungspunkte in der Versilberung nach Bielschowsky. Hierbei zeigten sich jeweils ähnliche Werte zwischen den Kontrollgruppen und den Knockout-Tieren. Vergleiche Abbildung 6.21 auf Seite 84. (Akut: Wildtyp-Mäuse: 543,2 \pm 35,2 APPpositive Sphäroide pro $\mathrm{mm}^{2}$; D3---Mäuse 562,2 \pm 112,4 APP-positive Sphäroide pro $\mathrm{mm}^{2}$; p-Wert des t-Tests: 0,8863. Chronisch:Wildtyp-Mäuse: 7,304 \pm 0,37 Axone pro 25 Kreuzungspunkte; D3-/--Mäuse 7,038 \pm 0,62 Axone pro 25 Kreuzungspunkte; p-Wert: $0,7220)$.

\subsection{Oligodendrozytendichte}

Oligodendrozyten bilden die Myelinschicht um Axone innerhalb der weißen Substanz des Zentralnervensystems. Bei einer Entmarkung kommt es zu einer Zerstörung der Myelinschicht und der Oligodendrozyten. Im weiteren Verlauf der Erkrankung kommt es wieder zu einer teilweisen Remyelinisierung. Eine vermehrte Anzahl an Oligodendrozyten kann auf eine stärkere Remyelinisierung hindeuten. Wir untersuchten, ob es zu einer unterschiedlichen Dichte der Oligodendrozyten bei D2-/--Mäusen oder D3-/--Mäusen im Vergleich zu Wildtyp-Mäusen kommt.

\subsubsection{Oligodendrozytendichte bei D2-defizienten Mäusen}

Wir bestimmten die Oligodendrozytendichte in den EAE-Läsionen. Diese lag sowohl bei den D2-/--Mäusen als auch bei den Wildtyp-Mäusen in einem ähnlichem Bereich. Vergleiche Abbildung 6.15 auf Seite 79. (Akut: D2-/-: 167,7 $\pm 28,38$ Oligodendrozyten pro $\mathrm{mm}^{2}$; WT: 183,1 \pm 26,67 Oligodendrozyten pro $\mathrm{mm}^{2}$; p-Wert des t-Tests: 0,6961. Chronisch: D2/--: 777,3 \pm 77,01 Oligodendrozyten pro $\mathrm{mm}^{2} ;$ 807,5 $\pm 56,36$ Oligodendrozyten pro $\mathrm{mm}^{2}$; p-Wert des t-Tests: 0,7567). 


\subsubsection{Oligodendrozytendichte bei D3-defizienten Mäusen}

Die Dichte der Oligodendrozyten innerhalb der Läsionen zeigte keine Unterschiede zwischen der Knockout- und Kontrollgruppe an. Vergleiche Abbildung 6.22 auf Seite 85. (Akut: WT: 0,1769 \pm 0,02306 Oligodendrozyten pro $\mathrm{mm}^{2}$; D3-/-: 0,1466 \pm 0,02635 Oligodendrozyten pro $\mathrm{mm}^{2}$; p-Wert des t-Tests: 0,4273. Chronisch: WT: 425,8 $\pm 36,75$ Oligodendrozyten pro $\mathrm{mm}^{2}$; $\mathrm{D}^{-/-}: 558,8 \pm 50,10$ Oligodendrozyten pro $\mathrm{mm}^{2}$; p-Wert des t-Tests: 0,0556). 


\section{Diskussion}

Sowohl das Dopaminsystem als auch die Erkrankungen EAE und MS betreffen viele Systeme des Organismus. Dementsprechend gibt es für Interaktionen eine ganze Reihe von denkbaren Möglichkeiten: Dopamin-Rezeptoren und Prolaktin-Rezeptoren sitzen auf Zellen des Immunsystems und könnten damit den Verlauf der Erkrankung verändern. Dopamin-Rezeptoren sind auf Gliazellen und Neuronen zu finden, dort können sie das Gleichgewicht zwischen Radikalen und antioxidativen Molekülen beeinflussen. Neben diesen Interaktionsmöglichkeiten sind aber noch viele weitere Schnittstellen denkbar: psychomotorische Veränderungen durch zentrale Störungen des Dopaminsystems könnten auf die Krankheit EAE bzw. MS einwirken. Eine Beeinflussung der Endothelzellen über die dort vorhandenen Dopamin-Rezeptoren erscheint gleichfalls als Möglichkeit. Eine Attenuierung der Erkrankung über eine Veränderung des Katecholaminsystems ist ebenso denkbar, insbesondere vor dem Hintergrund, dass Stress und nachfolgende Exazerbationen assoziiert sind (Mohr et al. 2004).

\subsection{Dopamin wirkt auf Immunzellen}

\subsubsection{Dopamin wirkt über Dopamin-Rezeptoren auf Immunzellen}

In den letzten Jahren hat sich die Bedeutung von Dopamin als Immunmodulator herauskristallisiert. Lymphozyten, ebenso wie Granulozyten und dendritische Zellen können Dopamin produzieren (Bergquist und Silberring 1998; Nakano et al. 2009), Lymphozyten haben intrazelluläre Dopamin-Transportsysteme, und viele Zellen des Immunsystem tragen Dopamin-Rezeptoren (McKenna et al. 2002). Aktivierte Lymphozyten und Makrophagen dringen über eine gestörte Blut-Gehirn-Schranke in das zentrale Nervensystem ein, wo sie lokal hohen Konzentrationen von Dopamin ausgesetzt sind (Ilani et al. 2004). Aber auch im Plasma und in der interstitiellen Flüssigkeit ist ein gewisses Level an Dopamin vorhanden. Es ist noch nicht geklärt, ob diese Konzentration hoch genug ist, um einen Einfluss auszuüben (Ilani et al. 2004). Autokrine und parakrine Wege 
mittels Ausschüttung von Dopamin aus Lymphozyten oder dendritischen Zellen stellen eine weitere Expositionsmöglichkeit dar. Nakano et al. postulieren eine Ausschüttung von Dopamin in der sogenannten Immunsynapse zwischen dendritischen Zellen und THelferzellen (Nakano et al. 2009). (Schaubild 6.2 auf Seite 67 zeigt eine schematische Übersicht.)

Die Frage, welche Dopamin-Rezeptoren auf welchen Zellen des Immunsystems vorhanden sind, beschäftigt seit ein paar Jahren mehrere Forschungsgruppen. Zur Klärung dieses Sachverhaltes wurden verschiedene Methoden wie Ligand Binding Assays, mRNA Expression und Durchflusszytometrie verwendet. Relativ durchgehend zeigt sich, dass aus der Gruppe der D1-ähnlichen Rezeptoren nur D5 auf Immunzellen präsent ist (Ricci et al. 1999; McKenna et al. 2002). Im Falle der D2-ähnlichen Rezeptoren zeigen alle Studien das Vorhandensein von D3 und D4-Rezeptoren. Die Rolle der D2-Rezeptoren ist weniger klar. Inzwischen wird von davon ausgegangen, dass D2-Rezeptoren auf BLymphozyten, T-Lymphozyten, NK-Zellen und Makrophagen vorhanden sind (Besser et al. 2005; McKenna et al. 2002; Kirillova et al. 2008). Dabei wurden bislang vor allem die leicht zu erreichenden menschlichen Zellen aus dem Blutsystem untersucht. Für murine Immunzellen zeigt sich das Vorhandensein von D1, D2, D3 und D5 (Caronti et al. 1998; Fur et al. 1980; Watanabe et al. 2006).

Die Reaktionen der Immunzellen auf Dopamin ist zur Zeit Gegenstand intensiver Forschung. Die am meisten untersuchten Zellen sind T-Lymphozyten. Postuliert wird, dass D1-ähnliche Rezeptoren eine Suppression von CD8 ${ }^{+}$-Zellen, CD4 ${ }^{+}$-Zellen (Saha et al. 2001) sowie regulatorische T-Lymphozyten (Cosentino et al. 2007) verursachen, naive CD4 ${ }^{+}$-Zellen zu T-Helferzellen vom Typ 17 umwandeln (Nakano et al. 2008) und einen Th2-Shift auslösen (Nakano et al. 2009). Die Aktivierung der D2-ähnlichen Rezeptoren auf Lymphozyten verursacht eine vermehrte IL10 und TNF $\alpha$ Produktion (Besser et al. 2005). Die Arbeitsgruppe um Nakano zeigt einen Shift zu Th1 durch Aktivierung der D2-ähnlichen Dopamin-Rezeptoren (Nakano et al. 2009). Ilani et al. zeigen, dass die Aktivierung von D3, also einem D2-ähnlichen Rezeptor, zu einem Th1-Shift führt (Ilani et al. 2004). Diese Studie geht davon aus, dass auf Lymphozyten keine D2-Rezeptoren sitzen, eine Annahme, die inzwischen als falsch erachtet wird (Besser et al. 2005). D2Rezeptor-Aktivierung besitzt auch eine Homing- und Adhäsionsfunktion (Levite et al. 2001). Die Angaben bei B-Lymphozyten sind zur Zeit noch widersprüchlich: So behaupten Morkawa et al., es gäbe eine Inhibierung der B-Lymphozytenfunktion in vitro 
(Morkawa et al. 1993), während Tsao et al. behaupten, es käme zu einer Proliferation der B-Lymphozyten in vitro und in vivo (Tsao et al. 1997). Für Makrophagen wird ein Weg über Katecholaminrezeptoren beschrieben, der IL12-p40 supprimieren soll, also in Richtung eines Th2-Shiftes zeigt (Haskó et al. 2002). Dendritische und weitere antigenpräsentierende Zellen könnten Dopamin als ko-stimulierenden Faktor in der Immunsynapse benutzen und eine Veränderung des Zytokinprofils der Lymphozyten hervorrufen (Nakano et al. 2009). Die Abbildung 6.3 auf Seite 68 fasst die vorgeschlagenen Wirkungen zusammen. Ein Review zu diesem Thema wurde von Pacheco et al. veröffentlicht (Pacheco et al. 2009). Die unterschiedliche und zum Teil gegensätzliche Wirkung von D1-ähnlichen und D2-ähnlichen Rezeptoren könnte an den unterschiedlichen Isoformen des D2-Rezeptors liegen. (Usiello et al. 2000).

Ein Wegfall der Dopamin-Rezeptoren, wie es bei D2-/--Mäusen und D3-/--Mäusen der Fall ist, könnte also einen Einfluss auf die Aktivierung und Anzahl der CD3-positiven Zellen (Marker für T-Lymphozyten), der B220-positiven Zellen (Marker für B-Lymphozyten) und Mac3-positiven Zellen (Marker für Makrophagen und aktivierte Mikroglia) ausüben. Im Falle der D2-/--Mäuse können wir keine Verschiebung in der Anzahl der Immunzellen beobachten. Bei den D3-/--Mäusen zeigt sich im akuten Stadium eine signifikant verringerte Anzahl an Makrophagen pro $\mathrm{mm}^{2}$, während im chronischen Stadium tendenziell mehr Makrophagen zu sehen sind. Dies spricht dafür, dass der Dopamin-Rezeptor einen Einfluss auf die Rekrutierung von Makrophagen besitzt. Allerdings ist die Signifikanz schwach, beruht auf einer Messung von nur 3 Mäusen und zeigt im chronischen Verlauf eine gegensätzliche Richtung an. Auf die Gesamtheit der Immunzellen bezogen können wir zeigen, dass die Ausschaltung der Dopamin-Rezeptoren keinen Einfluss auf die Aktivierung und Proliferation der Zellen ausübt. Weitere Studien, die eine Veränderung des Zytokinprofils erfassen und verschiedene Verfahren zur Messung der Immunzellen kombinieren können, wären für eine genauere Charakterisierung notwendig.

\subsubsection{Prolaktin übt einen Einfluss auf das Immunsystem aus.}

Da die MS vermehrt bei Frauen zu finden ist und Schwangerschaft eine stark modulierende Rolle spielt, wird angenommen, dass weibliche Hormone eine wichtige Rolle spielen. Während der Schwangerschaft kommt es zu einem starken Rückgang und post partum zu einer Erhöhung der Schubrate (Confavreux et al. 1998). Prolaktin steigt während der Schwangerschaft langsam an und erreicht in der Stillzeit seine höchste Konzentration. Das Verhältnis Prolaktin zu Östrogenen ist während der Schwangerschaft gering und 
nach der Schwangerschaft sehr hoch.

Die Rolle vom Prolaktin im Immunsystem ist schon seit längerem bekannt. Prolaktin ist strukturell mit verschiedenen Zytokinen verwandt und ähnelt stark dem Groth Hormon. Eine Hyperprolaktinämie ist beim systemischen Lupus erythematodes als wichtiger Einflussfaktor angesehen. Aber auch für eine Rolle bei der rheumatoiden Arthritis und der Autoimmunthyroiditis gibt es Hinweise (McMurray 2001). Für MS ist die Situation unklarer: es gibt eine Einzelfallstudie, in der vermutet wird, dass die MS-Schübe im Zusammenhang mit einer Hyperprolaktinämie zu sehen sind (Nociti et al. 2010). Allerdings ist noch nicht abschließend geklärt, ob MS mit einer Hyperprolaktinämie einhergeht (Azar und Yamout 1999; Kira et al. 1991; Harirchian et al. 2006). In einer Studie mit 132 Patienten untersuchten Heesen et al., ob Prolaktin als Marker für die Erkankung dienlich ist und kamen zu dem Ergebnis, dass sich keine Korrelation zeigt. Bei der EAE konnten Riskind et al. eine Hyperprolaktinämie nachweisen (Riskind et al. 1991).

Für die D2 ${ }^{-/-}$-Mäuse wird ein höheres Prolaktinniveau beschrieben, nicht jedoch für die D3-/--Mäuse. Da wir bei beiden Versuchsreihen keine Veränderung in der Anzahl der Immunzellen sehen können, schließen wir, dass Prolaktin in unserem Modell keinen wesentlichen Einfluß auf die Proliferation und Rekrutierung der Immunzellen ausübt. Von verschiedenen Autoren wird vorgeschlagen, dass Prolaktin eine Veränderung im Zytokinprofil hervorruft und eine Ausschüttung von Th1-Zytokinen verursacht (Tomio et al. 2008) oder eine erhöhte Aktivität von Plasmazellen zur Folge hat (Jara et al. 2009). Diese vorgeschlagenen Effekte auf die Veränderung des Zytokinprofils sind für uns nicht sichtbar. Eine Studie, die eine Quantifizierung der Subpopulationen der Lymphozyten vornimmt, z.B. durch Durchflusszytometrie, könnte eine Veränderung der Zellpopulationen sowie des Zytokinprofils zeigen.

Gregg et al. vermuten, dass Prolaktin einen proliferierenden Effekt auf Oligodendrozyten-Vorläufer-Zellen hat (Gregg 2009). Diesen Effekt sehen wir nicht. Mäuse mit Hyperprolaktinämie, wie unsere D2-/--Mäuse, zeigen dieselbe Anzahl an Oligodendrozyten innerhalb der Läsionen wie Wildtyp-Mäuse oder D3---Mäuse. 


\subsection{Dopamin wirkt auf Neurone und Gliazellen}

Eine Reihe von Studien beschäftigt sich mit der Frage, ob Dopamin neurotoxische oder neuroprotektive Effekte hat. Die bisherige Studienlage zeigt Anzeichen für beides. Es scheint dosis- und kontextabhängig zu sein, ob Dopamin protektiv oder toxisch wirkt (Bozzi und Borrelli 2006). Dabei gibt es Rezeptor-abhängige und Rezeptor-unabhängige Wege. Die Aktivierung der D2-Rezeptoren ist neuroprotektiv in Tiermodellen zerebraler Ischämie (Liu et al. 1995), außerdem kann eine Aktivierung Neurone in vitro gegen Glutamat induzierte Zytotoxizität schützen (Kihara et al. 2002). Die Arbeitsgruppe um Rosin et al. zeigt, dass auch Oligodendrozyten in vitro durch Aktivierung der DopaminRezeptoren D2 und D3 durch $10 \mu \mathrm{M}$ Bromocriptin oder $10 \mu \mathrm{M}$ L-741,626 oder $10 \mu \mathrm{M}$ Quinpirole gegen Glutamat-induzierten Stress oder Glukosemangel geschützt werden. Dabei verläuft der Mechanismus nicht über die Eigenschaft der Agonisten als Radikalfänger sondern über rezeptorabhängige Mechanismen (Rosin et al. 2005).

Auf der anderen Seite gibt es Untersuchungen, die einen vermehrten neuronalen Zelltod in vitro durch $250 \mu \mathrm{M}$ Dopamin zeigen. Dieser Effekt wird mithilfe von Antioxidanzien abgeschwächt (McLaughlin et al. 1998). Auch die Injektion von Dopamin in die Ventrikel verursacht einen vermehrten neuronalen Zelltod über eine Auto-oxidierung von Dopamin. Vermutlich spielt dabei Eisen eine Rolle, da dieser Effekt durch die Gabe eines Eisenchelators verhindert werden kann (Eisenchelatoren entziehen Eisen, das für die Oxidierung von Dopamin gebraucht wird) (Ben-Shachar et al. 1995). Mehrere Autoren gehen davon aus, dass sich eine hohe Konzentration von Dopamin negativ auf das Überleben der Neurone auswirkt und geringe Konzentrationen protektiv wirken (Armando et al. 2007). Armando et al. zeigen, dass eine Ausschaltung des D2-Rezeptors zu einem Hypertonus bei Ratten und zu vermehrtem oxidativen Stress führt. Dabei wurde der oxidative Stress gemessen durch die Exkretion von 8-Isoprostan, einem Produkt der nicht-enzymatischen Oxidation der Arachidonsäure. Die Autoren vermuten, dass der D2-Rezeptor die NADPH-Oxidase in der Niere und im vaskulären System reguliert (Armando et al. 2007). Auch andere Autoren berichten über eine vermehrte Produktion von ROS unter Gabe von Dopamin (Tinsley et al. 2009), zum Beispiel über das Nrf2/ARE System (Schreibelt et al. 2007). Eine Übersichtsarbeit wurde von Bozzi und Borrelli erstellt (Bozzi und Borrelli 2006).

Reaktive Sauerstoffspezies (ROS) spielen eine wichtige Rolle in der Pathologie der MS 
und der EAE. ROS entstehen durch ein Mißverhältnis an freien Radikalen und antioxidativen Molekülen. Freie Radikale können Elektronen von anderen Molekülen „stehlen“ und dadurch deren Funktion beeinträchtigen. Eine häufige Quelle der Sauerstoffradikale ist der Neurotransmitter Glutamat; dieses Phänomen ist als sogenannte Exzitotoxizität bekannt.

In MS-Läsionen zeigen sich mehrere Marker für oxidative Schäden (Gilgun-Sherki et al. 2004). Freie Radikale können in der Frühphase der Erkrankung die Blut-Hirn-Schranke stören (Schreibelt et al. 2007), Astrozyten, Oligodendrozyten und Makrophagen werden durch ROS geschädigt. Oligodendrozyten sind anfällig für exzitatorische Schädigung durch Glutamat, vor allem über AMPA und Kainat-Rezeptoren. Die Gabe von AMPA/Kainat-Antagonisten fördern das Überleben der Oligodendrozyten und reduzieren axonale Schäden. Versuche zeigen einen positiven Einfluss dieser Antagonisten auf den klinischen Verlauf der EAE (Pitt et al. 2000). Ebenso zeigt die Gabe von Antioxidanzien im EAE-Modell eine Besserung der Krankheit (Gilgun-Sherki et al. 2004). Bei MS bringt die Gabe von Antioxidanzien keine meßbare Veränderung (Gilgun-Sherki et al. 2004). Hier spielt eine Rolle, dass die meisten nicht-enzymatischen Antioxidanzien nur unzureichend die Blut-Hirn-Schranke durchqueren und für einen Effekt in hoher Konzentration vorhanden sein müssen. Eine antioxidative Therapie über enzymatische Antioxidanzien, wie zum Beispiel Superoxid-Dismutasen und Katalasen, könnte hier Erfolg bringen (Schreibelt et al. 2007).

Die von uns verwendeten D2-/-Mäuse haben einen erhöhten Level an ROS (Armando et al. 2007; Tinsley et al. 2009). Dadurch könnte es zu einer Verschlechterung des klinischen Verlaufs der EAE kommen. Unsere Versuche zeigen jedoch, dass D2/--Mäuse und D3-/--Mäuse keine Unterschiede in der Ausprägung der EAE haben. Die Anzahl der läsionalen Oligodendrozyten ist gleich und das Ausmaß der axonalen Schädigung divergiert nicht. Eventuell gibt es kompensatorische Mechanismen, die eine Schädigung durch das bei D2-/--Mäusen erhöht vorhandene Level an ROS ausgleichen können. Ein protektiver oder schädigender Einfluss von D2- und D3-Rezeptoren auf Oligodendrozyten und Neurone ist in unseren Studien nicht meßbar. Weitere Untersuchungen, insbesondere mit Messung der Marker für oxidativen Stress, könnten hier Hinweise geben. 


\subsection{Wirkungen von Dopamin auf die EAE}

Das bislang wenig untersuchte Feld der Interaktionen zwischen dem Dopaminsystem und EAE beruht auf Untersuchungen zur Gabe von Dopaminagonisten bei EAE (Riskind et al. 1991; Dijkstra et al. 1994) und einer Untersuchung zur MPTP induzierten Dopamin-Depletion bei EAE (Bałkowiec-Iskra et al. 2007). Wir führen nun durch die Untersuchung des EAE-Verlaufs bei Dopamin-Rezeptor-Knockout-Mäusen eine weitere Betrachtungsweise hinzu.

Die bisherigen Studien zum Verhältnis EAE und Dopamin schlagen vor, dass ein hoher Dopaminlevel sich positiv auf den Krankheitsverlauf der EAE auswirkt. Dijkstra et al. sowie Riskind et al. zeigen, dass der Dopamin-D2-Agonist Bromocriptin den Krankheitsverlauf der EAE bessert. Balkowiec et al. zeigen, dass bei Mäusen eine zentrale Dopamin-Depletion, hervorgerufen durch das Neurotoxin MPTP, eine Verschlimmerung der Erkrankung EAE nach sich zieht (Dijkstra et al. 1994; Riskind et al. 1991; BałkowiecIskra et al. 2007).

Die Grafik des Verlaufs der EAE bei D2/--Mäusen zeigt geringe Unterschiede an (vergleiche Abbildung 6.5). Ob eine Signifikanz vorliegt, hängt vom verwendeten statistischen Modell ab. Trotz des langen Bestehens von ähnlichen Fragestellungen sind die statistischen Modelle zur Untersuchung der EAE noch nicht ausgereift. Die gegenwärtig gängige Methode (zum Beispiel bei Liu Y et al., publiziert von der Nature Publishing Group (Liu et al. 2010)), einzelne Tage mit Hilfe eines Mann-Whitney-U-Tests auf ein Signifikanzniveau von $\mathrm{p} \leq 0,05 \mathrm{zu}$ vergleichen, beinhaltet einen Fehler durch die hohe Anzahl der Messzeitpunkte. Um dies zu umgehen, wird ein Signifikanzniveau von $p \leq(0,05 /$ Anzahl der Messzeitpunkte) vorgeschlagen. Für dieses Signifikanzniveau können wir keine Unterschiede zwischen den Gruppen zeigen. Allerdings ist die Rate an falsch-negativen Ergebnissen dadurch stark erhöht. Hier bleibt die Entwicklung und Verifizierung neuerer statistischer Modelle abzuwarten. Eines dieser neueren Modelle, ein nicht parametrisches Rangverfahren für abhängige longitudinale Daten nach Brunner (Edgar Brunner 2001) zeigt keine Signifikanz.

Um zu klären, ob ein Unterschied in der Ausprägung der chronischen EAE bei D2-/-Mäusen vorliegt, bietet sich im Sinne einer Paralleltest-Reliabilität an, weitere Parameter zu benutzen. Die Symptomatik bei EAE und MS beruht darauf, dass im Gehirn und 
Rückenmark entzündliche Läsionen entstehen. Eine erhöhte Symptomatik müsste sich also in einer erhöhten Anzahl beziehungsweise einer vergrößerten Fläche der Läsionen darstellen oder auf vermehrtem axonalen Schaden beruhen. Ebenso können andere Parameter des Krankheitsverlaufs der EAE wie die Inzidenz, der Beginn der Erkrankung sowie der Verlauf des akuten Experiments zu Rate gezogen werden.

- Der Entzündungsindex zeigt keine Unterschiede und auch der Anteil der entmarkten Areale am Anteil der normal erscheinenden weißen Substanz ist gleich (Vergleiche Abbildung 6.9 auf Seite 74 und Abbildung 6.13 auf Seite 77).

- Ein vermehrter axonaler Schaden ist ebenfalls nicht nachzuweisen (Vergleiche Abbildung 6.14 auf Seite 78).

- Die Krankheitsinzidenz, der Krankheitsbeginn ist bei beiden Gruppen ähnlich (Vergleiche Tabelle 6.3 auf Seite 54).

- Die Untersuchung des akuten Verlaufs der EAE zeigt keine Unterschiede (Vergleiche Abbildung 6.4 auf Seite 69).

Dementsprechend gehen wir davon aus, dass zwischen den Wildtyp-Mäusen und den D2//--Mäusen keine Unterschiede in der Ausprägung der EAE vorhanden sind.

Jedoch wäre es auch möglich, dass Dopamin-Rezeptor-Knockout-Mäuse schwerer erkranken als Wildtyp-Mäuse ohne gleichsinnige Unterschiede in der histologischen Untersuchung. Dem könnten mehrere Faktoren zugrunde liegen: Die Messung des axonalen Schadens und der Demyelinisierung auf Höhe des Rückenmarks spiegelt nicht das gesamte Krankheitsgeschehen wider. Eine Schädigung der normal erscheinenden weißen Substanz, Läsionen im Gehirn, sowie eine veränderte Sensitivität gegenüber Zytokinen könnte die Erkrankung der Tiere mit beeinflussen. Da ein starker Einfluss dieser Faktoren untypisch ist für EAE, könnte eine Attenuierung derselben durch das Dopaminsystem eine wichtige Rolle spielen. Das könnte an dem berichteten Zusammenhang zwischen dem Dopaminsystem und seinen neuroprotektiven Fähigkeiten liegen (Liu et al. 1995; Kihara et al. 2002). Weiterhin beinhaltet die EAE-Symptom-Skala unter anderem die Evaluation solcher hochkomplexen Bewegungen wie Laufen (vergleiche Tabelle 6.2 auf Seite 54), die sicherlich nicht ausschließlich durch die bislang entdeckten Schädigungsmuster der EAE bedingt sind, wie Myelinscheidendefekte, axonaler Schaden und der gerade eben benannten Schädigung der normal erscheinenden weißen Substanz. Eine Beeinflussung des 
Laufens durch das Ausschalten des D2-Rezeptors wurde noch nicht berichtet, doch lässt die Wichtigkeit des Dopaminsystems, dass unter anderem das Suchtverhalten, die Aufmerksamkeit und die Nahrungsaufnahme steuert, eine Beeinflussung möglich erscheinen. Insbesondere durch die vielfältige chronische Belastung der Erkrankung im Zusammenspiel mit der Veränderung des Dopaminsystems könnten Mechanismen greifen, die bei Mäusen das Verhalten ändern, und dadurch eine Verschiebung der EAE-Symptom-Skala verursachen. Weiterhin ist es aufgrund unseres Studiendesigns möglich, dass man eine stärkere Ausprägung der Erkrankung nicht in der Histologie abbilden kann, da die histologische Untersuchung an einem einzigen Zeitpunkt am Ende der Erkankung stattfindet, während die Krankheit sich als Verlauf darstellt. Ein eventueller Effekt im Verlauf muß also nicht zwangsläufig in der Histologie sichtbar sein.

Trotz dieser Problematik gehen wir davon aus, dass die grafisch sichtbaren Unterschiede im klinischen Verlauf auf einem statistischen Zufall beruhen und sich die D2-/--Mäuse in der Ausprägung der EAE nicht von den Wildtypen unterscheiden.

Im Falle der D3-/--Mäuse zeigen sowohl der klinische Verlauf als auch die Histologie keine Unterschiede zwischen den beiden Gruppen. Die Krankheitsinzidenz, der klinische Verlauf und der Krankheitsbeginn zeigen keine Unterschiede zwischen den beiden Gruppen. Ebenso sind die histologischen Untersuchungen, also die Anzahl der entzündlichen Infiltrate pro Rückenmarksquerschnitt, die Fläche der Läsionen und der axonale Schaden bei beiden Gruppen in ähnlichem Ausmaß vorhanden. Hier können wir die Aussage treffen, dass das Ausschalten des D3-Rezeptors keinen Einfluss auf die EAE hat.

Die Tatsache, dass das Ausschalten des D2- und des D3-Rezeptors keinen Einfluss auf die EAE hat, lässt darauf schließen, dass der Einfluss, den Dopamin über D2-ähnliche Rezeptoren auf Immunzellen sowie Oligodendrozyten und Neurone hat, nicht besonders stark ausgeprägt ist, oder dass dieser Einfluss keine Änderung der EAE hervorruft. Die von Riskind et al. und Dijkstra et al. beobachtete Veränderung der Ausprägung der EAE nach Gabe von Dopamin-Rezeptoragonisten scheint also unabhängig vom D2- und D3-Rezeptor zu funktionieren. 


\subsection{Wirkungen von Dopamin auf die MS}

Eine messbare Wirkung von Dopaminagonisten auf den Krankheitsverlauf der MS scheint nach bisheriger Studienlage eher unwahrscheinlich. Bissay et al. untersuchten die Gabe von Bromocriptin bei 18 Patienten als eine Open-Label-Studie mit dem Ergebnis, dass kein protektiver Effekt nachweisbar ist. Nur einer von 15 evaluierten Patienten - 3 Patienten brachen die Therapie vorher ab - zeigte keine Krankheitsprogression (Bissay et al. 1994). Die Wechselwirkungen von Prolakin und MS wurden in einer Studie von Heesen et al., mit der Fragestellung, ob Prolaktin als Indikator für den Krankheitsverlauf dienen kann, untersucht. Dabei wurde auch eine Untergruppe von Patienten mit Bromocriptin als Prolaktin-inhibierendes bzw. Metoclopramin als Prolaktin-stimulierendes Medikament verwendet. Die Studie kam zu dem Ergebnis, dass Prolaktin nicht als Marker für den Erkrankungsverlauf dienen kann. Dementsprechend scheint ein großer Einfluss von Prolaktin auf MS eher unwahrscheinlich. Eine 1987 publizierte Studie berichtet von einem günstigeren Krankheitsverlauf nach Gabe von L-Dopa und Antidepressiva (BerneFromell et al. 1987), allerdings ohne Angabe zur Methode.

MS-Patienten werden häufig in der klinischen Praxis mit Dopaminagonisten therapiert, vor allem im Zusammenhang mit dem Restless-Legs-Syndrom. Diese Krankheit hat eine höhere Prävalenz bei MS-Patienten als bei gesunden Individuen. Die Standardtherapie des Restless-Legs-Syndroms beinhaltet L-Dopa bzw. die Dopaminagonisten Pramipexol und Ropinirol (Ekbom und Ulfberg 2009). Hierbei wird nicht über einer Verbesserung des Verlaufs der MS berichtet. Vor diesem Hintergrund erscheint es unwahrscheinlich, dass Dopaminagonisten einen Einfluss auf die Erkrankung ausüben. Allerdings gibt es bis heute nach unserem Wissen keine ausreichenden Studien mit Evaluierung des Krankheitsverlauf der MS unter Restless-Legs-Therapie.

Patienten, die an Schizophrenie und Parkinson erkrankt sind, weisen ein Veränderung im Dopaminsystem der Immunzellen auf. So konnten Ilani et al. nachweisen, dass in humanen Lymphozyten von Schizophrenie-Patienten die Expression von D3 mRNA erhöht ist (Ilani et al. 2001). Parkinson-Patienten auf der anderen Seite weisen erniedrigte Werte für D3 mRNA auf (Nagai et al. 1996). Es gibt zudem viele generelle Änderungen im Immunsystem: Schizophrenie-Patienten zeigen eine erhöhte Anzahl an $\mathrm{CD}^{+}{ }^{+}$-Lymphozyten, während Parkinson-Patienten eine erniedrigte Anzahl an CD4 ${ }^{+}$Lymphozyten besitzen (Basu und Dasgupta 2000). Insofern ist es sehr interessant, ob 
eine Attenuierung der Erkrankung MS durch eine parallele Erkrankung an Schizophrenie bzw. Parkinson besteht. Bislang gibt es jedoch keine suffizienten Untersuchungen zu diesem Thema. Eine veränderte Prävalenzrate von MS bei vorhandener Schizophrenie oder vice versa ist nach unserem Wissen nicht in der Literatur beschrieben. Parkinsonismus nach MS ist vereinzelt beschrieben worden, ein ursächlicher Zusammenhang aber nicht belegt (Delgado et al. 2009; Folgar et al. 2003). Groß angelegte Studien zur Interaktion zwischen diesen Erkrankungen wären wünschenswert und könnten eventuell vorhandene Effekte aufspüren.

\subsection{Folgerungen für Forschung und Praxis}

Unsere Grundlagenforschung beinhaltet keine unmittelbaren Folgerungen für die medizinische Praxis. Dopaminagonisten kommen nach Studienlage nicht als Therapeutikum für die MS in Betracht. Trotzdem stellt das Verhältnis von Dopamin, Prolaktin und MS ein spannendes Feld dar. Die zunehmend erkennbare Verzahnung des Neurotransmittersystems mit dem Immunsystem ist ein wachsendes Forschungsfeld, das große Aufmerksamkeit verdient.

Die von Dijkstra et al. (Dijkstra et al. 1994) und Riskind et al. (Riskind et al. 1991) beobachteten Effekte von Bromocriptin auf die EAE verdienen Beachtung. Insbesondere die Wirkung der Dopaminagonisten als Antioxidanzien scheint einer Betrachtung wert zu sein. Die von diesen Autoren vorgeschlagenen Effekte des Prolaktins haben als Voraussetzung die Klärung des Sachverhaltes, wie und ob Hyperprolaktinämie mit MS zusammenhängt.

Es scheint Unterschiede zwischen der EAE und MS bezüglich der Reaktion auf Dopaminagonisten zu geben. Diese Diskrepanz könnte wichtige Hinweise für das Verständnis der Erkrankungen aus dem Formenkreis der idiopathischen inflammatorischen demyelinisierenden Erkrankungen geben und den Stellenwert der EAE genauer darstellen.

Als weitergehende Experimente zur Sicherung unserer Ergebnisse wären Untersuchungen zur Wirkung von Dopaminagonisten in Dopamin-Rezeptor Knockout-Mäusen hilfreich, ebenso Experimente mit Mäusen, denen der Rezeptor D5, als Vertreter der D1ähnlichen Rezeptoren fehlt. 


\section{Zusammenfassung}

Multiple Sklerose (MS) ist eine bedeutende neuroimmunologische Erkrankung, deren genaue Ursache unklar ist. In einem komplexen Zusammenspiel zwischen Zellen des Zentralnervensystems und Zellen des Immunsystems entstehen Entzündungsherde, die zu schweren Beeinträchtigungen führen. Als Tiermodell für die MS wird die experimentelle autoimmune Enzephalomyelitis (EAE) verwendet, die unter anderem bei Mäusen hervorgerufen werden kann. Die vorliegende Arbeit untersucht die Wechselwirkungen der Erkrankung EAE mit dem Dopaminsystem. Dopamin ist ein wichtiger Neurotransmitter, der auch das Immunsystem modulieren kann. Aus der Literatur ist bekannt, dass die EAE einen schwächeren Verlauf nimmt, wenn sie mit Dopaminagonisten behandelt wird.

Bei Mäusen, denen die Dopamin-Rezeptoren D2 bzw. D3 fehlen, lösten wir die Erkrankung EAE aus. Wir verglichen den Krankheitsverlauf dieser Knockout-Mäuse mit dem Krankheitsverlauf von Wildtyp-Mäusen, die diese Rezeptoren aufweisen. Außerdem untersuchten wir histologische Präparate von Rückenmarksquerschnitten dieser Mäuse. Dabei suchten wir nach Unterschieden in der Anzahl der Immunzellen sowie nach dem Ausmaß des entstandenen Schadens im zentralen Nervensystem. Wir konnten zeigen, dass sowohl die D2- als auch die D3-Knockout-Mäuse einen ähnlichen Krankheitsverlauf und eine ähnliche Aktivierung von Immunzellen wie die Wildtyp-Mäuse aufweisen. Es besteht zudem kein Unterschied im Ausmaß des Schadens im zentralen Nervensystem. Wir schlussfolgern daraus, dass die bekannten Effekte der Dopaminagonisten auf den Krankheitsverlauf der EAE nicht von den Dopamin-Rezeptoren D2 bzw. D3 abhängig sind.

Die Arbeit trägt einen Teil zum Verständnis des spannenden und komplexen Zusammenspiels zwischen den Zellen des Immunsytems und des Nervensystems bei. Wir hoffen, dass durch zunehmendes Wissen über die Fehlsteuerung des Nerven- und Immunsystems neue Therapie- und Präventionsmaßnahmen für die Erkrankung MS entwickelt werden können. 


\section{Anhang}

\subsection{Tabellen}

Tabelle 6.1: Literaturübersicht zu Dopamin-Rezeptoren auf humanen und murinen Lymphozyten sowie Oligodendrozyten.

\begin{tabular}{|c|c|c|c|}
\hline Ort & Rezeptor & Methoden & Literatur \\
\hline \multirow{4}{*}{$\begin{array}{l}\text { humane } \\
\text { Lymphozyten }\end{array}$} & $\begin{array}{l}\text { D1 nicht vorhan- } \\
\text { den, D5 vorhan- } \\
\text { den }\end{array}$ & selektive Agonisten & (Ricci et al. 1999) \\
\hline & D2 vorhanden & selektive Agonisten & (Besser et al. 2005) \\
\hline & $\begin{array}{l}\text { D2 nicht vorhan- } \\
\text { den, D3, D4 und } \\
\text { D5 vorhanden }\end{array}$ & mRNA Untersuchung & (Kirillova et al. 2008) \\
\hline & $\begin{array}{l}\text { D2,D3,D4,D5 } \\
\text { vorhanden }\end{array}$ & Durchflusszytometrie & (McKenna et al. 2002) \\
\hline \multirow{4}{*}{$\begin{array}{l}\text { murine } \\
\text { Lymphozyten }\end{array}$} & D2 vorhanden & selektive Agonisten & (Fur et al. 1980) \\
\hline & $\begin{array}{l}\text { D1, D3, D5 vor- } \\
\text { handen }\end{array}$ & mRNA Untersuchung & (Caronti et al. 1998) \\
\hline & $\begin{array}{l}\text { D1, D2 vorhan- } \\
\text { den }\end{array}$ & selektive Agonisten & (Tomassoni et al. 2002) \\
\hline & D3 vorhanden & mRNA Untersuchung & (Watanabe et al. 2006) \\
\hline \multirow{2}{*}{$\begin{array}{l}\text { murine } \\
\text { Oligodendro- } \\
\text { zyten }\end{array}$} & $\begin{array}{l}\text { D2, D3 vorhan- } \\
\text { den }\end{array}$ & mRNA Untersuchung & (Rosin et al. 2005) \\
\hline & D3 vorhanden & mRNA Untersuchung & (Bongarzone et al. 1998 \\
\hline $\begin{array}{l}\text { humane } \\
\text { Oligodendro- } \\
\text { zyten }\end{array}$ & keine Daten & & \\
\hline
\end{tabular}


Tabelle 6.2: Symptomskala zur Evaluation der EAE

\begin{tabular}{ll}
\hline Wert & Symptom \\
\hline 0 & Symptomfrei \\
\hline 0,5 & Schwanzspitzenparese \\
\hline 1 & komplette Schwanzparese \\
\hline 1,5 & Schwanzlähmung und milde Hinterbeinschwäche \\
\hline 2 & deutliche Hinterbeinschwäche \\
\hline 2,5 & unilaterale partielle Hinterbeinlähmung \\
\hline 3 & komplette Hinterbeinlähmung \\
\hline 3,5 & komplette Hinterbeinlähmung und Vorderbeinschwäche \\
\hline 4 & komplette Lähmung von Vorder- und Hinterbeinen \\
\hline 5,5 & schwere Tetraparese, präfinal \\
\hline
\end{tabular}

Tabelle 6.3: Krankheitsinzidenz und medianer Krankheitsbeginn der D2---Mäuse und Wildtyp-Mäuse.

\begin{tabular}{|l|l|l|l|l|}
\hline Experiment & Maustyp & $\begin{array}{l}\text { Inzidenz } \\
\text { in Zahlen }\end{array}$ & $\begin{array}{l}\text { Inzidenz } \\
\text { in Prozent }\end{array}$ & $\begin{array}{l}\text { medianer Tag des Krank- } \\
\text { heitsbeginns } \pm \text { mittlere } \\
\text { absolute Abweichung }\end{array}$ \\
\hline \multirow{2}{*}{ Experiment 21 Tage } & $\begin{array}{l}\text { WT } \\
\text { D2 }\end{array}$ & $\begin{array}{l}16 \text { von } 16 \\
13 \text { von } 13\end{array}$ & $\begin{array}{l}100 \% \\
100 \%\end{array}$ & $\begin{array}{l}8 \pm 1,6 \\
10 \pm 1,5\end{array}$ \\
\hline \multirow{2}{*}{ Experiment 77 Tage } & WT & 8 von 9 & $88 \%$ & $16 \pm 9,5$ \\
& D2 $2^{-/-}$ & 8 von 9 & $88 \%$ & $17 \pm 1,5$ \\
\hline
\end{tabular}

Tabelle 6.4: Krankheitsinzidenz und medianer Krankheitsbeginn der D3-/-Mäuse und Wildtyp-Mäuse.

\begin{tabular}{|c|c|c|c|c|}
\hline Experiment & Maustyp & $\begin{array}{l}\text { Inzidenz } \\
\text { in Zahlen }\end{array}$ & $\begin{array}{l}\text { Inzidenz } \\
\text { in Prozent }\end{array}$ & $\begin{array}{l}\text { medianer Tag des Krank- } \\
\text { heitsbeginns } \pm \text { mittlere } \\
\text { absolute Abweichung }\end{array}$ \\
\hline Experiment 25 Tage & $\begin{array}{l}\text { WT } \\
\text { D3-/- }\end{array}$ & $\begin{array}{l}7 \text { von } 9 \\
7 \text { von } 11\end{array}$ & $\begin{array}{l}77 \% \\
63 \%\end{array}$ & \\
\hline Experiment 43 Tage & $\begin{array}{l}\text { WT } \\
\text { D3 } 3^{-/-}\end{array}$ & $\begin{array}{l}4 \text { von } 5 \\
4 \text { von } 5\end{array}$ & $\begin{array}{l}80 \% \\
80 \%\end{array}$ & $\begin{array}{l}14 \pm 1,8 \\
14,5 \pm 1,9\end{array}$ \\
\hline Experiment 77 Tage & $\begin{array}{l}\text { WT } \\
\text { D3-/- }\end{array}$ & $\begin{array}{l}9 \text { von } 9 \\
7 \text { von } 9\end{array}$ & $\begin{array}{l}100 \% \\
76 \%\end{array}$ & $\begin{array}{l}19 \pm 2,8 \\
13 \pm 3,9\end{array}$ \\
\hline
\end{tabular}


Tabelle 6.5: Induktion der EAE

- Herstellung von komplettem Freund'schen Adjuvans aus 10ml inkomplettem Freund'schen Adjuvans und 100mg Mycobacterium tuberculosis H37RA

- Herstellung einer MOG-Peptid-Emulsion aus 300 $\mu$ g MOG-Peptid, 100 $\mu$ l Phosphatgepufferter Salzlösung (PBS) und 100 $\mu$ l komplettem Freund'schen Adjuvans und anschließender Sonifizierung mit einem Ultraschall-Homogenisator.

- Anästhesie der Mäuse mit Diethylether.

- Subkutane Injektion von $200 \mu \mathrm{l}$ MOG-Peptid-Emulsion pro Tier, jeweils $50 \mu \mathrm{l}$ periaxillär links, periaxillär rechts, periinguinal links und periinguinal rechts.

- Intraperitoneale Injektion von 0,3 $\mu \mathrm{g}$ in PBS-gelöstem Pertussis-Toxin am Tag der Immunisierung und zwei Tage später.

Tabelle 6.6: Perfusion und Präparation der Versuchstiere

- Betäubung durch Chloralhydrat intraperitoneal.

- Thorax-Eröffnung und Anlegen einer Kanüle in die linke Herzkammer.

- Perfusion für 5 min. mit PBS.

- Transkardiale Gewebefixierung mit 4\% Paraformaldehyd (in PBS).

- Entnahme des Gehirns und des Rückenmarks.

- Zerteilung des Gehirn- und Rückenmarkspräparats in ca. $3 \mathrm{~mm}$ dicke Schnitte.

- Dehydrierung duch eine aufsteigende Alkoholreihe.

- Einbettung in Paraffin. 
Tabelle 6.7: Durchführung der Bielschowsky-Versilberung

- Herstellung einer 20\%-Silbernitratlösung in Wasser.

- Herstellung einer 32\%-Ammoniaklösung in Wasser.

- Herstellung einer 2\%-Natriumthiosulfatlösung in Wasser.

- Herstellung einer Entwicklerlösung (20mg Formalin, 100ml Aqua bidest., 0,5g Citronensäure, 0,1 ml Salpetersäure 65\%).

- Herstellung der Paraffin-Schnitte und Aufbringung auf silanisierte Objektträger.

- Entparaffinierung durch Xylol.

- Rehydrierung in absteigender Alkoholreihe.

- Einbringen in die 20\%-Silbernitratlösung (20min.).

- Spülung mit Aqua bidest.

- Silbernitratlösung mit 32\%-Ammoniaklösung mischen, bis die Lösung klar wird.

- Inkubation der Präparate in dieser Lösung im Dunkeln (15min.).

- Spülung mit Aqua bidest.

- Zugabe von 13 Tropfen Entwicklerlösung zur Silbernitrat/Ammoniaklösung

- Einstellen der Schnitte in diese Lösung (1 min.)

- Spülung mit Aqua bidest.

- Einstellen in $2 \%$ Natriumthiosulfat.

- Dehydrierung in aufsteigender Alkoholreihe.

- Inkubation in Xylol.

- Eindeckelung. 
Tabelle 6.8: Durchführung der LFB/PAS-Färbung

- Herstellung einer Luxol-fast-blue-Lösung (1g Luxol fast blue, 1000ml Ethanol 95\%, $5 \mathrm{ml}$ Essigsäure 10\%).

- Herstellung einer 0,05\%-Lithiumcarbonatlösung in Aqua bidest.

- Herstellung einer 1\%-Periodsäurelösung.

- Herstellung der Paraffin-Schnitte und Auftragung auf Objektträger.

- Entparaffinierung durch Xylol.

- Rehydrierung in absteigender Alkoholreihe (bis 90\% Ethanol).

- Einstellen in einer 60 Grad heißen Luxol-fast-blue Lösung (1d).

- Weitere Rehydrierung in absteigender Alkoholreihe (bis 70\% Ethanol).

- Differenzierung durch 0,05\%-Lithiumcarbonatlösung und 70\%-Ethanol-Lösung.

- Färbung in 1\%-Perjodsäurelösung (5 min.).

- Spülung mit Leitungswasser (5 min.).

- Spülung mit Aqua bidest.

- Einstellen in das Schiff'sche Reagenz (20 min.)

- Spülung in Leitungswasser (5 min.).

- Färbung in Mayers Hämalaun-Lösung (2 min.).

- Differenzieren in einer Salzsäure-Alkohol-Lösung (kurz).

- Bläuen in Leitungswasser.

- Dehydrierung in aufsteigender Alkoholreihe.

- Inkubation in Xylol.

- Eindeckelung. 
Tabelle 6.9: Durchführung der immunhistochemischen Färbungen

- Herstellen einer 3\%- $\mathrm{H}_{2} \mathrm{O}_{2}$-Lösung in PBS.

- Herstellen einer 10\% FCS/PBS Lösung

- Anfertigung der Paraffin-Schnitte und Aufbringung auf Objektträger

- Entparaffinierung durch Xylol

- Rehydrierung in absteigender Alkoholreihe.

- Antigendemaskierung in kochendem Citratpuffer 10mM ph 6.0 (5 x 3 min.).

- Spülen mit PBS

- Blockierung der endogenen Peroxidase durch die $\mathrm{H}_{2} \mathrm{O}_{2}$-Lösung (20 min.).

- Spülen mit PBS.

- Blockieren unspezifischer Bindungstellen durch die FCS/PBS-Lösung (10min.).

- Hinzufügen des entsprechend verdünnten primären Antikörpers (über Nacht bei 4 Grad).

- Spülen mit PBS.

- Applikation des sekundären Antikörpers (1 Stunde bei Raumtemperatur).

- Spülen mit PBS.

- Zugabe von Extravidin-Peroxidase (1 Stunde).

- Spülen mit PBS.

- Zugabe von 3-3-Diaminobenzidin-Tetrahydrochlorid (DAB) und 30\% $\mathrm{H}_{2} \mathrm{O}_{2}$.

- Gegenfärben in einer Hämalaun-Lösung nach Mayer (30 Sekunden).

- Dehydrierung in aufsteigender Alkoholreihe.

- Inkubation in Xylol.

- Eindeckelung. 
Tabelle 6.10: Durchführung der immunhistochemischen Doppelfärbung

- Herstellen einer 3\%- $\mathrm{H}_{2} \mathrm{O}_{2}$-Lösung in PBS.

- Herstellung einer filtrierten Luxol-fast-blue-Lösung (49ml Tris Base pH 8,2,10mg Napthol ASMX, 1ml N-N-Dimethylformamid, 50 $\mu$ g Levamisol 1M, 25mg LuxolFast-Blue).

- Herstellen einer 10\% FCS/PBS-Lösung

- Anfertigung der Paraffin-Schnitte und Aufbringung auf Objektträger

- Entparaffinierung durch Xylol und Rehydrierung in absteigender Alkoholreihe.

- Antigendemaskierung in kochendem Citratpuffer 10mM ph 6.0 (5 x 3 min.). Dann spülen mit PBS.

- Blockierung der endogenen Peroxidase durch die $\mathrm{H}_{2} \mathrm{O}_{2}$-Lösung (20 min.). Dann spülen mit PBS.

- Blockieren unspezifischer Bindungstellen durch die FCS/PBS-Lösung (10min.).

- Hinzufügen des Antikörpers gegen MBP mit einer Verdünnung von 1:5000 (über Nacht bei 4 Grad). Dann spülen mit PBS.

- Applikation des mit alkalischer Phosphatase gekoppelten sekundären Antikörpers Ziege-anti-Maus in einer Verdünnung von 1:50 (2,5 Stunde bei Raumtemperatur). Dann spülen mit PBS.

- Einstellen in der Luxol-fast-blue-Lösung. Dann spülen mit PBS.

- Hinzufügen des Antikörpers gegen p25 mit einer Verdünnung von 1:2500 (über Nacht bei 4 Grad) in 10\%FCS in PBS. Dann spülen mit PBS.

- Applikation des biotinylierten Ziege-anti-Hase-Antikörpers mit einer Verdünnung von 1:500 (1 Stunde bei Raumtemperatur) in 10\%FCS in PBS. Dann spülen mit PBS.

- Zugabe von Extravidin-Peroxidase (1 Stunde). Dann spülen mit PBS.

- Zugabe von 3-3-Diaminobenzidin-Tetrahydrochlorid (DAB) und 30\% $\mathrm{H}_{2} \mathrm{O}_{2}$.

- Gegenfärben in einer Hämalaun-Lösung nach Mayer (30 Sekunden).

- Dehydrierung in aufsteigender Alkoholreihe.

- Inkubation in Xylol und Eindeckelung. 
Tabelle 6.11: Verwendete Tiermodelle

\begin{tabular}{|c|c|c|}
\hline Bezeichnung & Hersteller & Ort der Haltung \\
\hline C57BL/6J & $\begin{array}{l}\text { Charles River Laboratories Inc., } \\
\text { Wilmington, Vereinigte Staaten }\end{array}$ & $\begin{array}{l}\text { Zentrale } \\
\text { Tierexperimentelle }\end{array}$ \\
\hline B6.129S2-D2 ${ }^{\text {tm1Low }} / J$ & $\begin{array}{l}\text { The Jackson Laboratory, Bar Har- } \\
\text { bor, Vereinigte Staaten }\end{array}$ & $\begin{array}{l}\text { Einrichtung der } \\
\text { Universitätsmedizin }\end{array}$ \\
\hline B6.129S4-D3 ${ }^{\mathrm{tm} 1 \mathrm{Dac}} / \mathrm{J}$ & The Jackson Laboratory & Göttingen \\
\hline
\end{tabular}

Tabelle 6.12: Verwendete Chemikalien zum Hervorrufen der EAE, zur Perfusion und zur Präparation der Mäuse

\begin{tabular}{lllr}
\hline Bezeichnung & Hersteller & & \\
\hline Ethanol absolut & Merck KGaA, Darmstadt Dortmund \\
\hline inkomplettes Freund'sches Adjuvans & $\begin{array}{l}\text { Sigma-Aldrich GmbH, München, } \\
\text { Deutschland }\end{array}$ & \\
\hline MOG $_{35-554 \mathrm{mg} / \mathrm{ml} \text { in PBS }}$ & $\begin{array}{l}\text { Institut für Immunologie, } \\
\text { Charité, Berlin }\end{array}$ & \\
\hline Mycobacterium tuberculosis H37RA & Difco Laboratories, & Augsburg, \\
& Deutschland & \\
\hline Paraffin, Paraplast Plus & Tyco Healthcare GmbH, Neustadt an \\
& der Donau, Deutschland & \\
\hline Paraformaldehyd (PFA) 4\% in PBS & Merck & \\
\hline Pertussis Rocin 0,001 mg/ml in PBS & List, London, UK & \\
\hline PBS & AppliChem & GmbH, Darmstadt, \\
& Deutschland & \\
\hline Diethylether & Sigma-Aldrich & \\
\hline Chloralhydrat $14 \%$ in Aqua bidest. & Merck & \\
\hline Ultraschall-Homogenisator Sonopuls HD & Bandelin electronic GmbH \& Co.KG, & \\
\hline
\end{tabular}


Tabelle 6.13: Verwendete Chemikalien für die histologischen Färbungen Teil 1.

\begin{tabular}{ll}
\hline Bezeichnung & Hersteller \\
\hline Ammoniaklösung 32\% in Aqua bidest. & Merck \\
\hline Chlorwasserstoff 1Mol/Liter & Merck \\
\hline Citrat-Puffer 10mM pH 6.0 & Merck \\
\hline Citronensäure & Merck \\
\hline 3-3-Diaminobenzidin-Tetrahydrochlorid (DAB) & Sigma-Aldrich \\
\hline Eosin-G Certistain & Merck \\
\hline Ethanol absolut & Merck \\
\hline Ethylen-diamin-tetra-essigsäure 0,5M (EDTA) & Sigma-Aldrich \\
\hline Essigsäure & Merck \\
\hline Extravidin gekoppelt an Peroxidase & Sigma-Aldrich \\
\hline Fetales Kälberserum (FCS) 10\% in PBS & Biochrom AG, Berlin, Deutsch- \\
\hline Kupfersulfat & land \\
\hline Iso-Xylol & Merck \\
\hline
\end{tabular}


Tabelle 6.14: Verwendete Chemikalien für die histologischen Färbungen Teil 2.

\begin{tabular}{ll}
\hline Bezeichnung & Hersteller \\
\hline Levamisol 1M & $\begin{array}{l}\text { MP Biomedical, Fountain } \\
\text { Pkwy, Solon, Vereinigte } \\
\text { Staaten }\end{array}$ \\
\hline Lithiumcarbonat & Merck \\
\hline Luxol-fast-blue & $\begin{array}{l}\text { VWR International Ltd., } \\
\text { Poole, Großbritannien }\end{array}$ \\
\hline Mayers Hämalaunlösung & Merck \\
\hline N-N-Dimethylformamid & Sigma-Aldrich \\
\hline Naphthol AS-MX & Sigma-Aldrich \\
\hline Natriumthiosulfat & Merck \\
\hline Perjodsäure & Merck \\
\hline Salpetersäure & Merck \\
\hline Salzsäure 1M Gebrauchslösung 25\% in Aqua bidest. & Merck \\
\hline Schiff'sches Reagenz & Merck \\
\hline Silbernitrat & Carl Roth GmbH, Karlsru- \\
\hline Tris Base pH 8,2 & he, Deutschland \\
\hline Triton & Sigma-Aldrich \\
\hline Wasserstoffperoxid 30\% in Aqua bidest. & Merck \\
\hline Xylol & Merck \\
\hline
\end{tabular}


Tabelle 6.15: Verwendete Primärantikörper

\begin{tabular}{|c|c|c|c|c|c|}
\hline Antigen & $\begin{array}{l}\text { Herkunfts- } \\
\text { Spezies }\end{array}$ & Klon & Kat.Nr. & Hersteller & $\begin{array}{l}\text { Verdünnung } \\
\text { in } 10 \% \\
\text { FCS/PBS }\end{array}$ \\
\hline $\mathrm{APP}$ & Maus & $22 \mathrm{C} 11$ & MAB 348 & $\begin{array}{l}\text { Chemicon Interna- } \\
\text { tional, Temecula, } \\
\text { Vereinigte Staaten }\end{array}$ & $1: 3000$ \\
\hline CD3 & Ratte & CD3-12 & MCA 1477 & $\begin{array}{l}\text { AbD Serotec, Düs- } \\
\text { seldorf, Deutsch- } \\
\text { land }\end{array}$ & $1: 200$ \\
\hline B220 & Ratte & $\begin{array}{l}\text { RA3- } \\
6 B 2\end{array}$ & 557390 & $\begin{array}{l}\text { Becton Dickinson } \\
\text { GmbH, Heidelberg, } \\
\text { Deutschland }\end{array}$ & $1: 200$ \\
\hline Mac3 & Ratte & M3/84 & 553322 & $\begin{array}{l}\text { Becton Dickinson } \\
\text { GmbH }\end{array}$ & $1: 200$ \\
\hline MBP & Maus & - & SMI94 & $\begin{array}{l}\text { Sternberger Mo- } \\
\text { noclonals, Luther- } \\
\text { ville, Vereinigte } \\
\text { Staaten }\end{array}$ & $1: 5000$ \\
\hline p25 & Kaninchen & $\begin{array}{l}\text { freundlic } \\
\text { Jensen, }\end{array}$ & $\begin{array}{l}\text { e Gabe von } \\
\text { arhus, Däner }\end{array}$ & $\begin{array}{l}\text { Prof. Henning } \\
\text { ark }\end{array}$ & $1: 2500$ \\
\hline
\end{tabular}


Tabelle 6.16: Verwendete Sekundärantikörper

\begin{tabular}{lllll}
\hline Bezeichnung & $\begin{array}{l}\text { Konjugiert } \\
\text { mit }\end{array}$ & Kat.Nr. & Hersteller & $\begin{array}{l}\text { Verdünnung } \\
\text { mit }\end{array}$ \\
& FCS $/$ PBS
\end{tabular}


Tabelle 6.17: Verwendete Materialien für die Mikroskopie und Auswertung

\begin{tabular}{ll}
\hline Gerät & Hersteller \\
\hline Lichtmikroskop BX41 und BX51 & $\begin{array}{l}\text { Olympus GmbH, Hamburg, } \\
\text { Deutschland }\end{array}$ \\
\hline Okulare (10fache Vergrößerung) & Olympus \\
\hline Objektive (40fache bis 1000fache Vergrößerung) & Olympus \\
\hline standardisiertes Zellzählgitter & Olympus \\
\hline standardisiertes Axonzählgitter & Olympus \\
\hline 12,5 Megapixel CCD-Kamera DP71 & Olympus \\
\hline Bildanalyse Software Cell F & Olympus \\
\hline GNU Image Manuipulation Programm & Gimp.org \\
\hline Kommandozeilen Grafikprogramm ImageMagick & Imagemagick.org \\
\hline Tabellenkalkulationsprogramm Microsoft Excel & $\begin{array}{l}\text { Microsoft Deutschland } \\
\text { GmbH, Unterschleißheim, }\end{array}$ \\
\hline Tabellenkalkulationsprogramm Openoffice Calc & Deutschland \\
\hline Statistiksoftware Prism 4.0 und 5.0 & OpenOffice.org \\
\hline
\end{tabular}




\subsection{Abbildungen}

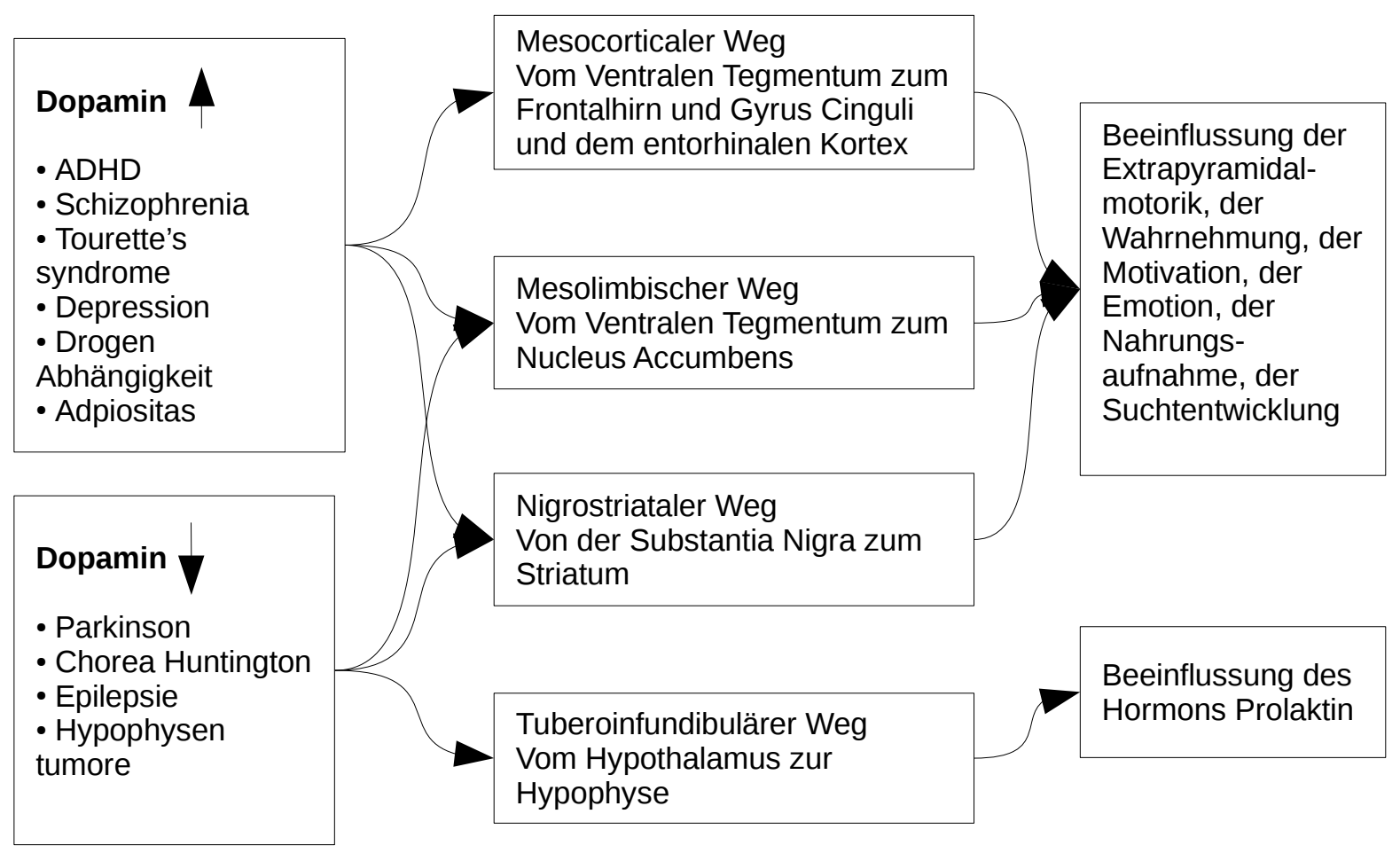

Abbildung 6.1: Krankheiten, die mit den Dopaminsystemen in Verbindung gebracht werden und ihre Auswirkungen 


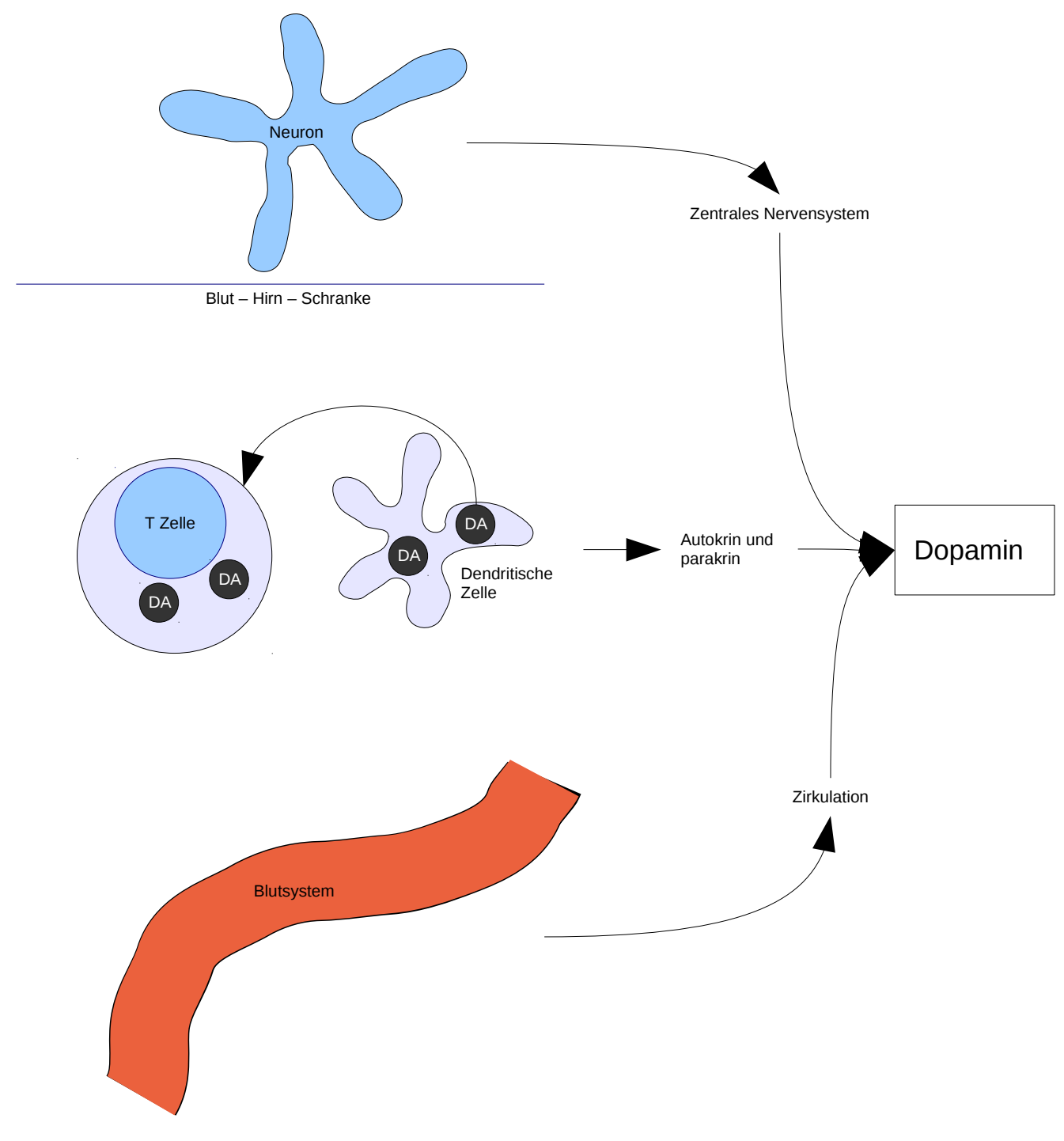

Abbildung 6.2: Expositionsmöglichkeiten der Immunzellen gegenüber Dopamin 


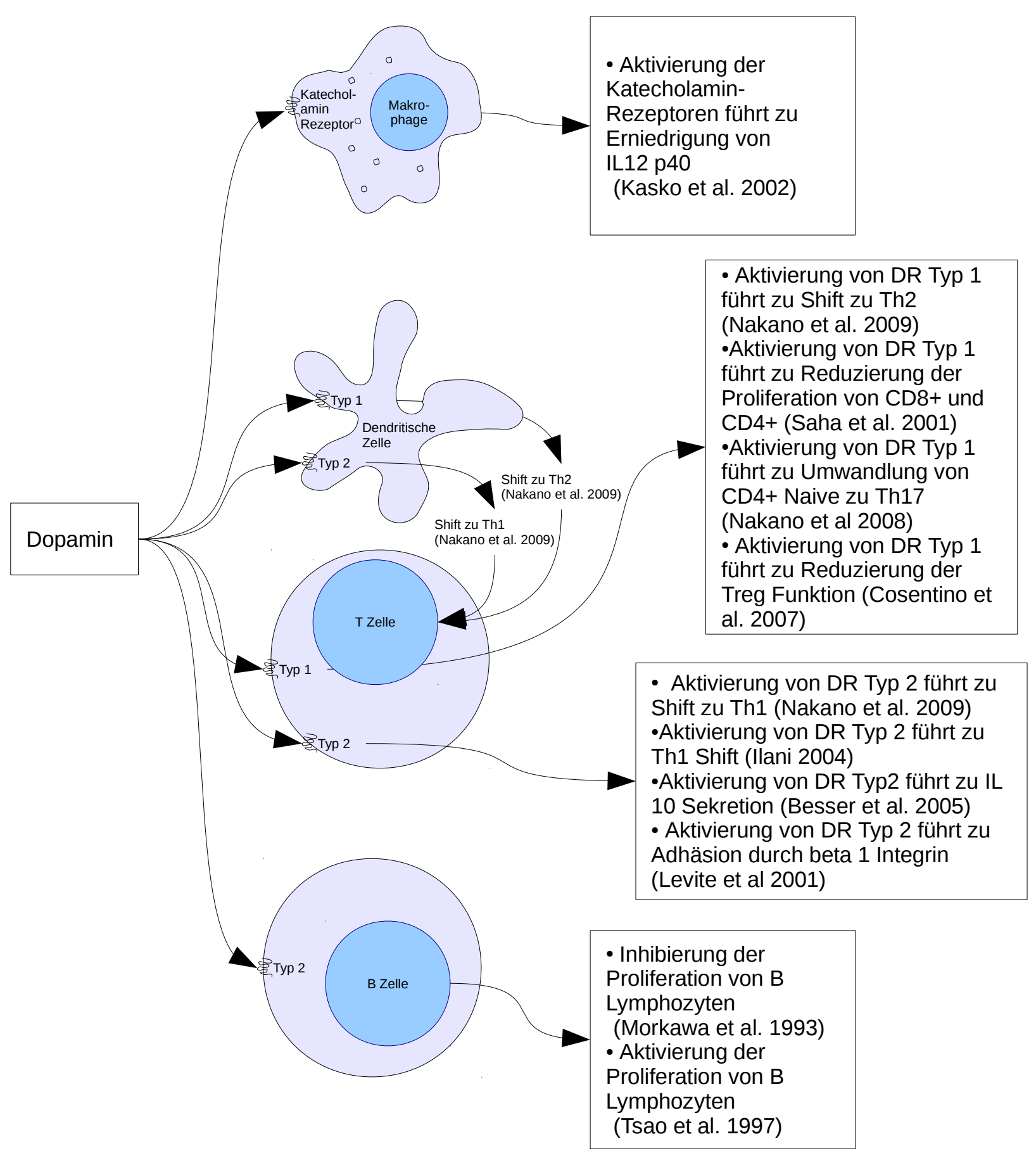

Abbildung 6.3: Schematische Darstellung der vorgeschlagenen Wirkungen von Dopamin auf Immunzellen. 


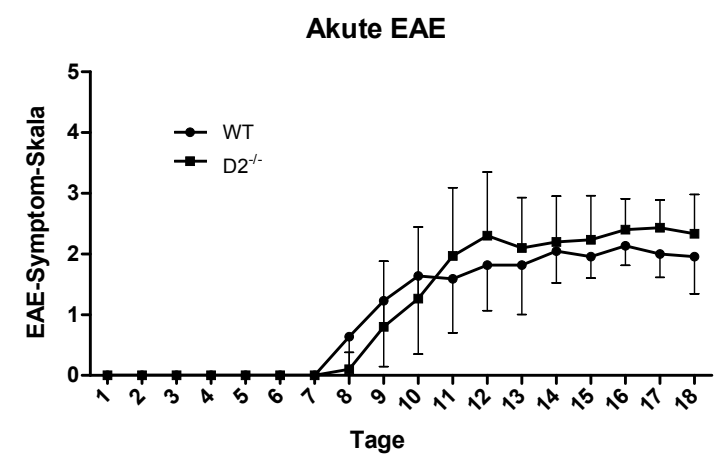

(a) Verlauf der EAE

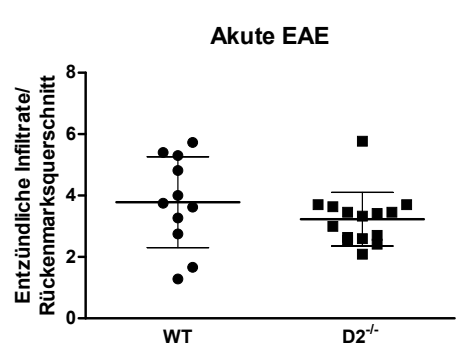

(b) Entzündliche Infiltrate pro Rückenmarksquerschnitt

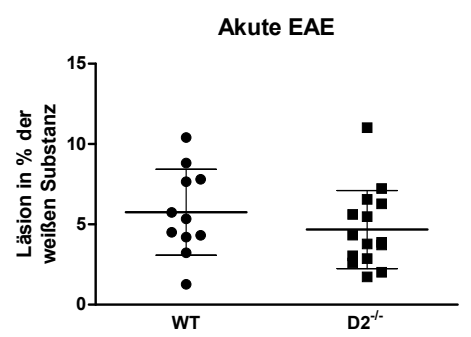

(e) Entmarkungsfläche in \% der gesamten weißen Substanz

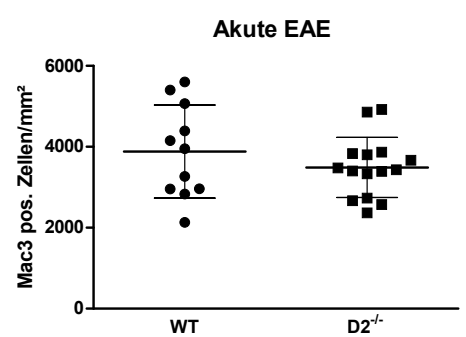

(c) Dichte der Makrophagen

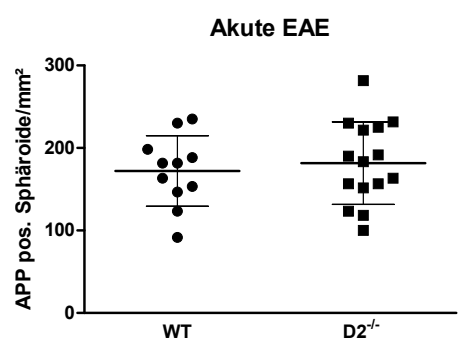

(f) Axonaler Schaden

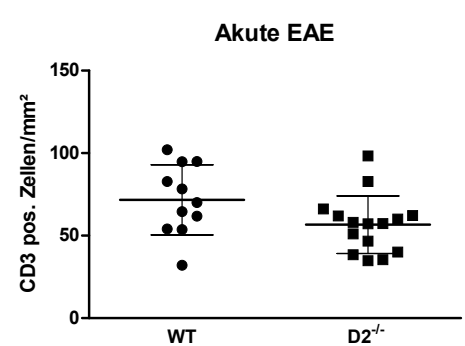

(d) Dichte der TLymphozyten

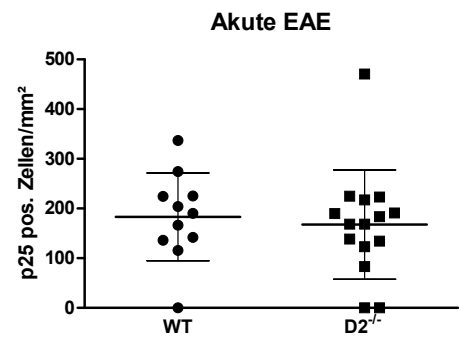

(g) Dichte der Oligodendrozyten

Abbildung 6.4: Ergebnisse der histologischen Untersuchungen der Wildtyp- und D2-/--Mäuse im akuten Stadium der EAE. Wir immunisierten 11 WT und $15 \mathrm{D}^{-/-}$mit $\mathrm{MOG}_{33-55}$. Die Perfusion erfolgte am 21. Tag. Wir fertigten histologische und immunhistochemische Färbungen der Rückenmakrsquerschnitte an und untersuchten diese nach der Anzahl der entzündlichen Infiltrate pro Rückenmarksquerschnitt, der Dichte der Makrophagen und T-Lymphozyten, der Fläche der entmarkten weißen Substanz, dem axonalen Schaden und der Dichte der Oligodendrozyten. Bild (a): Es sind keine Unterschiede erkennbar: die Krankheitsinzidenz, der Krankheitsbeginn und die Krankheitsausprägung waren gleich. Bild (b): Die Anzahl der entzündlichen Infiltrate pro Rückenmarksquerschnitt sind in beiden Gruppen ähnlich (Der p-Wert des t-Tests beträgt: 0,2877). Die Fehlerbalken zeigen die Standardabweichung. Bild (c): Die Dichte der Makrophagen ist vergleichbar (Der p-Wert des t-Tests beträgt: 0,3335). Bild (d): Die Dichte der T-Lymphozyten ist bei $\mathrm{D}^{-/ /}$-Mäusen tendenziell geringer, aber nicht signifikant (Der p-Wert des t-Tests beträgt: 0,0588). Bild (e): Die entmarkte Fläche in \% der gesamten weißen Substanz ist bei beiden Gruppen vergleichbar (Der p-Wert des t-Tests beträgt: 0,3047). Bild (f): Der axonale Schaden ist zwischen den Gruppen ähnlich (Der p-Wert des t-Tests beträgt: 0,6064). Bild (g): Die Dichte der Oligodendrozyten ist ähnlich (Der p-Wert des t-Tests beträgt: 0,6961). 


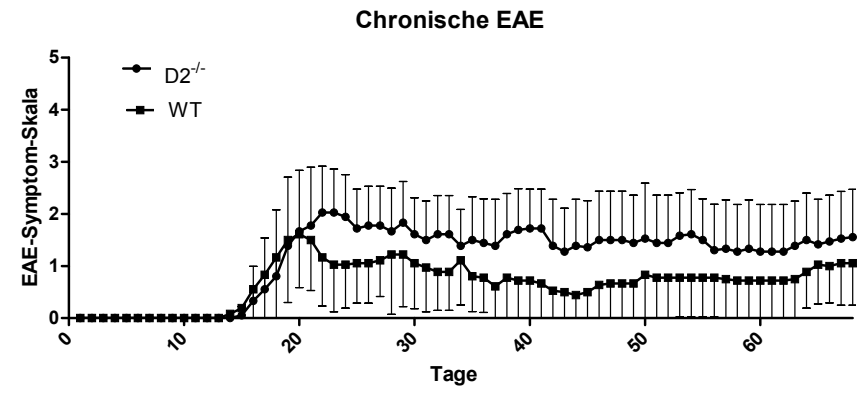

(a) Verlauf der EAE

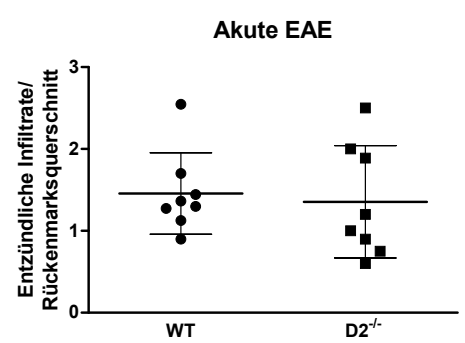

(b) Entzündliche Infiltrate pro Rückenmarksquerschnitt

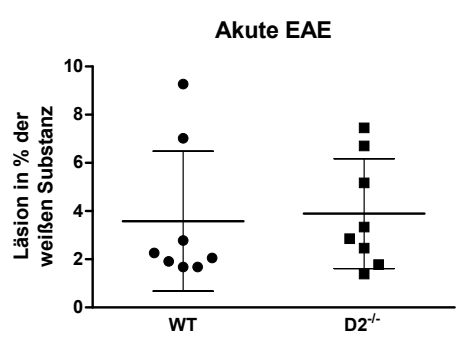

(e) Entmarkungsfläche in \% der weißen Substanz

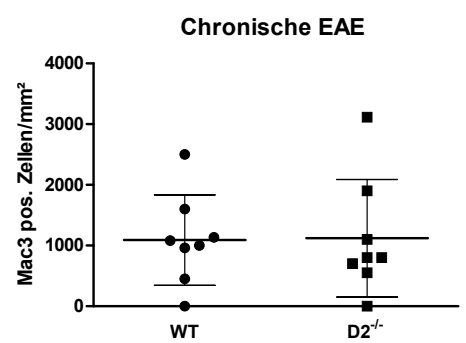

(c) Dichte der Makrophagen

Chronische EAE

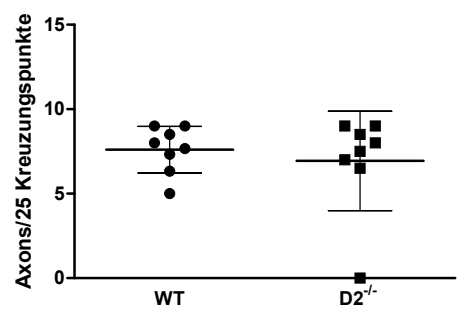

(f) Axonaler Verlust

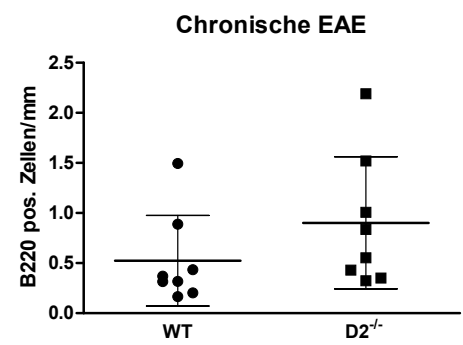

(d) Dichte der BLymphozyten

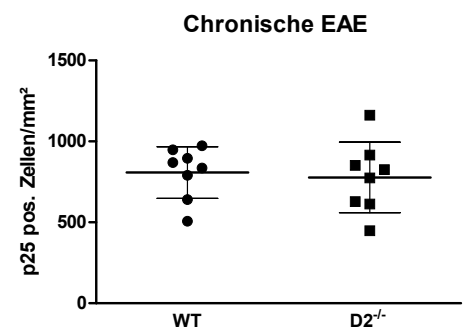

(g) Dichte der Oligodendrozyten

Abbildung 6.5: Ergebnisse der histologischen Untersuchungen der Wildtyp- und D2/--Mäuse im chronischen Stadium der EAE. Wir immunisierten 9 WT und $9 \mathrm{D}^{-/-}$mit $\mathrm{MOG}_{33-55}$. Die Perfusion erfolgte am 77. Tag. Wir fertigten histologische und immunhistochemische Färbungen der Rückenmakrsquerschnitte an, dabei verwendeten wir in beiden Gruppen 8 Tiere. Die histologischen Präparate untersuchten wir nach der Anzahl der entzündlichen Infiltrate pro Rückenmarksquerschnitt, der Dichte der Makrophagen und B-Lymphozyten, der Fläche der entmarkten weißen Substanz, dem axonalen Schaden und der Dichte der Oligodendrozyten. Bild (a): Krankheitsverlauf der chronischen EAE. Der grafische Verlauf erscheint unterschiedlich. Ein Tag-für-Tag-Vergleich mit Hilfe eines Mann-Whitney-U-Tests ergibt bei einem Signifikanzniveau von $\mathrm{p} \leq 0,05$ signifikante Unterschiede an Tag 23, 24, 27, 39, 40, 41 und 44. Bei einem Signifikanzniveau von $\mathrm{p} \leq(0,05 / 77)$ ergeben sich keine Unterschiede. Ein nicht parametrisches Rangverfahren für abhängige longitudinale Daten ergibt keine Signifikanz ( $\mathrm{p}=0,16908)$. Bild (b): Die Anzahl der entzündlichen Infiltrate pro Rückenmarksquerschnitt sind in beiden Gruppen ähnlich (Der p-Wert des t-Tests beträgt: 0,7408). Bild (c): Die Dichte der Makrophagen ist gleich (Der p-Wert des t-Tests beträgt: 0,9452). Die Fehlerbalken zeigen die Standardabweichung. Bild (d): Die Dichte der B-Lymphozyten ist nicht signifikant unterschiedlich (Der p-Wert des t-Tests beträgt: 0,2057). Bild (e): Die entmarkte Fläche in \% der gesamten weißen Substanz ist bei beiden Gruppen vergleichbar (Der p-Wert des t-Tests beträgt: 0,8150). Bild (f): Der axonale Verlust ist zwischen den Gruppen ähnlich (Der p-Wert des t-Tests beträgt: 0,5763). Bild (g): Die Dichte der Oligodendrozyten ist vergleichbar (Der p-Wert des t-Tests beträgt: 0,7567). 


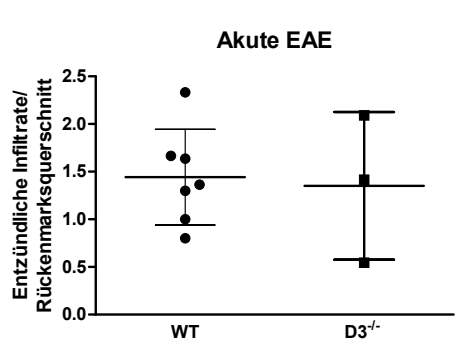

(a) Entzündliche Infiltrate pro Rückenmarksquerschnitt

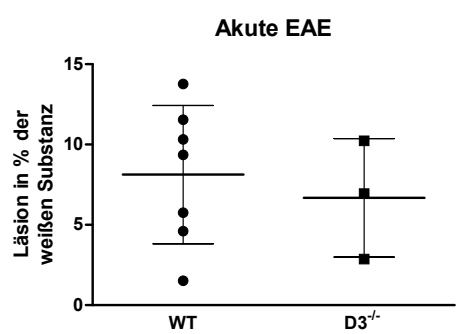

(d) Entmarkungsfläche in \% der gesamten weißen Substanz

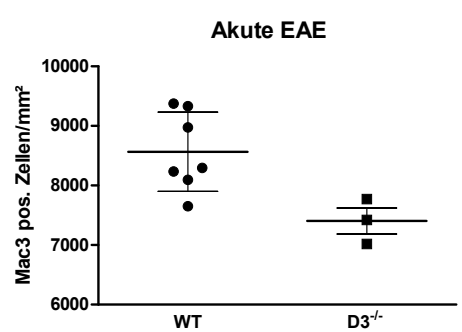

(b) Dichte der Makrophagen

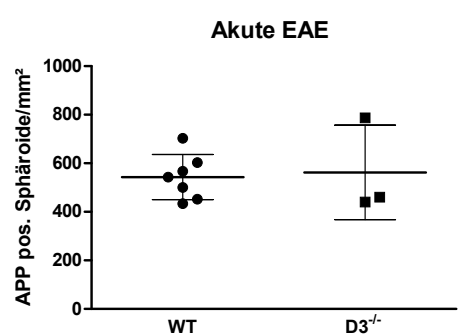

(e) Axonaler Schaden

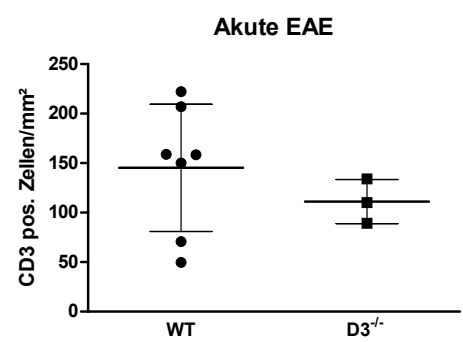

(c) Dichte der TLymphozyten

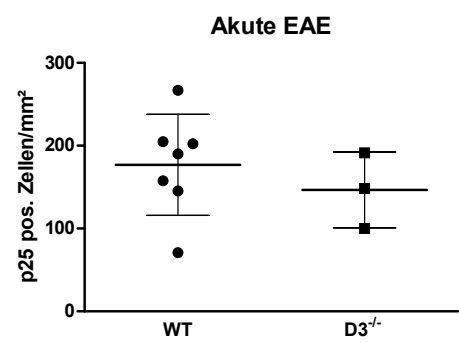

(f) Dichte der Oligodendrozyten

Abbildung 6.6: Ergebnisse der histologischen Untersuchungen der Wildtyp- und D3-/--Mäuse im akuten Stadium der EAE. Wir immunisierten 11 WT und $9 \mathrm{D}^{-/-}$mit $\mathrm{MOG}_{33-55}$. Die Perfusion erfolgte am 21. Tag. Wir fertigten histologische und immunhistochemische Färbungen bei 3 D3-/--Mäusen und 7 Wildtyp-Mäusen an und untersuchten diese nach der Anzahl der entzündlichen Infiltrate pro Rückenmarksquerschnitt, der Dichte der Makrophagen und T-Lymphozyten, der Fläche der entmarkten weißen Substanz, dem axonalen Schaden und der Dichte der Oligodendrozyten. Bild (a): Die Anzahl der entzündlichen Infiltrate pro Rückenmarksquerschnitt sind in beiden Gruppen ähnlich (Der p-Wert des t-Tests beträgt: 0,8676). Bild (b): Die Dichte der Makrophagen ist signifikant unterschiedlich (Der p-Wert des t-Tests beträgt: 0,0129). Bild (c): Die Dichte der T-Lymphozyten ist bei D3-/--Mäusen vergleichbar (Der p-Wert des t-Tests beträgt: 0,2545). Bild (d): Die entmarkte Fläche in \% der gesamten weißen Substanz ist bei beiden Gruppen vergleichbar (Der p-Wert des t-Tests beträgt: 0,6194). Bild (e): Der axonale Schaden ist zwischen den Gruppen gleich (Der p-Wert des t-Tests beträgt: 0,8863). Bild (f): Die Dichte der Oligodendrozyten ist ähnlich (Der p-Wert des t-Tests beträgt: 0,4273). 


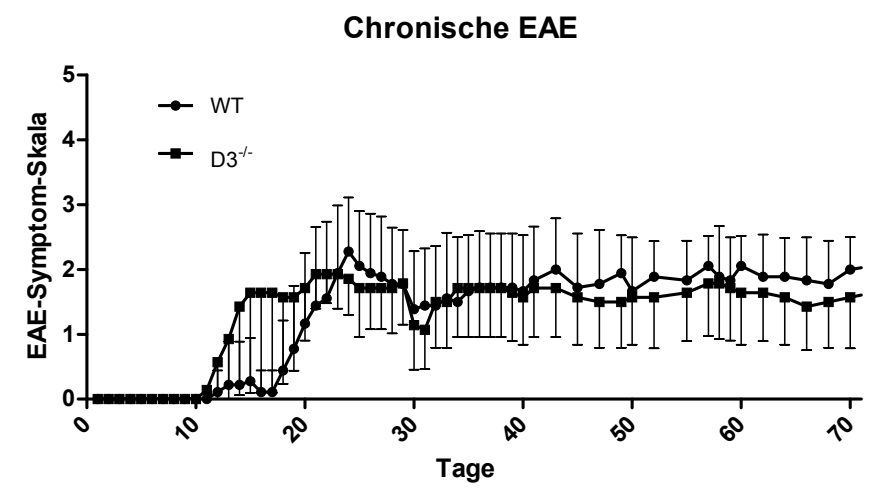

(a) Verlauf der EAE

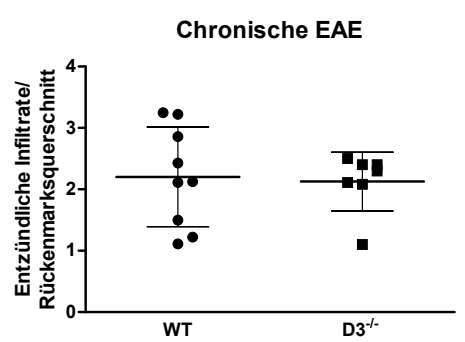

(b) Entzündliche Infiltrate pro Rückenmarksquerschnitt

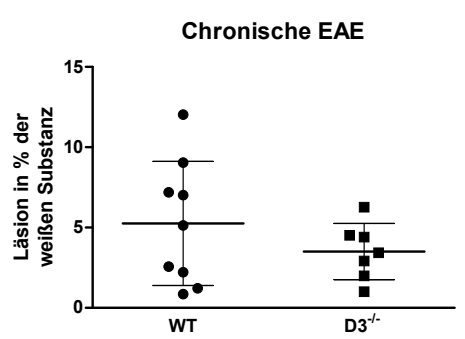

(e) Entmarkungsfläche in \% der weißen Substanz

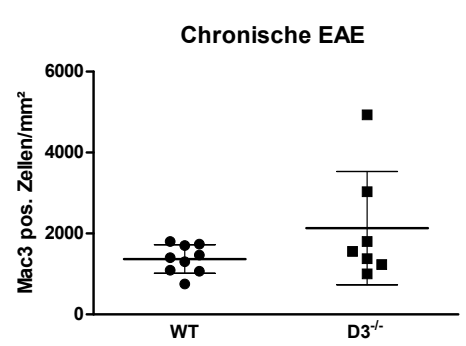

(c) Dichte der Makrophagen

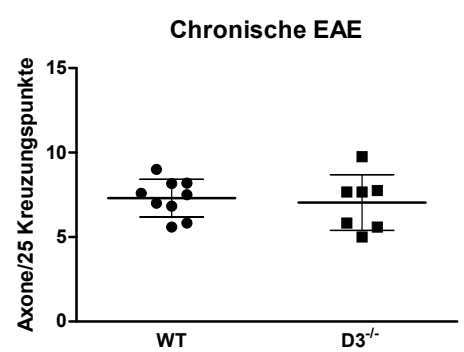

(f) Axonaler Verlust

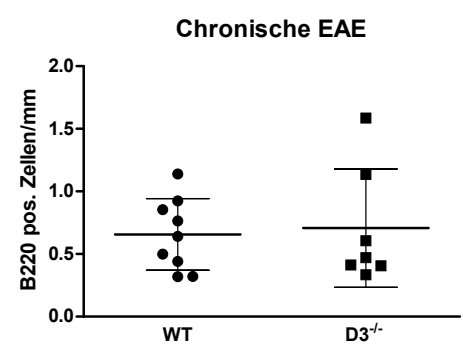

(d) Dichte der BLymphozyten

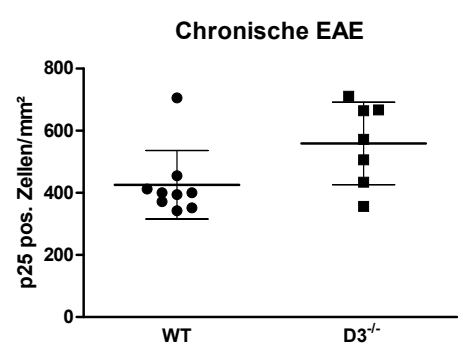

(g) Dichte der Oligodendrozyten

Abbildung 6.7: Ergebnisse der histologischen Untersuchungen der Wildtyp- und D3-/--Mäuse im chronischen Stadium der EAE. Wir immunisierten 9 Wildtyp-Mäuse und 9 D3 ${ }^{-/-}$-Mäuse. Histologisch untersuchten wir 7 D3-/--Mäuse und 9 Wildtyp-Mäuse auf die Anzahl der entzündlichen Infiltrate pro Rückenmarksquerschnitt, der Dichte der Makrophagen, T-Lymphozyten und Oligodendrozyten, der Fläche der entmarkten weißen Substanz, dem axonalen Schaden. Bild (a): Der Beginn der Erkrankung erfolgte bei den D3 $3^{-/}$-Mäusen später als bei den Wildtyp-Mäusen, Medianer Tag des Beginns bei den D3/--Mäusen am Tag $12 \pm$ 4,3 Tage mittlere absolute Abweichung und bei den Wildtyp-Mäusen am Tag $18 \pm 3,8$ Tage mittlere absolute Abweichung, signifikante Unterschiede im klinischen Verlauf bestanden nicht. Die Fehlerbalken zeigen die Standardabweichung. Bild (b): Die Anzahl der entzündlichen Infiltrate pro Rückenmarksquerschnitt sind in beiden Gruppen ähnlich (Der p-Wert des t-Tests beträgt: 0,8208). Bild (c): Die Dichte der Makrophagen ist nicht signifikant unterschiedlich (Der p-Wert des t-Tests beträgt: 0,2079). Bild (d): Die Dichte der B-Lymphozyten ist bei D3 ${ }^{-/-}$-Mäusen ähnlich (Der p-Wert des t-Tests beträgt: 0,8062). Bild (e): Die entmarkte Fläche in \% der gesamten weißen Substanz ist bei beiden Gruppen vergleichbar (Der p-Wert des t-Tests beträgt: 0,2525). Bild (f): Der axonale Verlust ist zwischen den Gruppen ähnlich (Der p-Wert des t-Tests beträgt: 0,7220). Bild (g): Die Dichte der Oligodendrozyten ist tendenziell geringer in der Gruppe der Wildtyp-Mäuse, jedoch besteht keine Signifikanz (Der p-Wert des t-Tests beträgt: 0,0556). 


\section{Chronische EAE}

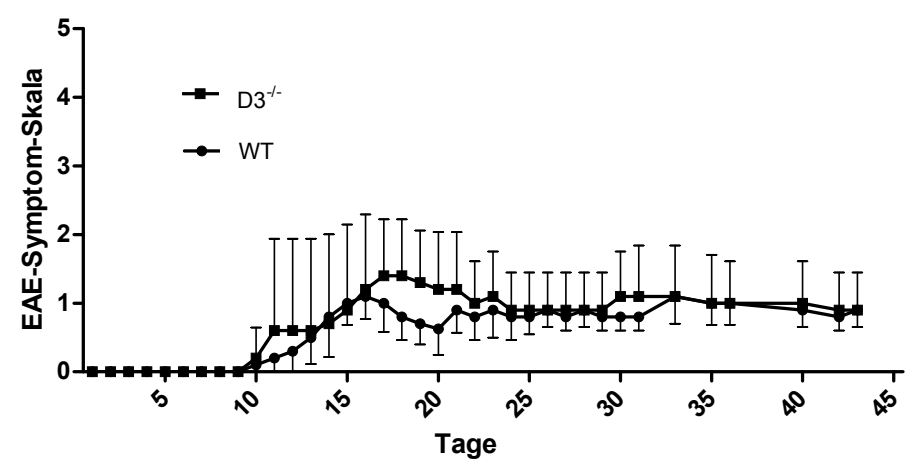

Abbildung 6.8: Krankheitsverlauf der chronischen EAE über 43 Tage. Vergleich von 5 D3-/--Mäusen $\left(\mathrm{D}^{-/-}\right.$) gegenüber 5 Wildtyp-Mäuse (WT). Immunisierung mit MOG $33-55$, tägliche Einstufung auf der EAE-Symptom-Skala, Perfusion am 43. Tag. Die Inzidenz betrug bei beiden Gruppen 80\%. Der Krankheitsbeginn erfolgte im selben Zeitraum, der klinische Verlauf erfolgte bei beiden im gleichen Ausmaß. Insgesamt zeigte die EAE eine milde Ausprägung. Die Fehlerbalken zeigen die Standardabweichung. 


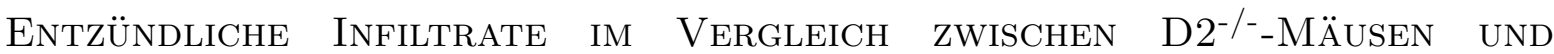 WILDTYP-MÄUSEN BEI AKUTER UND CHRONISCHER EAE.}

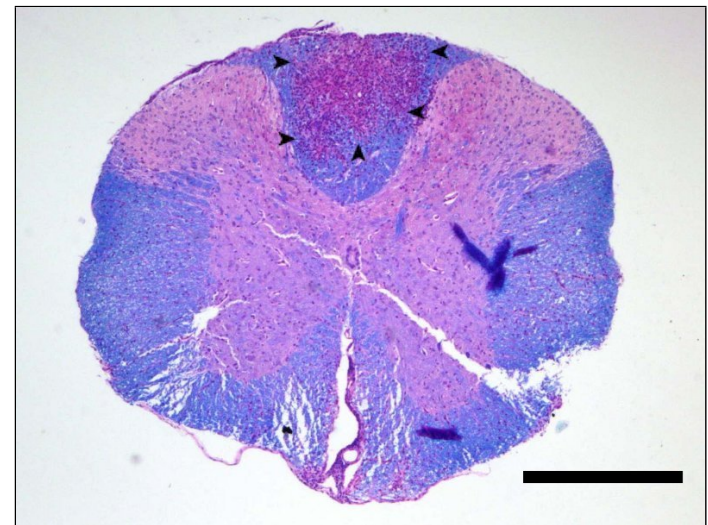

(a) Wildtyp-Mäuse, akutes Stadium

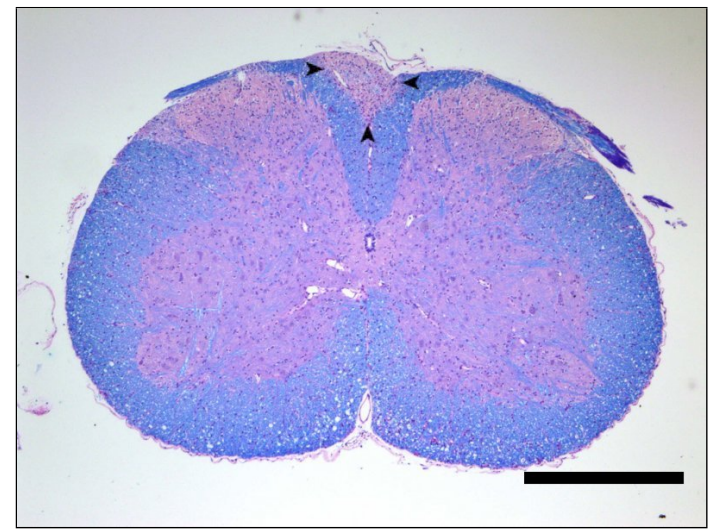

(c) Wildtyp-Mäuse, chronisches Stadium

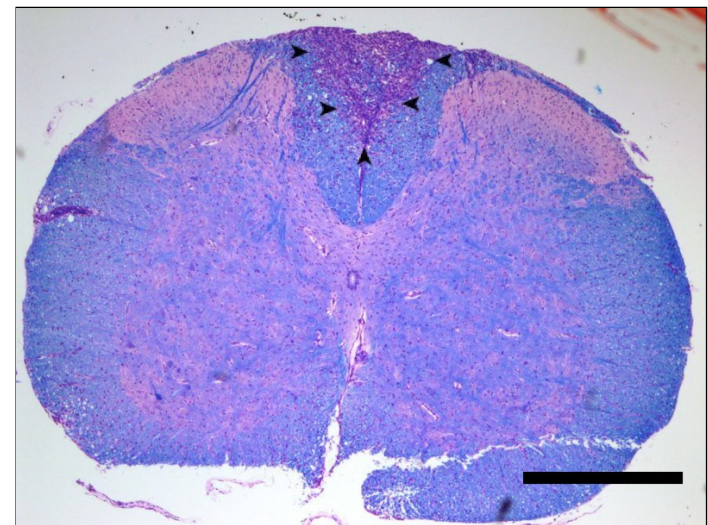

(b) D2-/--Mäuse, akutes Stadium

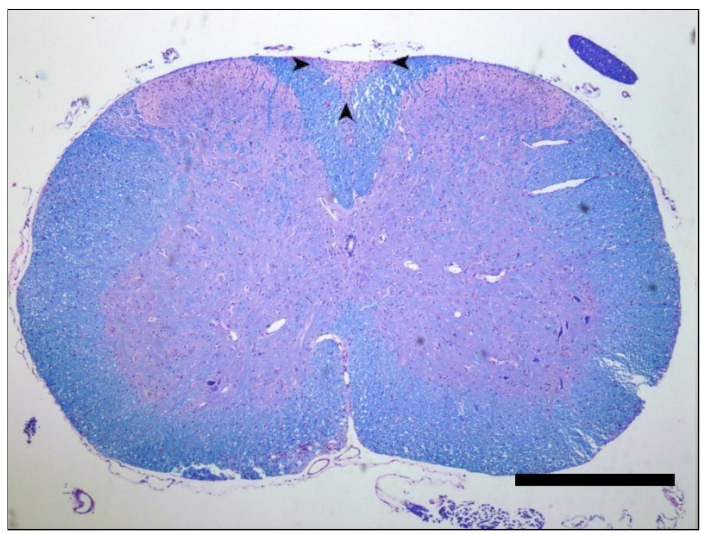

(d) D2/--Mäuse, chronisches Stadium

Abbildung 6.9: Entzündliche Infiltrate bei akuter und chronischer EAE. Zur Messung der Entzündungsaktivität nahmen wir die Anzahl der entzündlichen Infiltrate pro Rückenmarksquerschnitt zu Hilfe. Diese Infiltrate bestehen aus eingewanderten Immunzellen, insbesondere aus Makrophagen, TLymphozyten und B-Lymphozyten. Diese verursachen eine Entmarkung und schädigen die Axone. Die mit LFB-PAS gefärbten Rückenmarksquerschnitte zeigen keine Unterschiede in der Anzahl der Infiltrate pro Rückenmarksquerschnitt zwischen den Wildtyp-Mäusen und den D2-/--Mäusen. Dies gilt sowohl für das akute als auch für das chronische Stadium. Pfeilköpfe grenzen entzündliche Infiltrate ein. Färbung: LFB-PAS (Myelinscheiden: blau, Zellkerne:blau, graue Substanz: rötlich, entmarkte Areale: rötlich). Messbalken: $500 \mu \mathrm{m}$. 
Dichte DeR MAKrophagen/AKTIVerte Mikroglia im Vergleich ZWischen D2/--MÄUsen und WildTYP-MÄUSEN BEI AKUTER UND CHRONischer EAE.

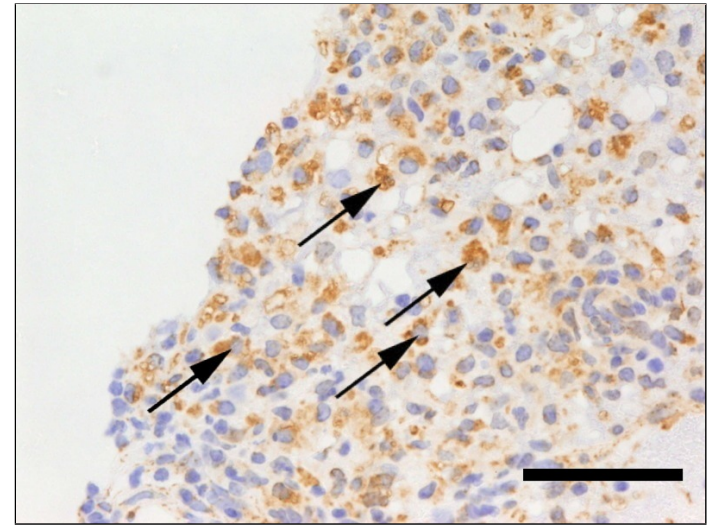

(a) Wildtyp-Mäuse, akutes Stadium

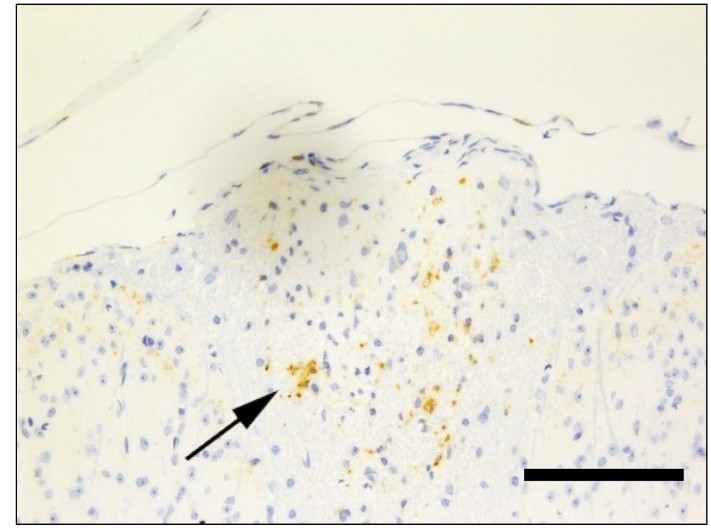

(c) Wildtyp-Mäuse, chronisches Stadium

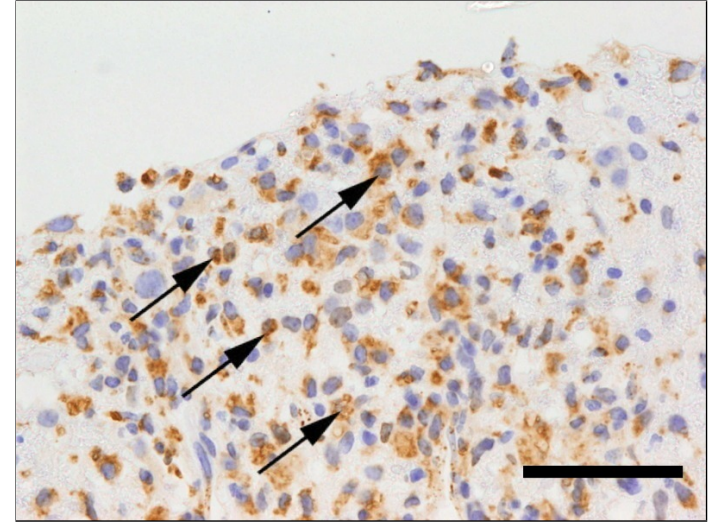

(b) D2-/--Mäuse, akutes Stadium

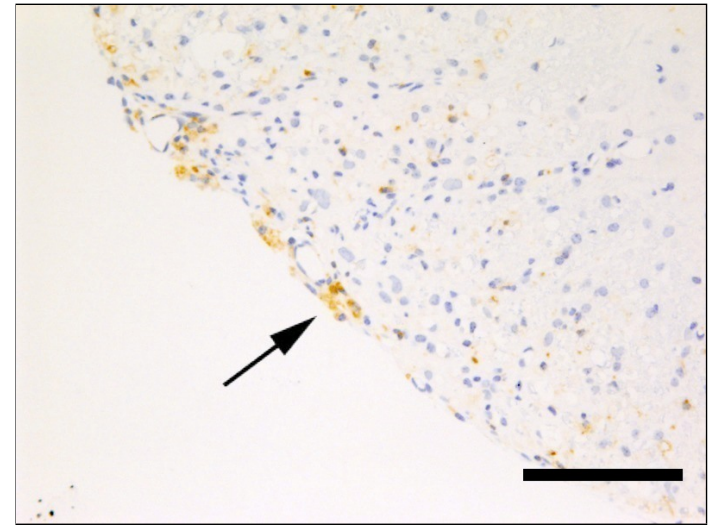

(d) D2-/--Mäuse, chronisches Stadium

Abbildung 6.10: Dichte der Makrophagen im Vergleich zwischen Wildtyp-Mäusen und D2-/--Mäusen. Makrophagen spielen eine wichtige Rolle in der Pathogenese der MS. Wir verglichen die Dichte der Makrophagen innerhalb der bei der EAE entstehenden, Infiltrate im Rückenmark. Dazu verwendeten wir eine immunhistochemische Färbung gegen Mac3, welches spezifisch für Makrophagen/aktivierte Mikroglia ist. Es zeigt sich kein Unterschied in der Dichte der Makrophagen bei einem Vergleich zwischen den Wildtyp-Mäusen und den D2-/--Mäusen, weder im akuten noch im chronischen Stadium der Erkrankung. Gut zu sehen ist die geringere Dichte der Makrophagen im chronischen Stadium. Pfeile zeigen beispielhaft auf Makrophagen. Färbung: Immunhistochemie gegen Mac3 (Makrophagen: bräunlich,

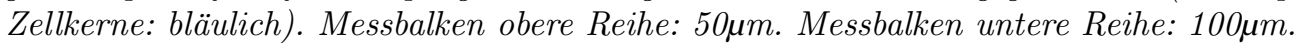


Dichte Der T-Lymphozyten Im Vergleich ZWischen D2-/--MäUsen und WILDTYP-MÄUSEN BEI AKUTER EAE.

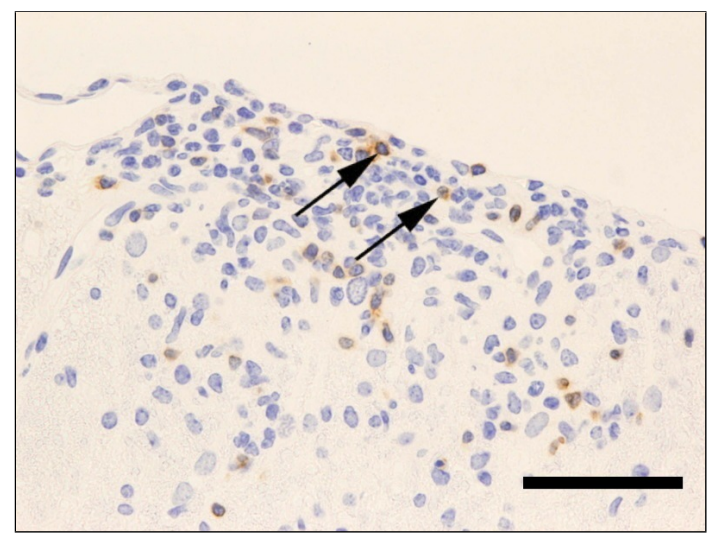

(a) Wildtyp-Mäuse

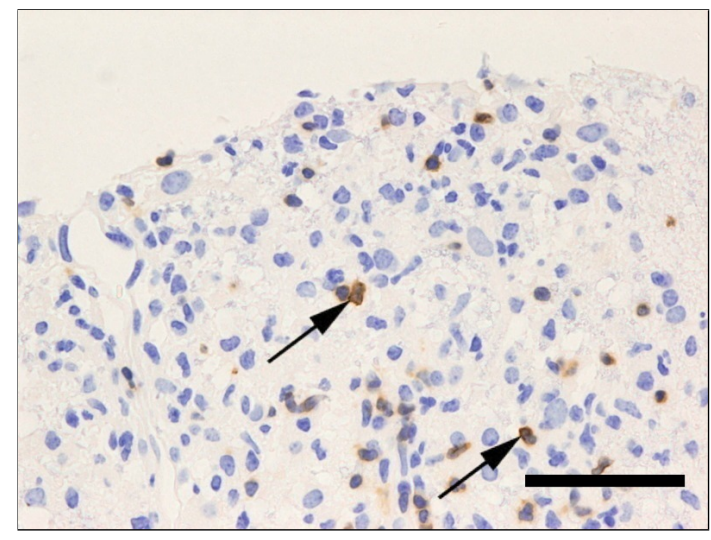

(b) D2-/--Mäuse

Abbildung 6.11: Dichte der T-Lymphozyten im Vergleich zwischen Wildtyp-Mäusen und D2//Mäusen. Entzündliche Infiltrate mit T-Lymphozyten und anderen Zellen gehört zur Charakteristik der MS und EAE. Wir verglichen die Dichte der T-Lymphozyten innerhalb der entzündlichen Infiltrate im akuten Stadium der EAE und fanden keine Unterschiede zwischen den beiden Gruppen. Pfeile zeigen beispielhaft auf T-Lymphozyten. Färbung: Immunhistochemie gegen Cd3 (T-Lymphozyten: bräunlich, Zellkerne: bläulich). Messbalken: 50um.

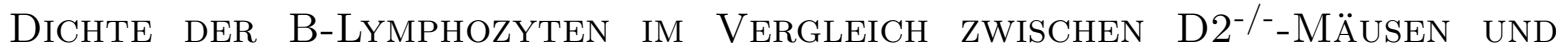
WILDTYP-MÄUSEN BEI CHRONISCHER EAE.

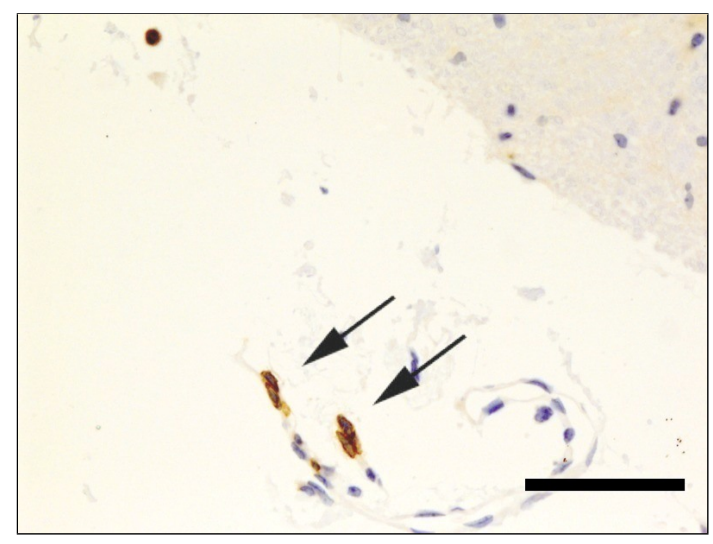

(a) Wildtyp-Mäuse

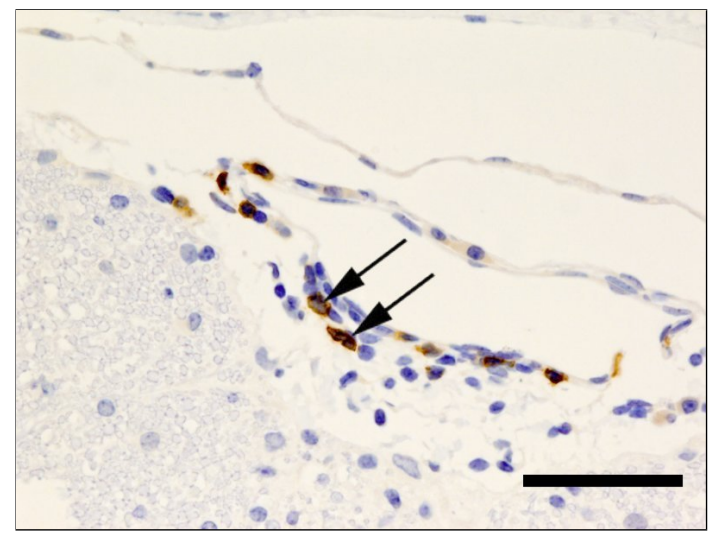

(b) D2/--Mäuse

Abbildung 6.12: Dichte der B-Lymphozyten im Vergleich zwischen Wildtyp-Mäusen und D2 $2^{-/-}$ Mäusen. B-Lymphozyten wandern im Falle der MS oder EAE in das zentrale Nervensystem ein und nehmen Teil am Entzündungsprozess. Wir fanden B-Lymphozyten vor allem im chronischen Stadium der EAE, wobei die B-Lymphozyten vor allem meningeal lokalisiert waren. Wir verglichen die Anzahl der meningealen B-Lympozyten pro $\mathrm{mm}^{2}$ zwischen den beiden Gruppen. Wir konnten keine Unterschiede nachweisen. Pfeile zeigen beispielhaft auf B-Lymphozyten. Färbung: Immunhistochemie gegen B220 (B-Lymphozyten: bräunlich, Zellkerne: bläulich). Messbalken: 50um. 


\section{ENTMARKUnG IM VERGLEICH ZWISChEN D2/--MÄUSEN UND WILDTYP-MÄUSEN BEI AKUTER UND CHRONISCHER EAE.}

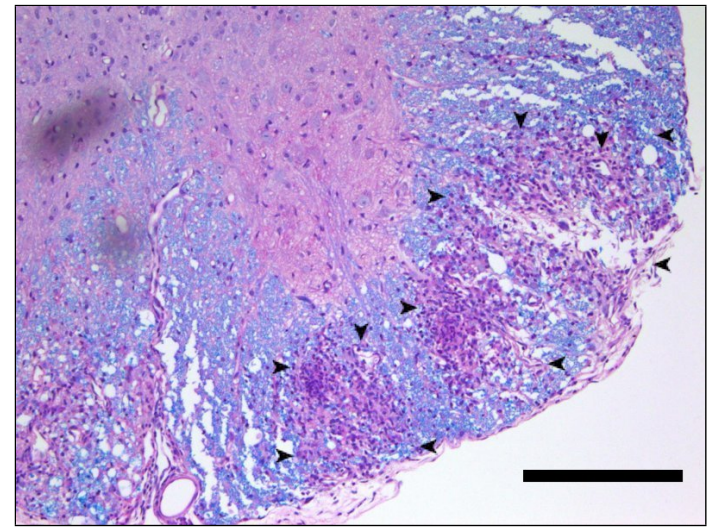

(a) Wildtyp-Mäuse, akutes Stadium

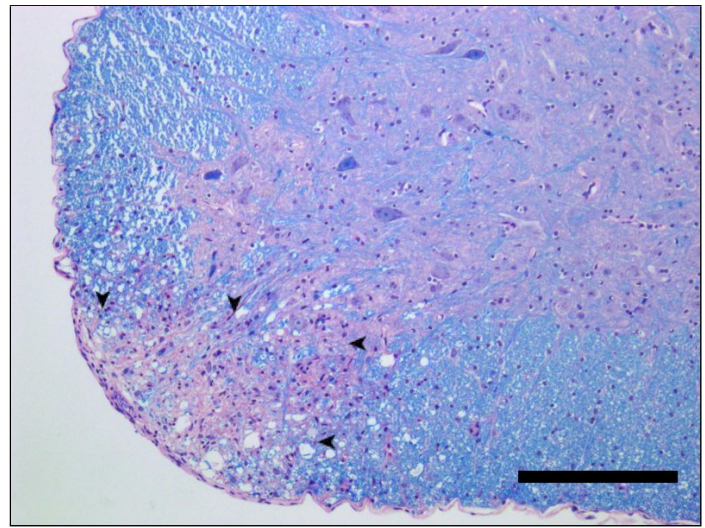

(c) Wildtyp-Mäuse, chronisches Stadium

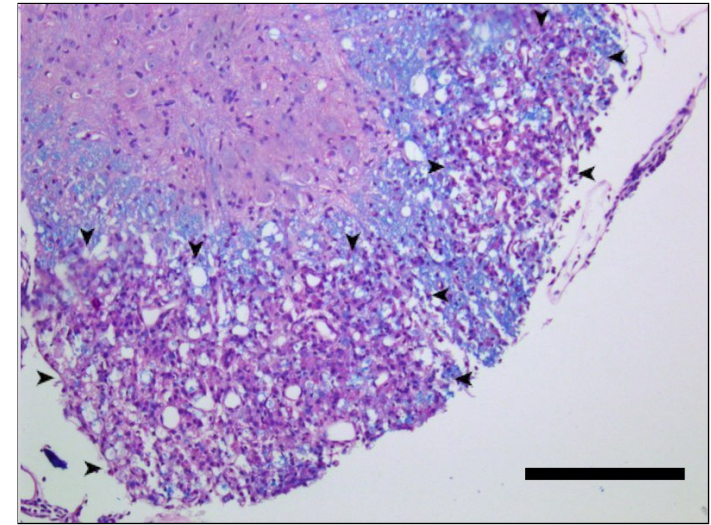

(b) D2-/--Mäuse, akutes Stadium

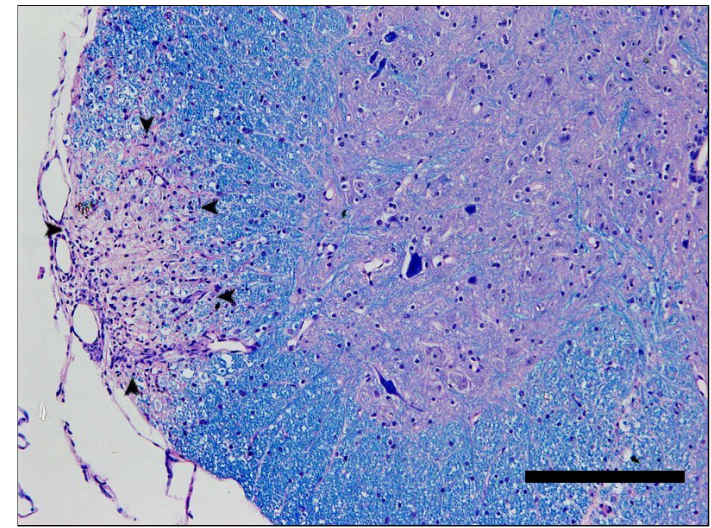

(d) D2//--Mäuse, chronisches Stadium

Abbildung 6.13: Entmarkung im Vergleich zwischen Wildtyp-Mäusen und D2-/--Mäusen. Bei der MS und der EAE kommt es durch Entzündungsprozesse zu einer Entmarkung, das heißt zu einem Verlust von Myelinscheiden. Es entstehen Läsionen, bei der EAE vor allem im Rückenmark. Wir verglichen die Größe der Läsionen in Prozent der gesamten weißen Substanz der Rückenmarkquerschnitte. Wir konnten keine Unterschiede zwischen den Wildtyp-Mäusen und den D2/--Mäusen zeigen. Sowohl im akuten Stadium als auch im chronischen Stadium unterscheiden sich die Entmarkungen nicht. Pfeilköpfe grenzen entmarkte Stellen ein. Färbung: LFB-PAS (Myelinscheiden: blau, Zellkerne:blau, graue Substanz: rötlich, entmarkte Areale: rötlich). Messbalken: 200um. 


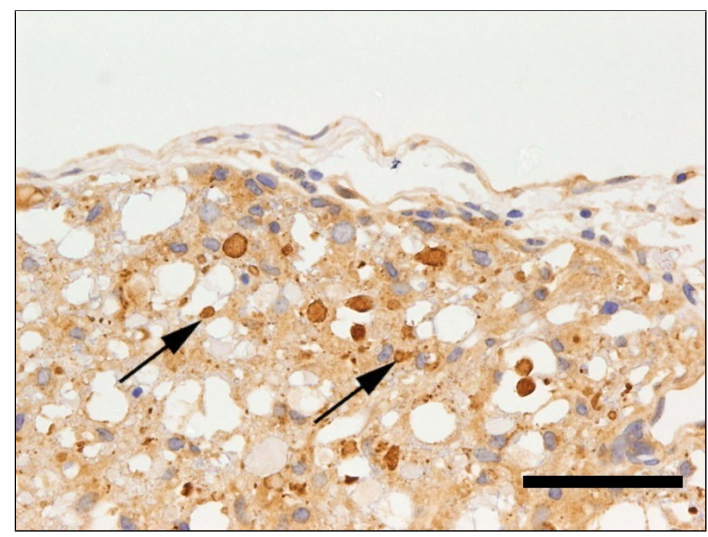

(a) Wildtyp-Mäuse, akutes Stadium

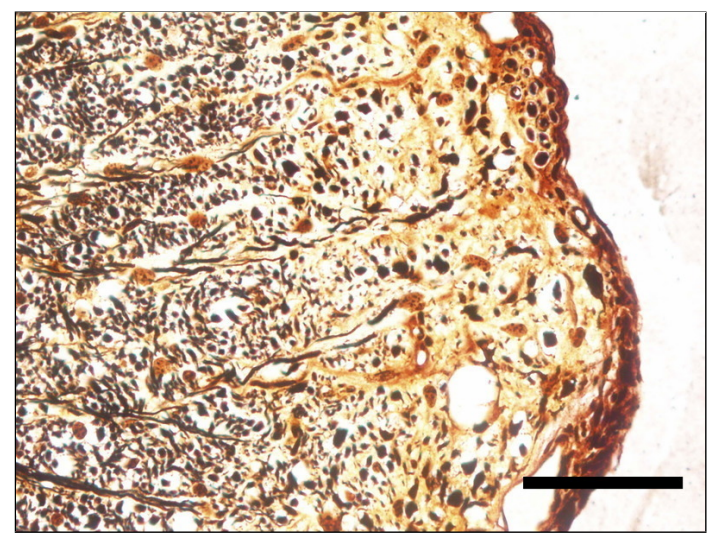

(c) Wildtyp-Mäuse, chronisches Stadium

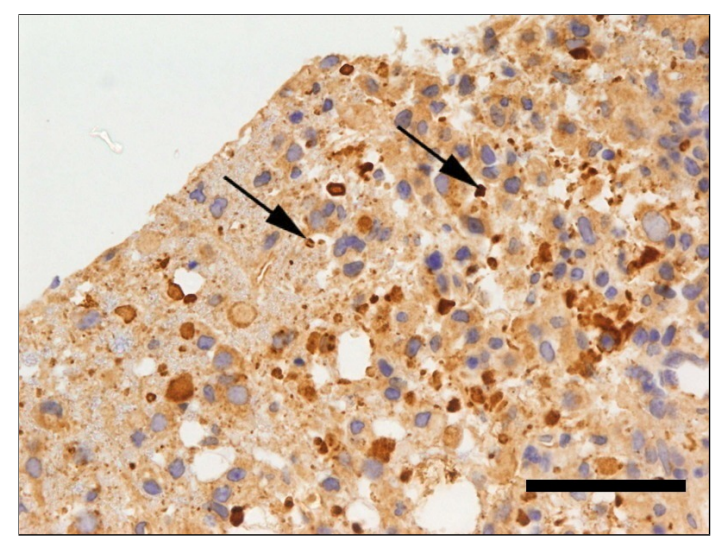

(b) D2-/--Mäuse, akutes Stadium

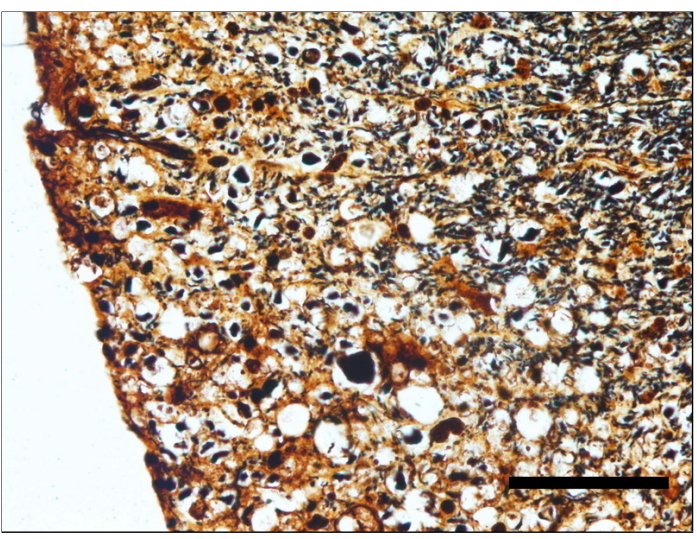

(d) D2-/--Mäuse, chronisches Stadium

Abbildung 6.14: Axonale Schädigung und axonaler Verlust bei akuter und chronischer EAE. D2-/Mäuse (D2-/-) im Vergleich zu Wildtyp-Mäusen (WT). Bei der MS und der EAE kommt es neben Zellinfiltrationen und Verlust der Myelinscheiden zu einem axonalen Schaden. Zur Kennzeichnung des axonalen Schadens verwendeten wir im akuten Stadium der EAE (Bilder a und b) eine Färbung gegen APP. Dieses Protein wird anterograd in den Axonen transportiert. Bei einer Schädigung kommt es zu einem Anstau dieses Proteins, welches dann durch immunhistochemische Färbungen als sogenannte App-positiven-Sphäroide sichtbar gemacht werden kann. Im chronischen Fall (Bilder c und d) verwendeten wir eine Färbung der Axone durch eine Bielschowsky-Versilberung und zählten die Axone in den Läsionen mithilfe eines Zählgitters mit 25 Kreuzungspunkten. Gut zu sehen ist die geringere Axondichte in den entmarkten Arealen (Abwesenheit der schwarz gefärbten Areale). Es war kein Unterschied in der axonalen Schädigung bzw. im axonalen Verlust erkennbar. Bilder a und b: Pfeile zeigen beispielhaft auf APP-positive Sphäroide. Färbung: Antikörper gegen APP (APP-positive-Sphäroide: bräunlich, Zellkerne: bläulich). Messbalken: 50um. Bilder c und d: Färbung: Bielschowsky-Versilberung (Axone: schwarz) Messbalken: $50 \mu \mathrm{m}$. 
Dichte Der Oligodendrozyten im Vergleich ZWischen D2-/--MäUSEN Und WILDTYP-MÄUSEN BEI AKUTER UND CHRONISCHER EAE.

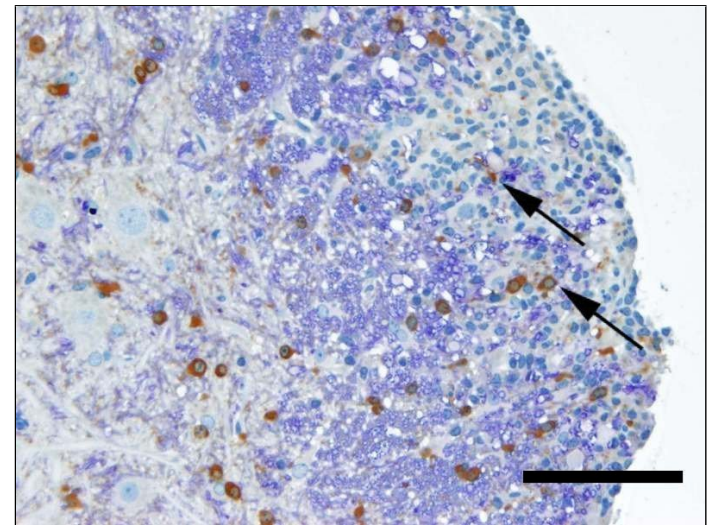

(a) Wildtyp-Mäuse, akutes Stadium

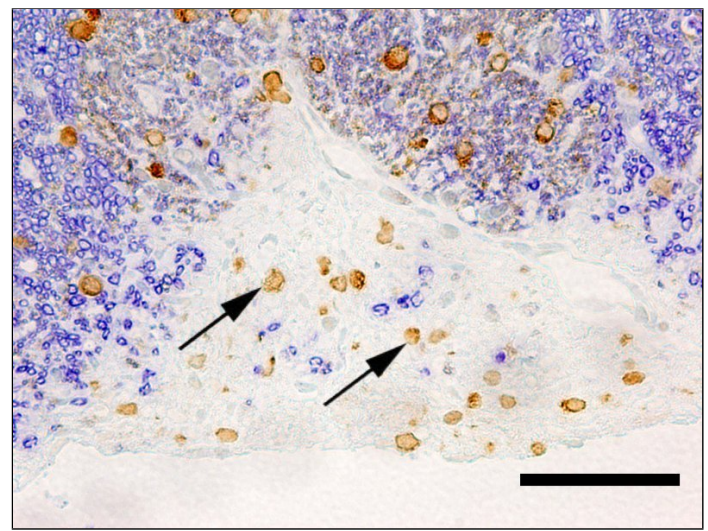

(c) Wildtyp-Mäuse, chronisches Stadium

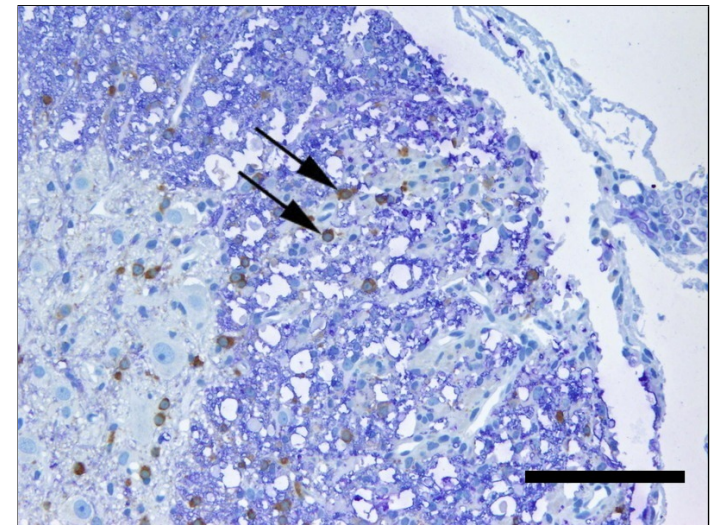

(b) D2-/--Mäuse, akutes Stadium

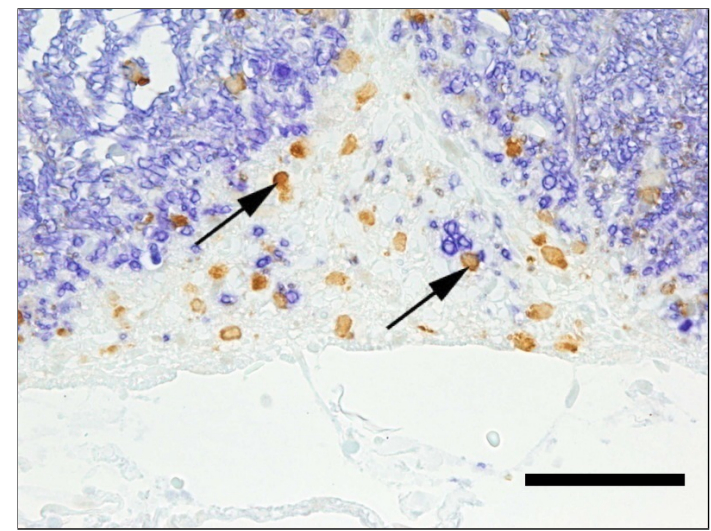

(d) D2-/--Mäuse, chronisches Stadium

Abbildung 6.15: Dichte der Oligodendrozyten im Vergleich zwischen Wildtyp-Mäusen und D2 $2^{-/-}$ Mäusen. Oligodendrozyten bilden im zentralen Nervensystem die Myelinscheiden um die Axone. Die Myelinscheiden werden bei der EAE und der MS angegriffen, dadurch entstehen entmarkte Areale (Im Bild als helle Fläche zu sehen) und es kommt zu einem neurologischen Ausfall. Im weiteren Verlauf der Erkrankung kommt es zu einer teilweisen Remyelinisierung. Wir verglichen die Dichte der Oligodendrozyten zwischen den beiden Gruppen und fanden keine Unterschiede, weder im akuten Stadium noch im chronischen Stadium. Pfeile zeigen beispielhaft auf Oligodendrozyten. Färbung: Doppelimmunhistochemie gegen p25 und MBP (p25-positive-Zellen bräunlich angefärbt, Myelinscheiden: hellblau, Zellkerne:

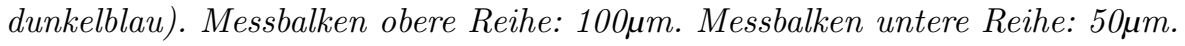




\section{ENTZÜNDLICHE INFILTRATE IM VERGLEICH ZWISChEN D3 $3^{-/-}$-MÄUSEN UND WILDTYP-MÄUSEN BEI AKUTER EAE.}

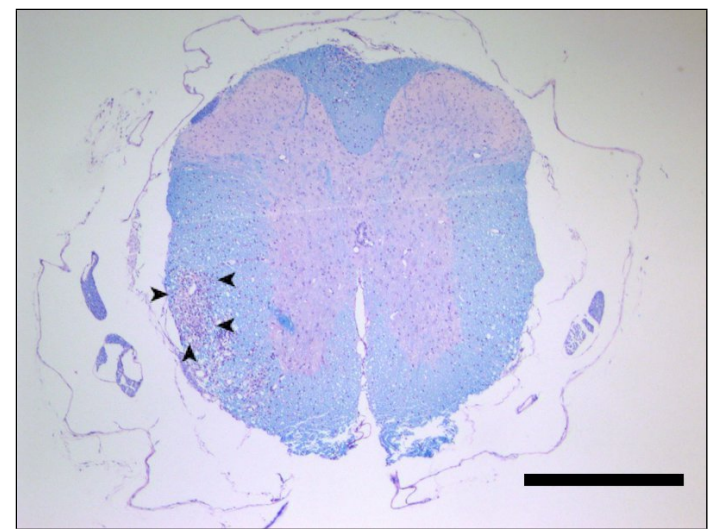

(a) Wildtyp-Mäuse, akutes Stadium

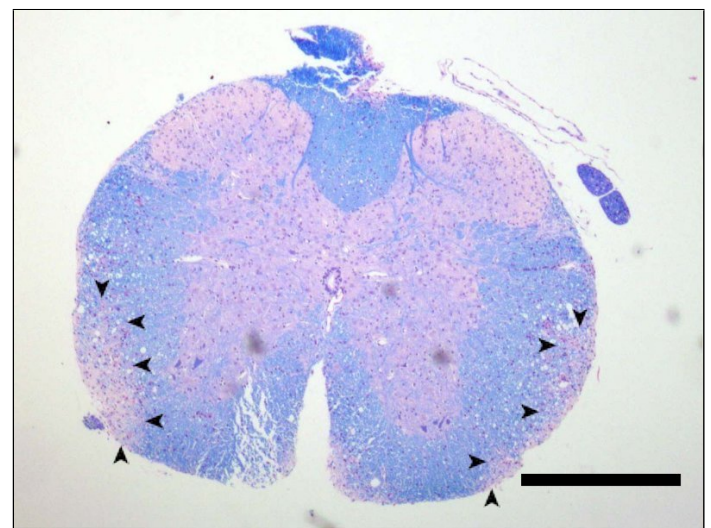

(c) Wildtyp-Mäuse, chronisches Stadium

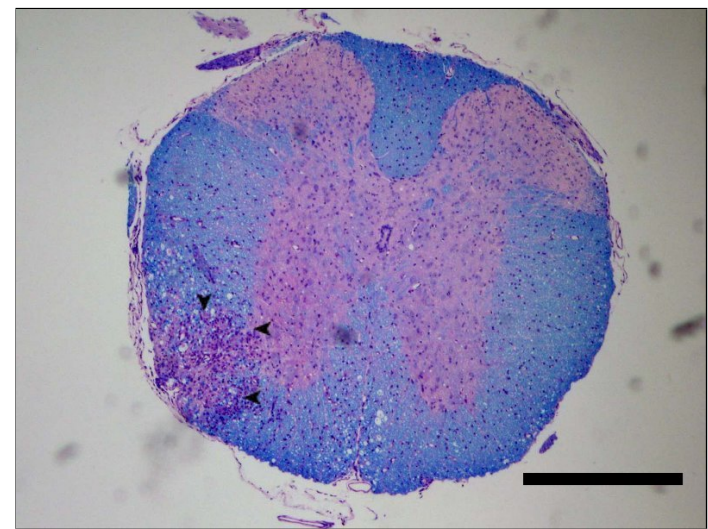

(b) D3-/--Mäuse, akutes Stadium

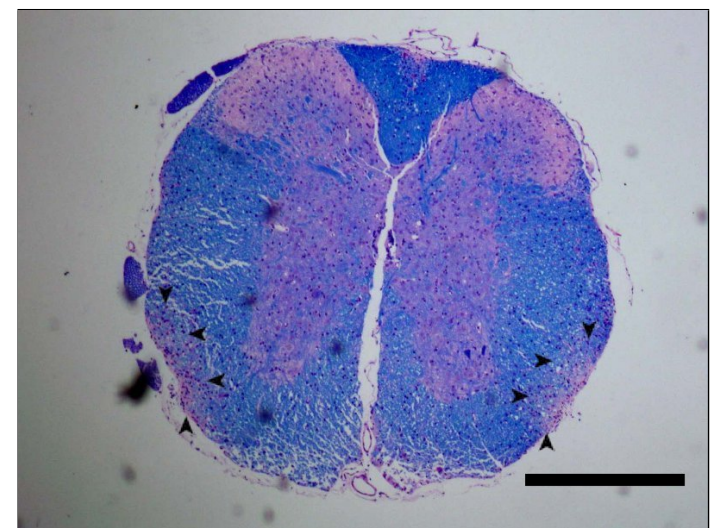

(d) D3-/--Mäuse, chronisches Stadium

Abbildung 6.16: Entzündliche Infiltrate bei akuter und chronischer EAE. Zur Messung der Entzündungsaktivität nahmen wir die Anzahl der entzündlichen Infiltrate pro Rückenmarksquerschnitt zu Hilfe. Diese Infiltrate bestehen aus eingewanderten Immunzellen, insbesondere aus Makrophagen, TLymphozyten und B-Lymphozyten. Diese verursachen eine Entmarkung und schädigen die Axone. Die mit LFB-PAS gefärbten Rückenmarksquerschnitte zeigen keine Unterschiede in der Anzahl der Infiltrate pro Rückenmarksquerschnitt zwischen den Wildtyp-Mäusen und den D3-/--Mäusen. Dies gilt sowohl für das akute als auch für das chronische Stadium. Pfeilköpfe grenzen entzündliche Infiltrate ein. Färbung: LFB-PAS (Myelinscheiden: blau, Zellkerne: blau, graue Substanz: rötlich, entmarkte Areale: rötlich). Messbalken: $500 \mu \mathrm{m}$. 
Dichte Der Makrophagen/AKTiverte Mikroglia im Vergleich ZWischen D3-/--MÄUSEN UND WILDTYP-MÄUSEN BEI AKUTER UND CHRONISCHER EAE.

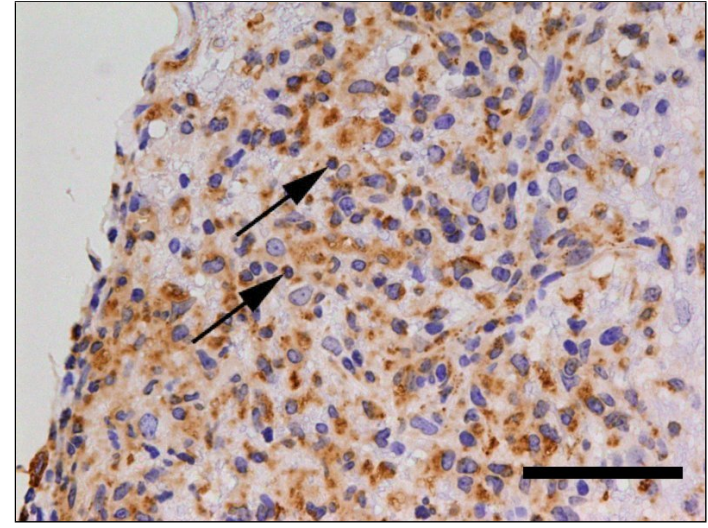

(a) Wildtyp-Mäuse, akutes Stadium

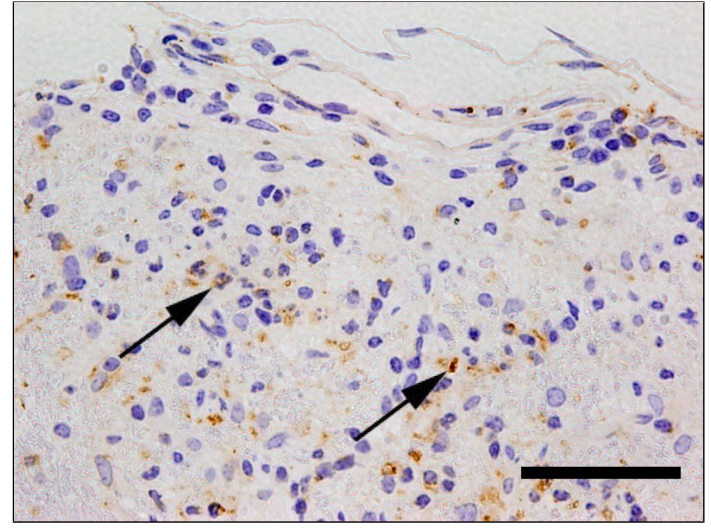

(c) Wildtyp-Mäuse, chronisches Stadium

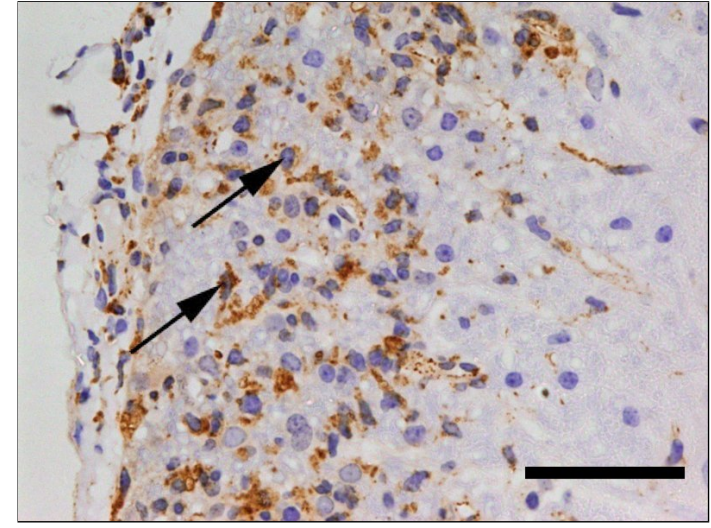

(b) D3 $3^{-/-}$-Mäuse, akutes Stadium

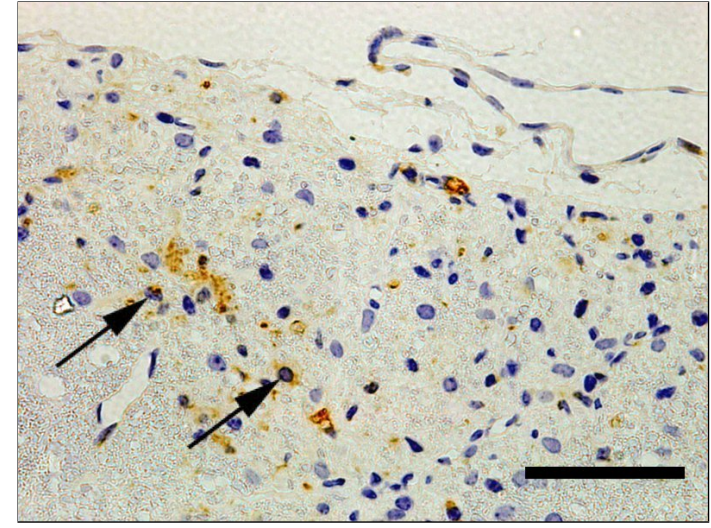

(d) D3-/--Mäuse, chronisches Stadium

Abbildung 6.17: Dichte der Makrophagen im Vergleich zwischen Wildtyp-Mäusen und D3-/--Mäusen. Makrophagen spielen eine wichtige Rolle in der Pathogenese der MS. Wir verglichen die Dichte der Makrophagen innerhalb der bei der EAE entstehenden, Infiltrate im Rückenmark. Dazu verwendeten wir eine immunhistochemische Färbung gegen Mac3, welche spezifisch für Makrophagen/aktivierte Mikroglia ist. Es zeigt sich eine signifikant geringere Dichte der Makrophagen im akuten Stadium bei den D3 ${ }^{-/-}$-Mäusen. Dies zeigt sich nicht im chronischen Stadium der Erkrankung. Pfeile zeigen beispielhaft auf Makrophagen. Färbung: Immunhistochemie gegen Mac3 (Makrophagen: bräunlich, Zellkerne:

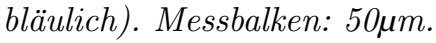


Dichte Der T-Lymphozyten Im Vergleich ZWischen D3-/--MäUsen und WILDTYP-MÄUSEN BEI AKUTER EAE.

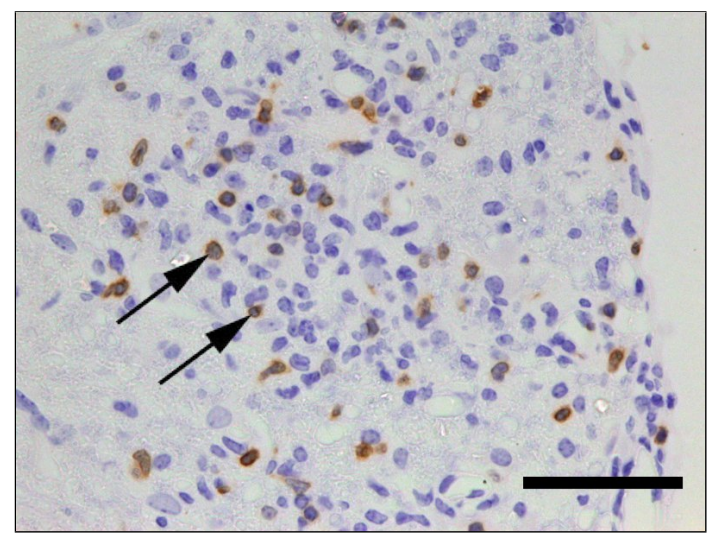

(a) Wildtyp-Mäuse

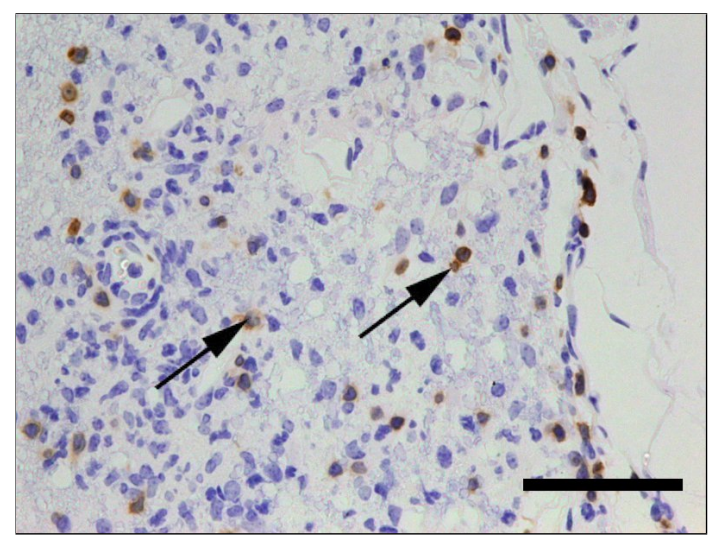

(b) D3-/--Mäuse

Abbildung 6.18: Dichte der T-Lymphozyten im Vergleich zwischen Wildtyp-Mäusen und D3-/Mäusen. Entzündliche Infiltrate mit T-Lymphozyten und anderen Zellen gehören zur Charakteristik der MS und EAE. Wir verglichen die Dichte der T-Lymphozyten innerhalb der entzündlichen Infiltrate im akuten Stadium der EAE und fanden keine Unterschiede zwischen den beiden Gruppen. Pfeile zeigen beispielhaft auf T-Lymphozyten. Färbung: Immunhistochemie gegen Cd3 (T-Lymphozyten: bräunlich, Zellkerne: bläulich). Messbalken: 50um.

Dichte DER B-LYMPhOZYTEN IM VERGLEICH ZWISCHEN D3-/--MÄUSEN UND WILDTYP-MÄUSEN BEI CHRONISCHER EAE.

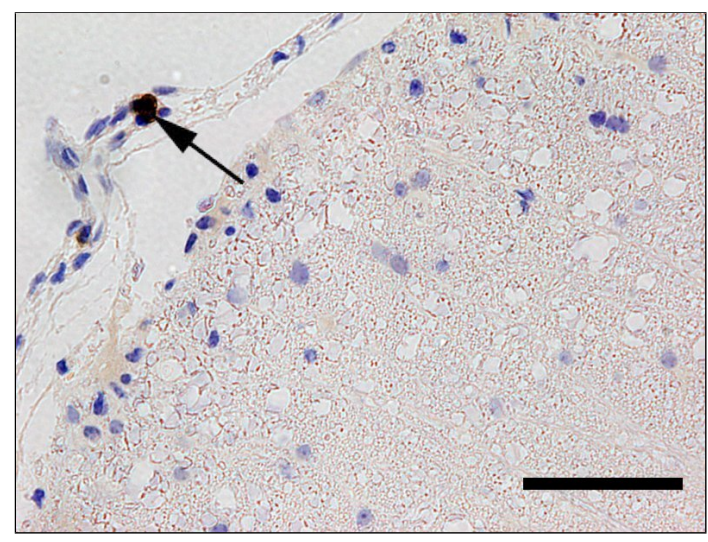

(a) Wildtyp-Mäuse

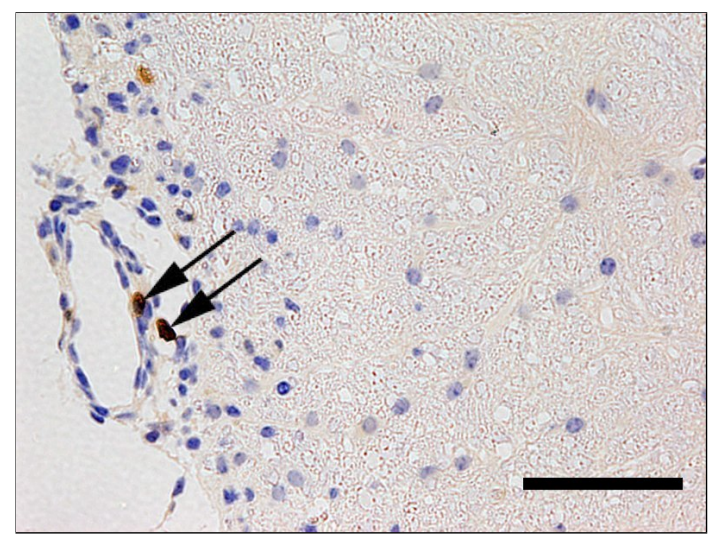

(b) D3-/--Mäuse

Abbildung 6.19: Dichte der B-Lymphozyten im Vergleich zwischen Wildtyp-Mäusen und D3 $3^{-/-}$ Mäusen. B-Lymphozyten wandern im Falle der MS oder EAE in das zentrale Nervensystem ein und nehmen Teil am Entzündungsprozess. Wir fanden B-Lymphozyten vor allem im chronischen Stadium der EAE, wobei die B-Lymphozyten vor allem meningeal lokalisiert waren. Wir verglichen die Anzahl der meningealen B-Lympozyten pro mm zwischen den beiden Gruppen. Wir konnten keine Unterschiede nachweisen. Pfeile zeigen beispielhaft auf B-Lymphozyten. Färbung: Immunhistochemie gegen B220 (B-Lymphozyten: bräunlich, Zellkerne: bläulich). Messbalken: 50um. 


\section{Entmarkung im Vergleich ZWischen D3-/--MäUSEn Und Wildtyp-MÄUsen BEI AKUTER UND CHRONISCHER EAE.}

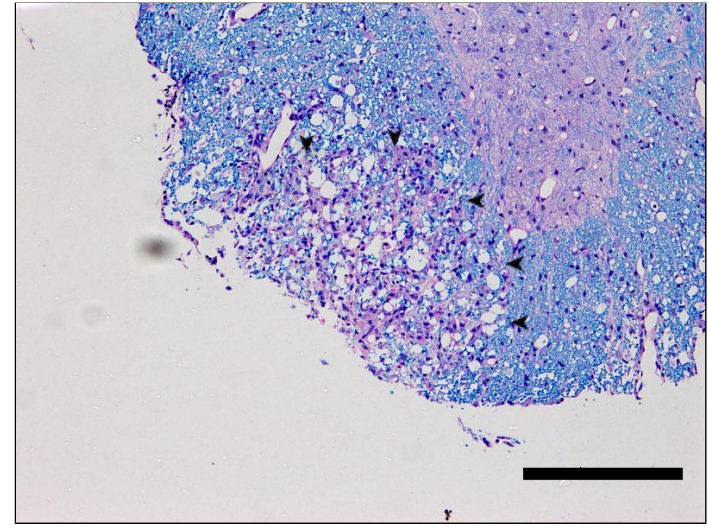

(a) Wildtyp-Mäuse, akutes Stadium

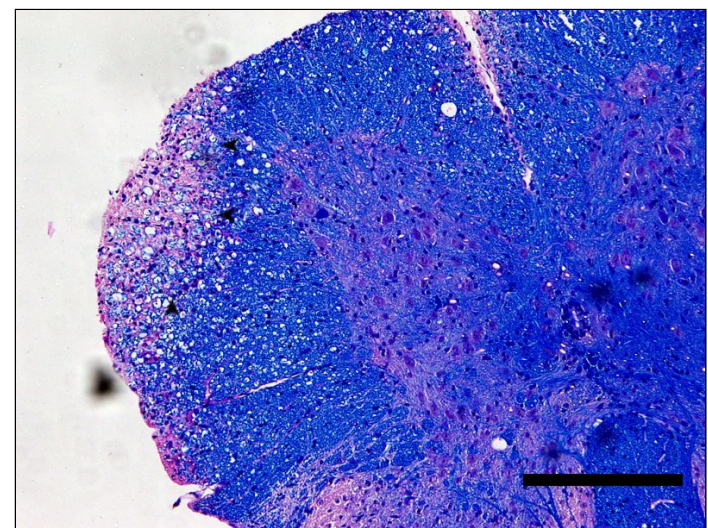

(c) Wildtyp-Mäuse, chronisches Stadium

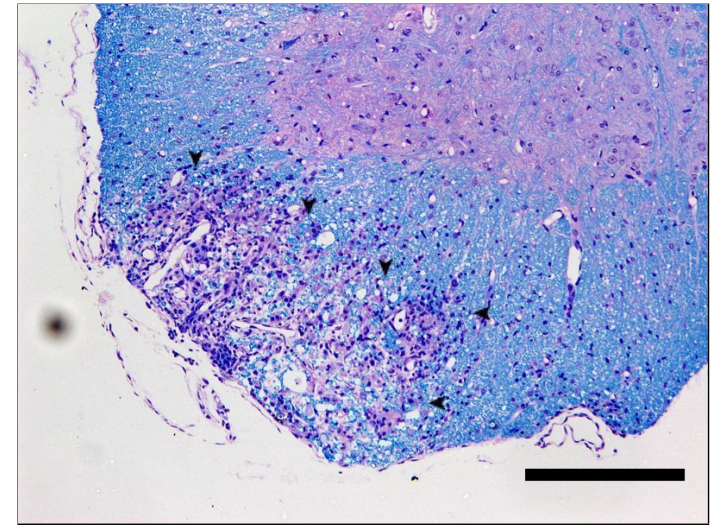

(b) D3-/--Mäuse, akutes Stadium

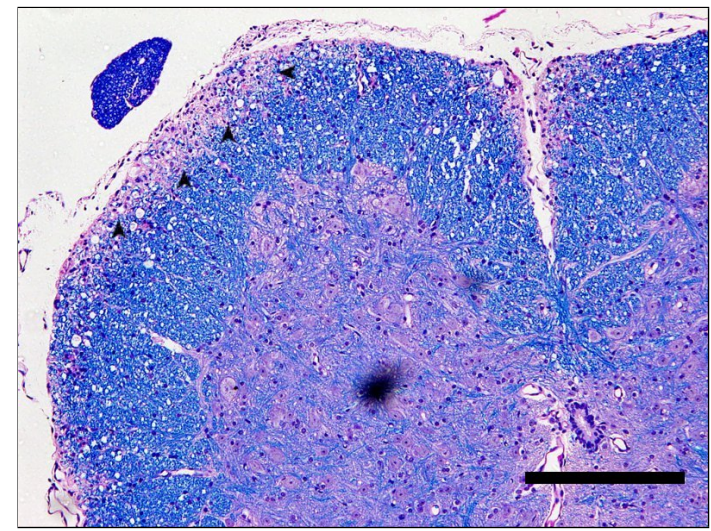

(d) D3//--Mäuse, chronisches Stadium

Abbildung 6.20: Entmarkung im Vergleich zwischen Wildtyp-Mäusen und D3---Mäusen. Bei der MS und der EAE kommt es durch Entzündungsprozesse zu einer Entmarkung, das heißt zu einem Verlust von Myelinscheiden. Es entstehen Läsionen. Wir verglichen die Größe der Läsionen in Prozent der gesamten weißen Substanz der Rückenmarkquerschnitte. Weder im akuten noch im chronischen Stadium der Erkrankung konnten wir Unterschiede zwischen den Wildtyp-Mäusen und den D3-/--Mäusen zeigen. Pfeilköpfe grenzen entmarkte Stellen ein. Färbung: LFB-PAS (Myelinscheiden: blau, Zellkerne: blau, graue Substanz: rötlich, entmarkte Areale: rötlich). Messbalken: 200um. 


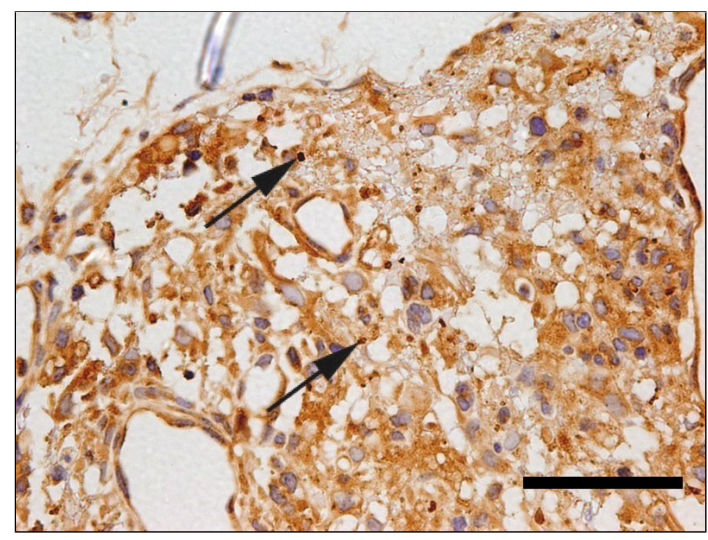

(a) Wildtyp-Mäuse, akutes Stadium

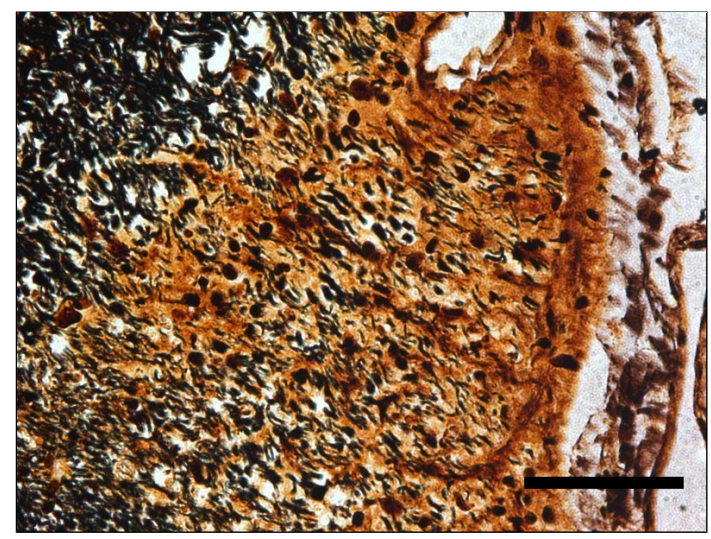

(c) Wildtyp-Mäuse, chronisches Stadium

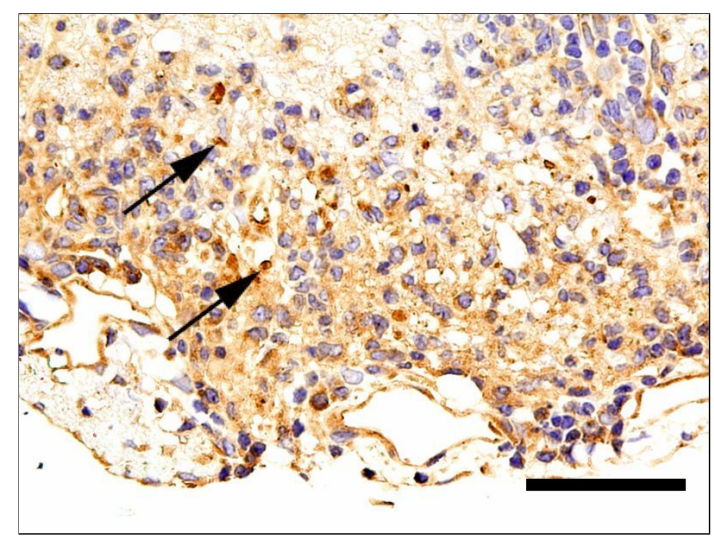

(b) D3-/--Mäuse, akutes Stadium

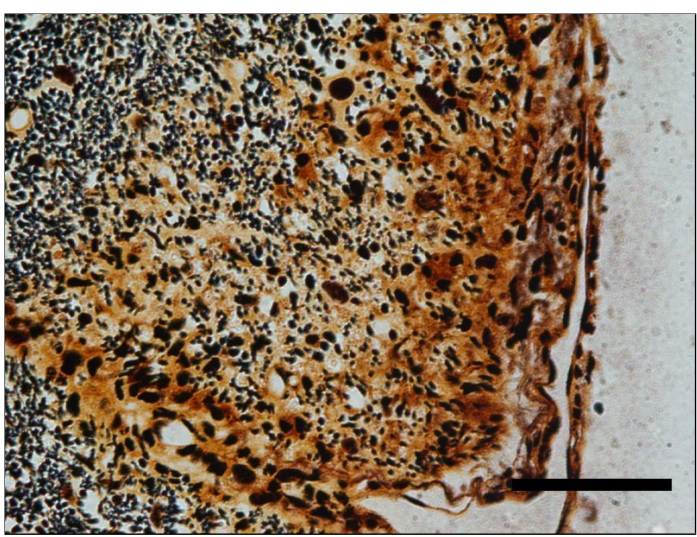

(d) D3-/--Mäuse, chronisches Stadium

Abbildung 6.21: Axonale Schädigung und axonaler Verlust bei akuter und chronischer EAE. D3 ${ }^{-/-}$ Mäuse (D3-/-) im Vergleich zu Wildtyp-Mäusen (WT). Bei der MS und der EAE kommt es neben Zellinfiltrationen und Verlust der Myelinscheiden zu einem axonalen Schaden. Zur Kennzeichnung des axonalen Schadens verwendeten wir im akuten Stadium der EAE (Bilder a und b) eine Färbung gegen APP. Dieses Protein wird anterograd in den Axonen transportiert. Bei einer Schädigung kommt es zu einem Anstau dieses Proteins, welches dann durch immunhistochemische Färbungen als sogenannte App-positiven-Sphäroide sichtbar gemacht werden kann. Im chronischen Fall (Bilder c und d) verwendeten wir eine Färbung der Axone durch eine Bielschowsky-Versilberung und zählten die Axone in den Läsionen mithilfe eines Zählgitters mit 25 Kreuzungspunkten. Gut zu sehen ist die geringere Axondichte in den entmarkten Arealen (Abwesenheit der schwarz gefärbten Areale). Es war kein Unterschied in der axonalen Schädigung bzw. im axonalen Verlust erkennbar. Bilder a und b: Pfeile zeigen beispielhaft auf APP-positive Sphäroide. Färbung: Antikörper gegen APP (APP-positive-Sphäroide: bräunlich, Zellkerne: bläulich). Messbalken: 50um. Bilder c und d: Färbung: Bielschowsky-Versilberung (Axone: schwarz) Messbalken: $50 \mu$. 


\section{Dichte DeR Oligodendrozyten im Vergleich ZWischen D3\%-/-MäUSEN UND WILDTYP-MÄUSEN BEI AKUTER UND CHRONISCHER EAE.}

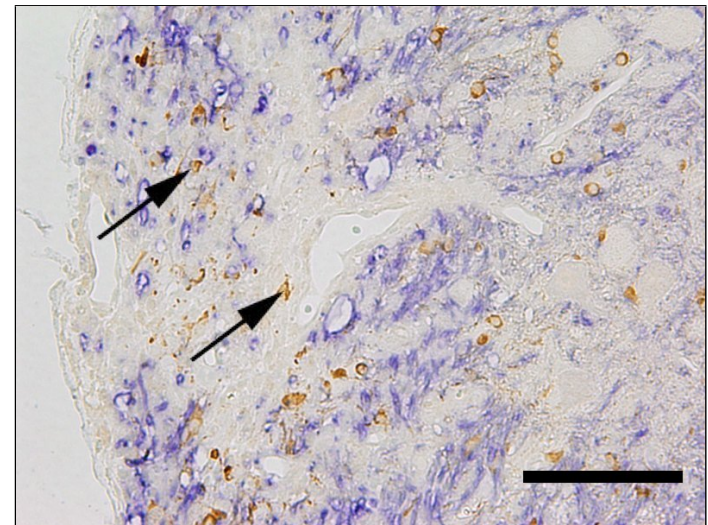

(a) Wildtyp-Mäuse, akutes Stadium

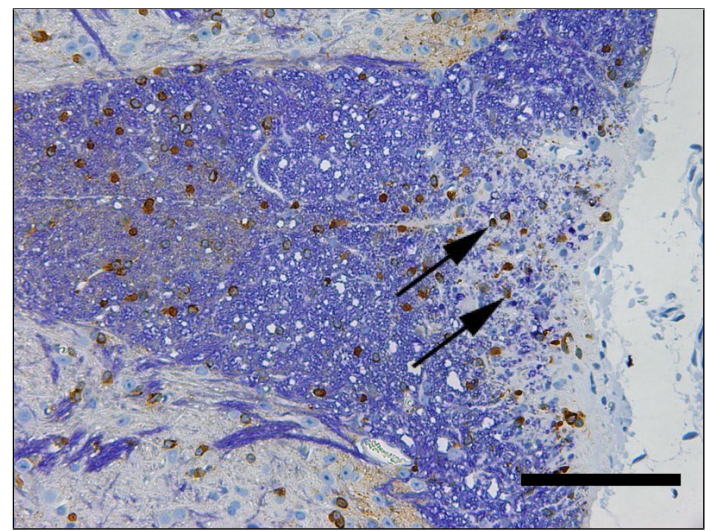

(c) Wildtyp-Mäuse, chronisches Stadium

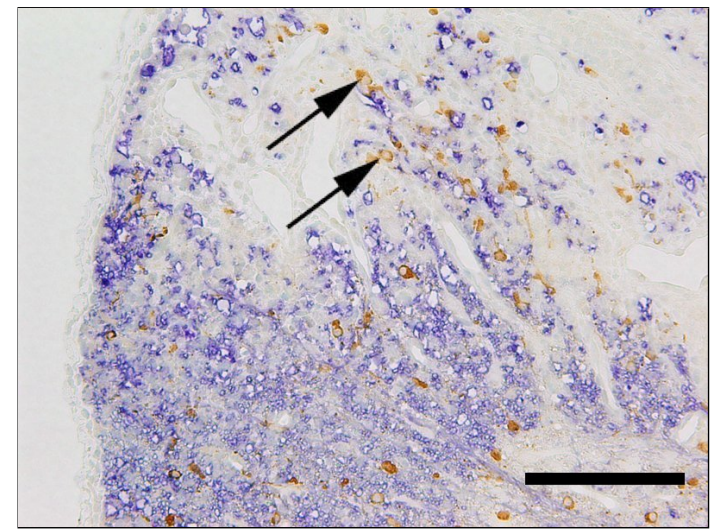

(b) D3-/--Mäuse, akutes Stadium

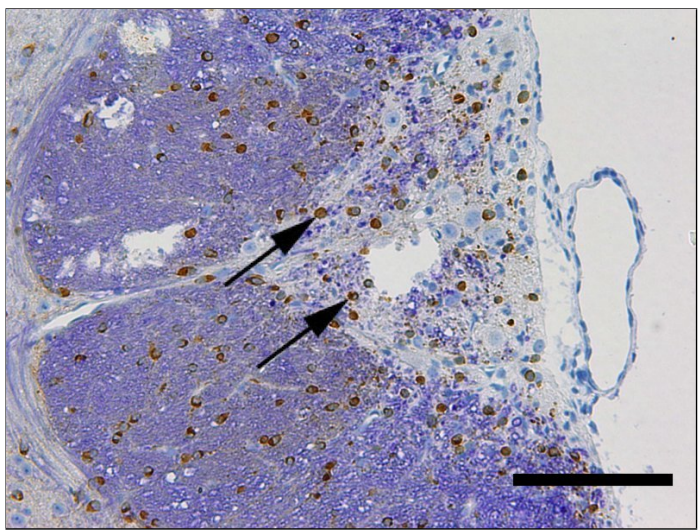

(d) D3-/--Mäuse, chronisches Stadium

Abbildung 6.22: Dichte der Oligodendrozyten im Vergleich zwischen Wildtyp-Mäusen und D3//Mäusen. Oligodendrozyten bilden im zentralen Nervensystem die Myelinscheiden um die Axone. Die Myelinscheiden werden bei der EAE und der MS angegriffen, dadurch entstehen entmarkte Areale (Im Bild als helle Fläche zu sehen) und es kommt zu einem neurologischen Ausfall. Im weiteren Verlauf der Erkrankung kommt es zu einer teilweisen Remyelinisierung. Wir verglichen die Dichte der Oligodendrozyten zwischen den beiden Gruppen und fanden keine Unterschiede, weder im akuten Stadium noch im chronischen Stadium. Pfeile zeigen beispielhaft auf Oligodendrozyten. Färbung: Doppelimmunhistochemie gegen p25 und MBP (p25-positive-Zellen bräunlich angefärbt, Myelinscheiden: hellblau, Zellkerne:

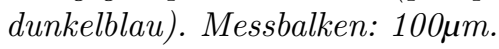




\section{Literaturverzeichnis}

Accili D, Fishburn CS, Drago J, Steiner H, Lachowicz JE, Park BH, Gauda EB, Lee EJ, Cool MH, Sibley DR, et al. (1996): A targeted mutation of the d3 dopamine receptor gene is associated with hyperactivity in mice., Proc Natl Acad Sci U S A $\underline{93}$, 5, 1945-1949

Armando I, Wang X, Villar VAM, Jones JE, Asico LD, Escano C, Jose PA (2007): Reactive oxygen species-dependent hypertension in dopamine $\mathrm{d} 2$ receptor-deficient mice., Hypertension 49 , 3, 672-678

Azar ST, Yamout B (1999): Prolactin secretion is increased in patients with multiple sclerosis., Endocr Res 25, 2, 207-214

Baik JH, Picetti R, Saiardi A, Thiriet G, Dierich A, Depaulis A, Meur ML, Borrelli E (1995): Parkinsonian-like locomotor impairment in mice lacking dopamine d2 receptors., Nature $\underline{377}, 6548,424-428$

Barnett MH, Sutton I (2006): The pathology of multiple sclerosis: a paradigm shift., Curr Opin Neurol 19, 3, 242-247

Basu S, Dasgupta PS (2000): Dopamine, a neurotransmitter, influences the immune system., J Neuroimmunol 102, 2, 113-124

Baxter AG (2007): The origin and application of experimental autoimmune encephalomyelitis., Nat Rev Immunol ㅁ, 11, 904-912

Bałkowiec-Iskra E, Kurkowska-Jastrzebska I, Joniec I, Ciesielska A, Muszynska A, Przybyłkowski A, Członkowska A, Członkowski A (2007): Mptp-induced central dopamine depletion exacerbates experimental autoimmune encephalomyelitis (eae) in c57bl mice., Inflamm Res $\underline{56}, 8,311-317$

Beck GC, Brinkkoetter P, Hanusch C, Schulte J, van Ackern K, van der Woude FJ, Yard BA (2004): Clinical review: immunomodulatory effects of dopamine in general inflammation., Crit Care $\underline{8}$, 6, 485-491 
Ben-Shachar D, Zuk R, Glinka Y (1995): Dopamine neurotoxicity: inhibition of mitochondrial respiration., J Neurochem $\underline{64}, 2,718-723$

Bergquist J, Silberring J (1998): Identification of catecholamines in the immune system by electrospray ionization mass spectrometry., Rapid Commun Mass Spectrom $\underline{12}$, 11, $683-688$

Berne-Fromell K, Fromell H, Lundkvist S, Lundkvist P (1987): Is multiple sclerosis the equivalent of parkinson's disease for noradrenaline?, Med Hypotheses 23, 4, 409-415

Besser MJ, Ganor Y, Levite M (2005): Dopamine by itself activates either d2, d3 or d1/d5 dopaminergic receptors in normal human t-cells and triggers the selective secretion of either il-10, tnfalpha or both., J Neuroimmunol 169, 1-2, 161-171

Bissay V, Klippel ND, Herroelen L, Schmedding E, Buisseret T, Ebinger G, Keyser JD (1994): Bromocriptine therapy in multiple sclerosis: an open label pilot study., Clin Neuropharmacol 17, 5, 473-476

Bitsch A, Brück W (2002): Differentiation of multiple sclerosis subtypes: implications for treatment., CNS Drugs 16, 6, 405-418

Bongarzone ER, Howard SG, Schonmann V, Campagnoni AT (1998): Identification of the dopamine $\mathrm{d} 3$ receptor in oligodendrocyte precursors: potential role in regulating differentiation and myelin formation., J Neurosci $\underline{18}, 14,5344-5353$

Bouchard B, Ormandy CJ, Santo JPD, Kelly PA (1999): Immune system development and function in prolactin receptor-deficient mice., J Immunol $\underline{163}, 2$, 576-582

Bozzi Y, Borrelli E (2006): Dopamine in neurotoxicity and neuroprotection: what do d2 receptors have to do with it?, Trends Neurosci $\underline{29}$, 3, 167-174

Breij ECW, Brink BP, Veerhuis R, van den Berg C, Vloet R, Yan R, Dijkstra CD, van der Valk P, Bö L (2008): Homogeneity of active demyelinating lesions in established multiple sclerosis., Ann Neurol $\underline{63}, 1,16-25$

Brueck W, Stadelmann C (2005): The spectrum of multiple sclerosis: new lessons from pathology., Curr Opin Neurol 18, 3, 221-224

Brusaferri F, Candelise L (2000): Steroids for multiple sclerosis and optic neuritis: a meta-analysis of randomized controlled clinical trials., J Neurol 247, 6, 435-442 
Caronti B, Calderaro C, Passarelli F, Palladini G, Pontieri FE (1998): Dopamine receptor mrnas in the rat lymphocytes., Life Sci $\underline{62}$, 21, 1919-1925

Chitnis T (2006): Pediatric multiple sclerosis., Neurologist 12, 6, 299-310

Coffman RL, Weissman IL (1981): B220: a b cell-specific member of th t200 glycoprotein family., Nature 289, 5799, 681-683

Compston A, Coles A (2002): Multiple sclerosis., Lancet 359, 9313, 1221-1231

Confavreux C, Hutchinson M, Hours MM, Cortinovis-Tourniaire P, Moreau T (1998): Rate of pregnancy-related relapse in multiple sclerosis. pregnancy in multiple sclerosis group., N Engl J Med $\underline{339}$, 5, 285-291

Confavreux C, Vukusic S (2006): Natural history of multiple sclerosis: a unifying concept., Brain 129, Pt 3, 606-616

Cosentino M, Fietta AM, Ferrari M, Rasini E, Bombelli R, Carcano E, Saporiti F, Meloni F, Marino F, Lecchini S (2007): Human cd4+cd25+ regulatory t cells selectively express tyrosine hydroxylase and contain endogenous catecholamines subserving an autocrine/paracrine inhibitory functional loop., Blood 109, 2, 632-642

Delgado S, Baez S, Singer C, Sengun C, Sheremata WA, Papapetropoulos S (2009): Parkinsonism/dystonia syndrome secondary to multiple sclerosis with anti-basal-ganglia antibodies., Mov Disord 24, 2, 309-311

Dijkstra CD, van der Voort ER, Groot CJD, Huitinga I, Uitdehaag BM, Polman CH, Berkenbosch F (1994): Therapeutic effect of the d2-dopamine agonist bromocriptine on acute and relapsing experimental allergic encephalomyelitis., Psychoneuroendocrinology $\underline{19}, 2,135-142$

Edgar Brunner FL Sebastian Donnhof (2001): Nonparametric Analysis of longitudinal Data in factorial Experiments, John Wiley \& Sons

Ekbom K, Ulfberg J (2009): Restless legs syndrome., J Intern Med 266, 5, 419-431

Ferrari-Toninelli G, Maccarinelli G, Uberti D, Buerger E, Memo M (2010): Mitochondriatargeted antioxidant effects of $\mathrm{s}(-)$ and $\mathrm{r}(+)$ pramipexole., BMC Pharmacol $\underline{10}, 2$

Fitzgerald P, Dinan TG (2008): Prolactin and dopamine: what is the connection? a review article., J Psychopharmacol 22, 2 Suppl, 12-19 
Folgar S, Gatto EM, Raina G, Micheli F (2003): Parkinsonism as a manifestation of multiple sclerosis., Mov Disord $\underline{18}, 1,108-110$

Fur GL, Phan T, Uzan A (1980): Identification of stereospecific [3h]spiroperidol binding sites in mammalian lymphocytes., Life Sci $\underline{26}, 14,1139-1148$

Gilgun-Sherki Y, Melamed E, Offen D (2004): The role of oxidative stress in the pathogenesis of multiple sclerosis: the need for effective antioxidant therapy., J Neurol 251, 3, 261-268

Glickstein SB, Schmauss C (2001): Dopamine receptor functions: lessons from knockout mice [corrected]., Pharmacol Ther $\underline{91}, 1,63-83$

Gold R, Linington C, Lassmann H (2006): Understanding pathogenesis and therapy of multiple sclerosis via animal models: 70 years of merits and culprits in experimental autoimmune encephalomyelitis research., Brain $\underline{129}$, Pt 8, 1953-1971

Goldschmidt T, Antel J, König FB, Brück W, Kuhlmann T (2009): Remyelination capacity of the ms brain decreases with disease chronicity., Neurology $\underline{72}, 22,1914-1921$

Gregg C (2009): Pregnancy, prolactin and white matter regeneration., J Neurol Sci $\underline{285}$, $1-2,22-27$

Harauz G, Ladizhansky V, Boggs JM (2009): Structural polymorphism and multifunctionality of myelin basic protein., Biochemistry $\underline{48}$, 34, 8094-8104

Harirchian MH, Sahraian MA, Shirani A (2006): Serum prolactin level in patients with multiple sclerosis: a case control study., Med Sci Monit 12, 4, CR177-CR180

Haskó G, Szabó C, Németh ZH, Deitch EA (2002): Dopamine suppresses il-12 p40 production by lipopolysaccharide-stimulated macrophages via a beta-adrenoceptormediated mechanism., J Neuroimmunol 122, 1-2, 34-39

Hein T, Hopfenmüller W (2000): Projection of the number of multiple sclerosis patients in germany, Nervenarzt $\underline{71}, 4,288-294$

Ho MK, Springer TA (1983): Tissue distribution, structural characterization, and biosynthesis of mac-3, a macrophage surface glycoprotein exhibiting molecular weight heterogeneity., J Biol Chem 258, 1, 636-642 
Hoffjan S, Akkad DA (2010): The genetics of multiple sclerosis: An update 2010., Mol Cell Probes

Hogancamp WE, Rodriguez M, Weinshenker BG (1997): The epidemiology of multiple sclerosis., Mayo Clinic proceedings. Mayo Clinic $\underline{72}$, 9, 871-878

Ilani T, Ben-Shachar D, Strous RD, Mazor M, Sheinkman A, Kotler M, Fuchs S (2001): A peripheral marker for schizophrenia: Increased levels of d3 dopamine receptor mrna in blood lymphocytes., Proc Natl Acad Sci U S A $\underline{98}$, 2, 625-628

Ilani T, Strous RD, Fuchs S (2004): Dopaminergic regulation of immune cells via d3 dopamine receptor: a pathway mediated by activated t cells., FASEB J $\underline{18}$, 13, 16001602

Jara LJ, Medina G, Saavedra MA, Vera-Lastra O, Navarro C (2009): Prolactin and autoimmunity., Clin Rev Allergy Immunol

Kalman B, Lublin FD (1999): The genetics of multiple sclerosis. a review., Biomed Pharmacother $\underline{53}$, 8, 358-370

Kelley KW, Weigent DA, Kooijman R (2007): Protein hormones and immunity., Brain Behav Immun 21, 4, 384-392

Kelly MA, Rubinstein M, Asa SL, Zhang G, Saez C, Bunzow JR, Allen RG, Hnasko R, Ben-Jonathan N, Grandy DK, et al. (1997): Pituitary lactotroph hyperplasia and chronic hyperprolactinemia in dopamine d2 receptor-deficient mice., Neuron $\underline{19}$, 1 , $103-113$

Kihara T, Shimohama S, Sawada H, Honda K, Nakamizo T, Kanki R, Yamashita H, Akaike A (2002): Protective effect of dopamine d2 agonists in cortical neurons via the phosphatidylinositol 3 kinase cascade., J Neurosci Res 므, 3, 274-282

Kipnis J, Cardon M, Avidan H, Lewitus GM, Mordechay S, Rolls A, Shani Y, Schwartz M (2004): Dopamine, through the extracellular signal-regulated kinase pathway, downregulates cd4+cd25+ regulatory t-cell activity: implications for neurodegeneration., J Neurosci 24, 27, 6133-6143

Kira J, Harada M, Yamaguchi Y, Shida N, Goto I (1991): Hyperprolactinemia in multiple sclerosis., J Neurol Sci 102, 1, 61-66 
Kirillova GP, Hrutkay RJ, Shurin MR, Shurin GV, Tourkova IL, Vanyukov MM (2008): Dopamine receptors in human lymphocytes: radioligand binding and quantitative rtpcr assays., J Neurosci Methods 174, 2, 272-280

Lassmann H, Brück W, Lucchinetti C (2001): Heterogeneity of multiple sclerosis pathogenesis: implications for diagnosis and therapy., Trends Mol Med ㄱ, 3, 115-121

Lassmann H, Brück W, Lucchinetti CF (2007): The immunopathology of multiple sclerosis: an overview., Brain Pathol 17, 2, 210-218

Levite M, Chowers Y, Ganor Y, Besser M, Hershkovits R, Cahalon L (2001): Dopamine interacts directly with its $\mathrm{d} 3$ and $\mathrm{d} 2$ receptors on normal human $\mathrm{t}$ cells, and activates beta1 integrin function., Eur J Immunol 31, 12, 3504-3512

Liu XH, Kato H, Chen T, Kato K, Itoyama Y (1995): Bromocriptine protects against delayed neuronal death of hippocampal neurons following cerebral ischemia in the gerbil., J Neurol Sci 129, 1, 9-14

Liu Y, Teige I, Ericsson I, Navikas V, Issazadeh-Navikas S (2010): Suppression of eae by oral tolerance is independent of endogenous ifn-beta whereas treatment with recombinant ifn-beta ameliorates eae., Immunol Cell Biol $\underline{4}, 494-5$

Lucchinetti C, Brück W, Parisi J, Scheithauer B, Rodriguez M, Lassmann H (2000): Heterogeneity of multiple sclerosis lesions: implications for the pathogenesis of demyelination., Ann Neurol 47, 6, 707-717

Marrie RA (2004): Environmental risk factors in multiple sclerosis aetiology., Lancet Neurol $\underline{3}, 12,709-718$

McKenna F, McLaughlin PJ, Lewis BJ, Sibbring GC, Cummerson JA, Bowen-Jones D, Moots RJ (2002): Dopamine receptor expression on human t- and b-lymphocytes, monocytes, neutrophils, eosinophils and nk cells: a flow cytometric study., J Neuroimmunol $132,1-2,34-40$

McLaughlin BA, Nelson D, Erecińska M, Chesselet MF (1998): Toxicity of dopamine to striatal neurons in vitro and potentiation of cell death by a mitochondrial inhibitor., J Neurochem 무, 6, 2406-2415

McMurray RW (2001): Bromocriptine in rheumatic and autoimmune diseases., Semin Arthritis Rheum 1ㅗ, 1, 21-32 
Missale C, Nash SR, Robinson SW, Jaber M, Caron MG (1998): Dopamine receptors: from structure to function., Physiol Rev $\underline{78}, 1,189-225$

Mohr DC, Hart SL, Julian L, Cox D, Pelletier D (2004): Association between stressful life events and exacerbation in multiple sclerosis: a meta-analysis., BMJ $\underline{328}$, 7442, 731

Morkawa K, Oseko F, Morikawa S (1993): Immunosuppressive property of bromocriptine on human b lymphocyte function in vitro., Clin Exp Immunol 93, 2, 200-205

Nagai Y, Ueno S, Saeki Y, Soga F, Hirano M, Yanagihara T (1996): Decrease of the d3 dopamine receptor mrna expression in lymphocytes from patients with parkinson's disease., Neurology $\underline{46}, 3,791-795$

Nakano K, Higashi T, Hashimoto K, Takagi R, Tanaka Y, Matsushita S (2008): Antagonizing dopamine d1-like receptor inhibits th17 cell differentiation: preventive and therapeutic effects on experimental autoimmune encephalomyelitis., Biochem Biophys Res Commun 373, 2, 286-291

Nakano K, Higashi T, Takagi R, Hashimoto K, Tanaka Y, Matsushita S (2009): Dopamine released by dendritic cells polarizes th2 differentiation., Int Immunol 21, 6, $645-654$

Nociti V, Frisullo G, Tartaglione T, Patanella AK, Iorio R, Tonali PA, Batocchi AP (2010): Multiple sclerosis attacks triggered by hyperprolactinemia., J Neurooncol $\underline{98}$, 3, 407-409

Pacheco R, Prado CE, Barrientos MJ, Bernales S (2009): Role of dopamine in the physiology of t-cells and dendritic cells., J Neuroimmunol 216, 1-2, 8-19

Pitt D, Werner P, Raine CS (2000): Glutamate excitotoxicity in a model of multiple sclerosis., Nat Med $\underline{6}, 1,67-70$

Pivonello R, Ferone D, Lombardi G, Colao A, Lamberts SWJ, Hofland LJ (2007): Novel insights in dopamine receptor physiology., Eur J Endocrinol 156 Suppl 1, S13-21

Polman CH, Reingold SC, Edan G, Filippi M, Hartung HP, Kappos L, Lublin FD, Metz LM, McFarland HF, O'Connor PW, et al. (2005): Diagnostic criteria for multiple sclerosis: 2005 revisions to the "mcdonald criteria"., Ann Neurol $\underline{58}$, 6, 840-846 
Ricci A, Bronzetti E, Mignini F, Tayebati SK, Zaccheo D, Amenta F (1999): Dopamine d1-like receptor subtypes in human peripheral blood lymphocytes., J Neuroimmunol $\underline{96}, 2,234-240$

Rieckmann P (2006): Escalating immunomodulatory therapy of multiple sclerosis. update, Nervenarzt $\underline{77}, 12,1506-1518$

Rieckmann P, Toyka KV (1999): Escalating immunotherapy of multiple sclerosis. austrian-german- swiss multiple sclerosis therapy consensus group, Eur Neurol $\underline{42}$, $3,121-127$

Rieckmann P, Toyka KV, Bassetti C, Beer K, Beer S, Buettner U, Chofflon M, GötschiFuchs M, Hess K, Kappos L, et al. (2004): Escalating immunotherapy of multiple sclerosis-new aspects and practical application., J Neurol 251, 11, 1329-1339

Riskind PN, Massacesi L, Doolittle TH, Hauser SL (1991): The role of prolactin in autoimmune demyelination: suppression of experimental allergic encephalomyelitis by bromocriptine., Ann Neurol 29, 5, 542-547

Rosin C, Colombo S, Calver AA, Bates TE, Skaper SD (2005): Dopamine d2 and d3 receptor agonists limit oligodendrocyte injury caused by glutamate oxidative stress and oxygen/glucose deprivation., Glia $\underline{52}$, 4, 336-343

Rothwell PM, Charlton D (1998): High incidence and prevalence of multiple sclerosis in south east scotland: evidence of a genetic predisposition., J Neurol Neurosurg Psychiatry $\underline{64}, 6,730-735$

Roxburgh RHSR, Seaman SR, Masterman T, Hensiek AE, Sawcer SJ, Vukusic S, Achiti I, Confavreux C, Coustans M, le Page E, et al. (2005): Multiple sclerosis severity score: using disability and disease duration to rate disease severity., Neurology $\underline{64}, 7$, $1144-1151$

Russell DH, Matrisian L, Kibler R, Larson DF, Poulos B, Magun BE (1984): Prolactin receptors on human lymphocytes and their modulation by cyclosporine., Biochem Biophys Res Commun 121, 3, 899-906

Saha B, Mondal AC, Majumder J, Basu S, Dasgupta PS (2001): Physiological concentrations of dopamine inhibit the proliferation and cytotoxicity of human cd4+ and cd8 $+\mathrm{t}$ cells in vitro: a receptor-mediated mechanism., Neuroimmunomodulation $\underline{9}, 1$, $23-33$ 
Sawada H, Ibi M, Kihara T, Urushitani M, Akaike A, Kimura J, Shimohama S (1998): Dopamine d2-type agonists protect mesencephalic neurons from glutamate neurotoxicity: mechanisms of neuroprotective treatment against oxidative stress., Ann Neurol $\underline{44}, 1,110-119$

Schreibelt G, van Horssen J, van Rossum S, Dijkstra CD, Drukarch B, de Vries HE (2007): Therapeutic potential and biological role of endogenous antioxidant enzymes in multiple sclerosis pathology., Brain Res Rev $\underline{56}$, 2, 322-330

Schüle C, Baghai TC, Rupprecht R (2007): [new insights into the pathogenesis and pathophysiology of depression], Nervenarzt 78 Suppl 3, 531-47; quiz 548-9

Sibley DR (1999): New insights into dopaminergic receptor function using antisense and genetically altered animals., Annu Rev Pharmacol Toxicol 39, 313-341

Simpson D, Noble S, Perry C (2002): Glatiramer acetate: a review of its use in relapsingremitting multiple sclerosis., CNS drugs $\underline{16}$, 12, 825-850

Song YJC, Lundvig DMS, Huang Y, Gai WP, Blumbergs PC, Hojrup P, Otzen D, Halliday GM, Jensen PH (2007): p25alpha relocalizes in oligodendroglia from myelin to cytoplasmic inclusions in multiple system atrophy., Am J Pathol 171, 4, 1291-1303

Spencer JP, Jenner A, Butler J, Aruoma OI, Dexter DT, Jenner P, Halliwell B (1996): Evaluation of the pro-oxidant and antioxidant actions of l-dopa and dopamine in vitro: implications for parkinson's disease., Free Radic Res 24 , 2, 95-105

Sriram S, Steiner I (2005): Experimental allergic encephalomyelitis: a misleading model of multiple sclerosis., Ann Neurol $\underline{58}$, 6, 939-945

Struck LK, Rodnitzky RL, Dobson JK (1990): Stroke and its modification in parkinson's disease., Stroke 21, 10, 1395-1399

Thompson A (2004): Overview of primary progressive multiple sclerosis (ppms): similarities and differences from other forms of ms, diagnostic criteria, pros and cons of progressive diagnosis., Mult Scler 10 Suppl 1, S2-S7

Tinsley RB, Bye CR, Parish CL, Tziotis-Vais A, George S, Culvenor JG, Li QX, Masters CL, Finkelstein DI, Horne MK (2009): Dopamine d2 receptor knockout mice develop features of parkinson disease., Ann Neurol $\underline{66}$, 4, 472-484 
Tomassoni D, Bronzetti E, Cantalamessa F, Mignini F, Ricci A, Sabbatini M, Tayebati SK, Zaccheo D (2002): Postnatal development of dopamine receptor expression in rat peripheral blood lymphocytes., Mech Ageing Dev 123, 5, 491-498

Tomio A, Schust DJ, Kawana K, Yasugi T, Kawana Y, Mahalingaiah S, Fujii T, Taketani Y (2008): Prolactin can modulate cd4+ t-cell response through receptor-mediated alterations in the expression of t-bet., Immunol Cell Biol 투, 7, 616-621

Tsao CW, Lin YS, Cheng JT (1997): Effect of dopamine on immune cell proliferation in mice., Life Sci $\underline{61}$, 24, PL 361-PL 371

Usiello A, Baik JH, Rougé-Pont F, Picetti R, Dierich A, LeMeur M, Piazza PV, Borrelli E (2000): Distinct functions of the two isoforms of dopamine d2 receptors., Nature $\underline{408}, 6809,199-203$

Watanabe Y, Nakayama T, Nagakubo D, Hieshima K, Jin Z, Katou F, Hashimoto K, Yoshie O (2006): Dopamine selectively induces migration and homing of naive cd8+ t cells via dopamine receptor d3., J Immunol 176, 2, 848-856

Whitacre CC (2001): Sex differences in autoimmune disease., Nat Immunol 2, 9, 777-780 


\section{Danksagungen}

Mein Dank für die hilfreiche Unterstützung bei der Erstellung der Doktorarbeit geht an meine Betreuerin Frau Prof. Dr. med. Christine Stadelmann, an meine Kolleginnen und Kollegen, insbesondere Dr. Angelika Escher, Tobias Dallenga und Dr. Enrique GareaRodriguez, sowie den Mitarbeiterinnen und Mitarbeitern der Abteilung Neuropathologie Göttingen und der Abteilung Medizinische Statistik Göttingen. 